University of South Florida

DIGITAL COMMONS Digital Commons @ University of @ UNIVERSITY OF SOUTH FLORIDA South Florida

$12-1-2012$

\title{
Evaluation of Camera-Based Systems to Reduce Transit Bus Side Collisions - Phase II
}

CUTR

Follow this and additional works at: https://digitalcommons.usf.edu/cutr_nctr

\section{Recommended Citation}

"Evaluation of Camera-Based Systems to Reduce Transit Bus Side Collisions - Phase II," National Center for Transit Research (NCTR) Report No. CUTR-NCTR-RR-2012-11, Center for Urban Transportation Research, University of South Florida, 2012.

DOI: https://doi.org/10.5038/CUTR-NCTR-RR-2012-11

Available at: https://scholarcommons.usf.edu/cutr_nctr/110

This Technical Report is brought to you for free and open access by the National Center for Transit Research (NCTR) Archive (2000-2020) at Digital Commons @ University of South Florida. It has been accepted for inclusion in Research Reports by an authorized administrator of Digital Commons @ University of South Florida. For more information, please contact digitalcommons@usf.edu. 

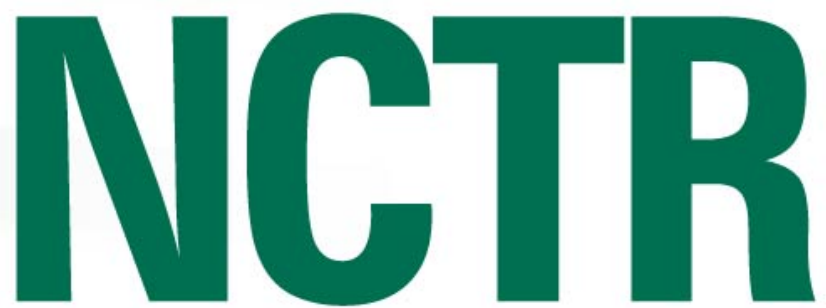

NATIONAL CENTER for TRANSIT RESEARCH Evaluation of Camera-Based Systems to Reduce
Transit Bus Side Collisions-Phase II

BDK85 977-35

December 2012

FINAL REPORT

Prepared for:

Florida Department of Transportation

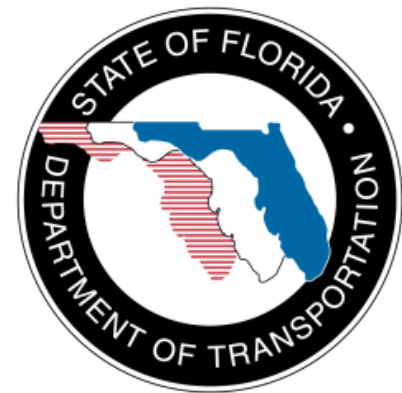




\title{
Evaluation of Camera-Based Systems to Reduce Transit Bus Side Collisions-Phase II
}

\author{
BDK85 977-35 \\ Final Report
}

Prepared for:

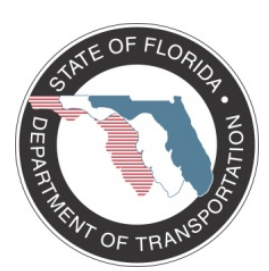

Mr. Victor Wiley, CPM

Project Manager

Florida Department of Transportation

Research Center

605 Suwannee Street, MS 30

Tallahassee, FL 32399-0450

Prepared by:

Pei-Sung Lin, Ph.D., P.E., PTOE, FITE

Achilleas Kourtellis, Ph.D.

Matthew Wills, E.I.T.
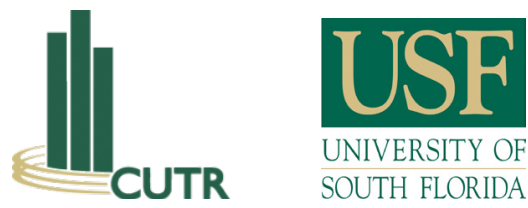

Center for Urban Transportation Research (CUTR)

University of South Florida

4202 E. Fowler Ave. CUT100

Tampa, FL 33620-5375

December 2012 


\section{Disclaimer}

The opinions, findings, and conclusions expressed in this publication are those of the authors and not necessarily those of the State of Florida Department of Transportation. 


\section{Metric Conversion}

\begin{tabular}{|c|c|c|c|c|}
\hline SYMBOL & \multicolumn{3}{|c|}{ LENGTH } & SYMBOL \\
\hline in & inches & 25.4 & millimeters & $\mathrm{mm}$ \\
\hline $\mathbf{f t}$ & feet & 0.305 & meters & $\mathrm{m}$ \\
\hline yd & yards & 0.914 & meters & $\mathrm{m}$ \\
\hline $\mathbf{m i}$ & miles & 1.61 & kilometers & $\mathrm{km}$ \\
\hline \multicolumn{5}{|c|}{ VOLUME } \\
\hline fl oz & fluid ounces & 29.57 & milliliters & $\mathrm{mL}$ \\
\hline gal & gallons & 3.785 & liters & $L$ \\
\hline $\mathrm{ft}^{3}$ & cubic feet & 0.028 & cubic meters & $\mathrm{m}^{3}$ \\
\hline$y d^{3}$ & cubic yards & 0.765 & cubic meters & $\mathrm{m}^{3}$ \\
\hline \multicolumn{5}{|c|}{ NOTE: volumes greater than $1000 \mathrm{~L}$ shall be shown in $\mathrm{m}^{3}$} \\
\hline \multicolumn{5}{|c|}{ MASS } \\
\hline $\mathbf{o z}$ & ounces & 28.35 & grams & $g$ \\
\hline lb & pounds & 0.454 & kilograms & $\mathrm{kg}$ \\
\hline $\mathbf{T}$ & short tons $(2000 \mathrm{lb})$ & 0.907 & $\begin{array}{c}\text { megagrams } \\
\text { (or "metric ton") }\end{array}$ & $\mathrm{Mg}($ or "t") \\
\hline \multicolumn{5}{|c|}{ TEMPERATURE (exact degrees) } \\
\hline${ }^{\circ} \mathbf{F}$ & Fahrenheit & $\begin{array}{c}5(F-32) / 9 \\
\operatorname{or}(F-32) / 1.8\end{array}$ & Celsius & ${ }^{\circ} \mathrm{C}$ \\
\hline
\end{tabular}




\section{Technical Report Documentation}

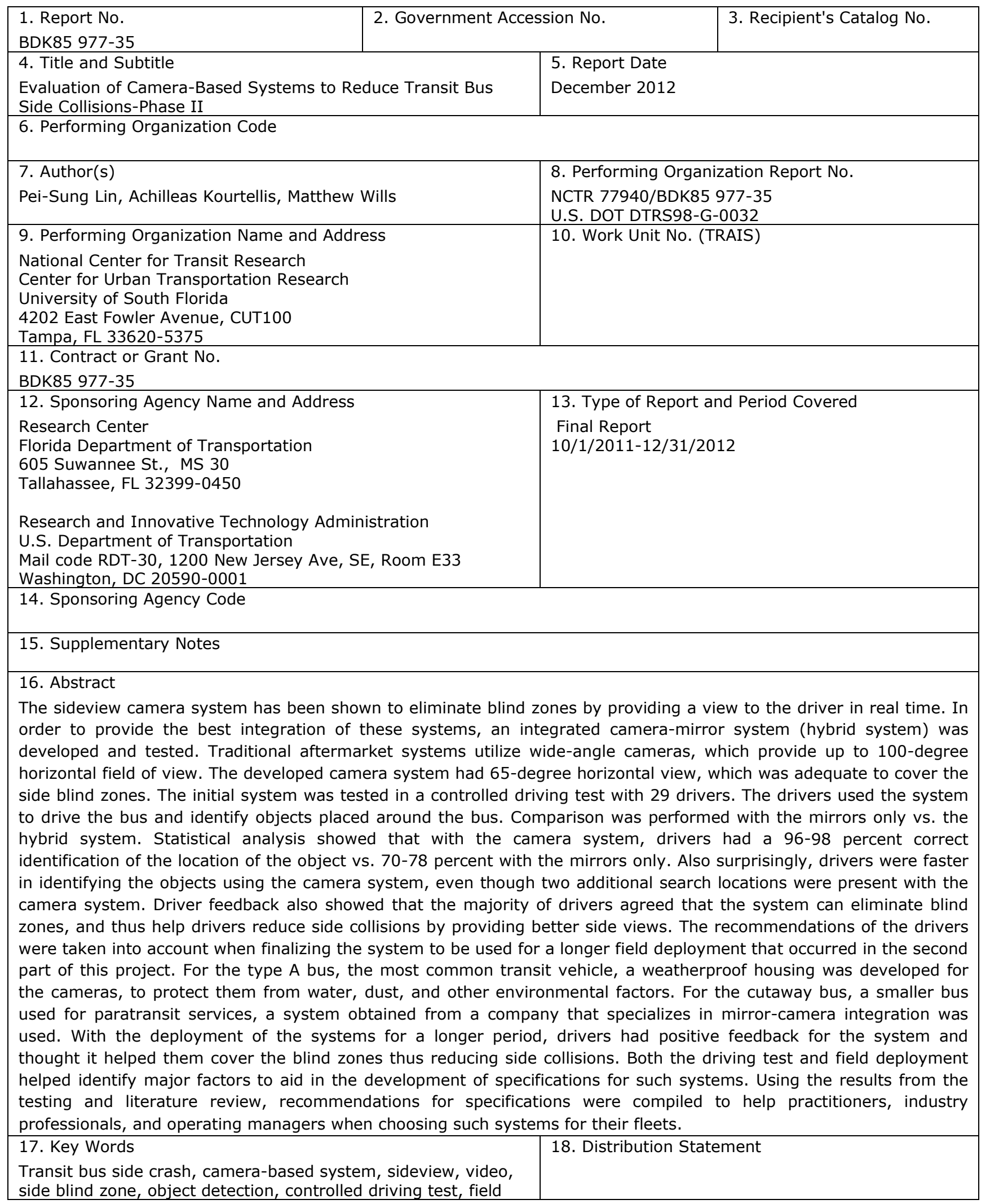




\begin{tabular}{|l|l|l|l|}
\hline \multicolumn{2}{|l|}{ deployment } & \multicolumn{2}{|l|}{ 22. Price } \\
\hline $\begin{array}{l}\text { 19. Security Classification } \\
\text { (of this report) } \\
\text { Unclassified }\end{array}$ & $\begin{array}{l}\text { 20. Security Classification } \\
\text { (of this page) } \\
\text { Unclassified }\end{array}$ & $\begin{array}{l}21 . \text { No. of Pages } \\
59\end{array}$ & \begin{tabular}{l} 
Free \\
\hline
\end{tabular}
\end{tabular}




\section{Acknowledgments}

The authors would like to express their gratitude to the Florida Department of Transportation project manager, Mr. Victor Wiley, for his help and guidance during the course of this project. The authors would also like to thank StarMetro in Tallahassee and LeeTran in Ft. Myers for their assistance in the controlled driving test and field deployment of the camera systems, respectively. 


\section{Executive Summary}

Aftermarket sideview camera systems have been used in the RV industry in recent years to effectively provide the driver better side views eliminating the blind zones. During the first phase of this project, available aftermarket sideview systems were tested for their effectiveness in reducing or eliminating blind zones, thus aiding drivers in reducing side collisions on transit buses. The first phase showed positive results and the potential for further implementation. The cameras used were had wide angle views (100 degrees), and potentially provide too much information to the drivers.

During this second phase of the project, an integrated camera-mirror system (hybrid system) was developed and tested. The developed camera system had 65-degree horizontal view, which was adequate to cover the side blind zones. The initial system was tested in a controlled driving test with 29 drivers. The drivers used the system to drive the bus and identify objects placed around the bus. Comparison was performed with the mirrors only vs. the hybrid system. Statistical analysis showed that with the camera system, drivers had a 96-98 percent correct identification of the location of the object vs. 70-78 percent with the mirrors only. Also surprisingly, drivers were faster in identifying the objects using the camera system, even though two additional search locations were present with the camera system. Driver feedback also showed that the majority of drivers agreed that the system can eliminate blind zones, and thus help drivers reduce side collisions by providing better side views.

The recommendations of the drivers were taken into account when finalizing the system to be used for a longer field deployment that occurred in the second part of this project. For the type A bus, the most common transit vehicle, a weatherproof housing was developed for the cameras, to protect them from water, dust, and other environmental factors. For the cutaway bus, a smaller bus used for paratransit services, a system obtained from a company that specializes in mirror-camera integration was used.

The field deployment showed that the camera system must meet stringent criteria to be used in the field. Drivers were overall positive about the experience even though there were initial problems with fogging that were overcome. The majority of drivers agreed that the camera system reduces or eliminates the blind zones and is effective in reducing side crashes. One of the reported problems of the system is that during nighttime driving, the headlights of passing vehicles tend to be distracting. This particular issue was not investigated further, even though the cameras were chosen because they reduce blooming and light bleed-through, and they recover relatively fast from this effect. Further research might shed light on this problem, because if it is not addressed, the system can become potentially hazardous in extreme cases.

Both the driving test and field deployment helped identify major factors to aid in the development of specifications for such systems. Using the results from the testing and literature review, recommendations for specifications were compiled to help practitioners, industry professionals, and operating managers when choosing such systems for their fleets. 


\section{Table of Contents}

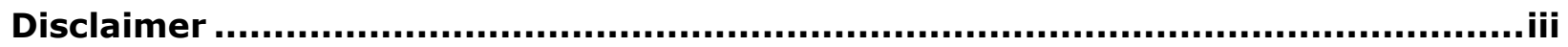

Metric Conversion ........................................................................................ iv

Technical Report Documentation..................................................................v

Executive Summary ................................................................................. viii

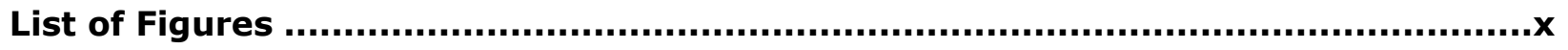

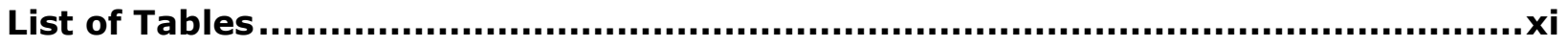

Chapter 1 Introduction ............................................................................. 1

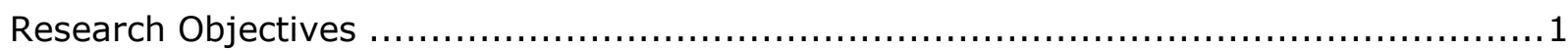

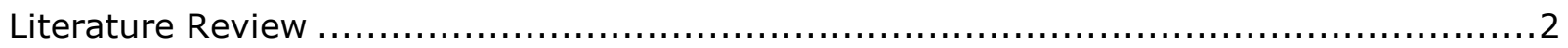

Chapter 2 Development of Sideview Camera System ...................................... 4

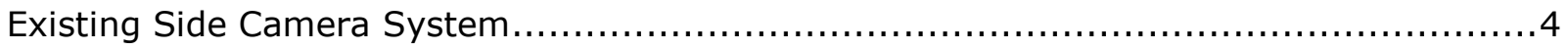

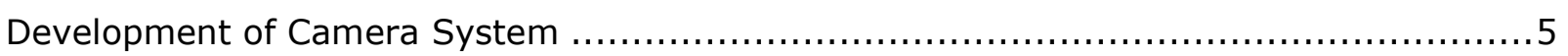

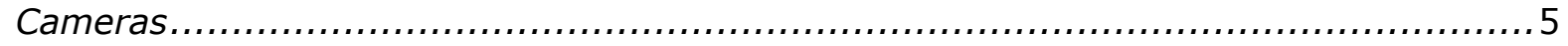

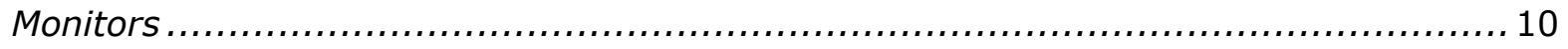

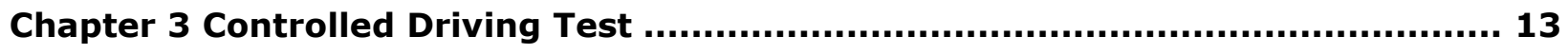

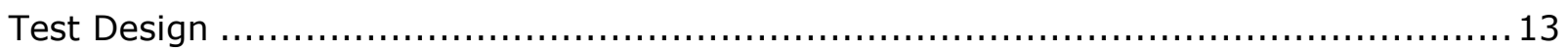

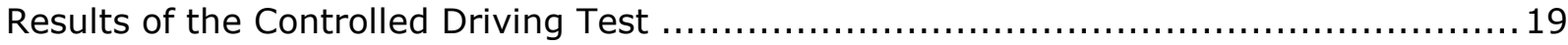

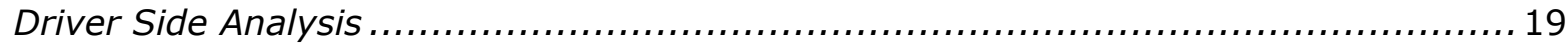

Passenger Side Analysis ............................................................ 20

Response Time................................................................... 20

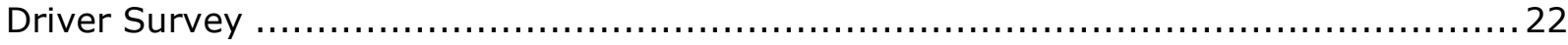

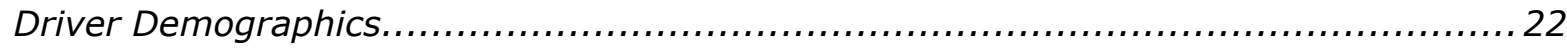

Responses to Questions............................................................ 23

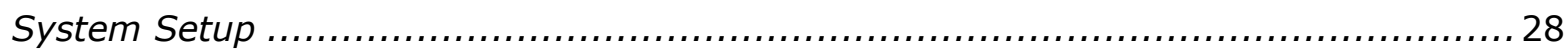

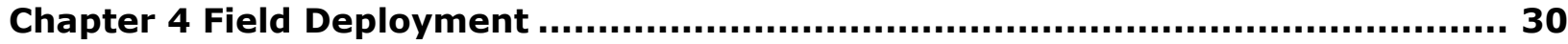

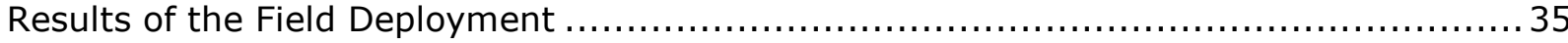

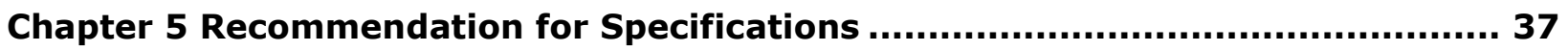

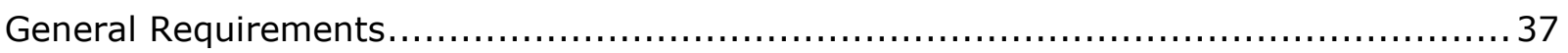

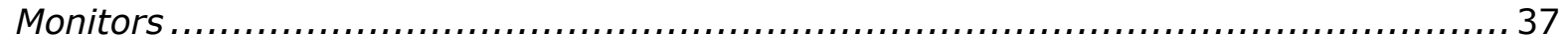

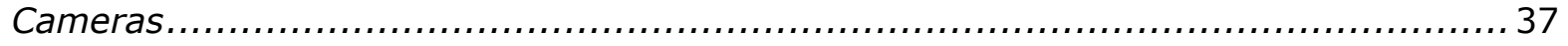

Side Mirror-Camera Enhancement Recommended Specifications....................... 38

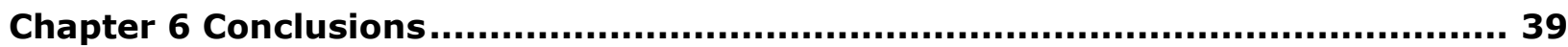

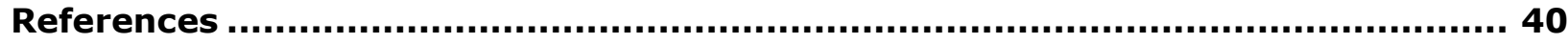

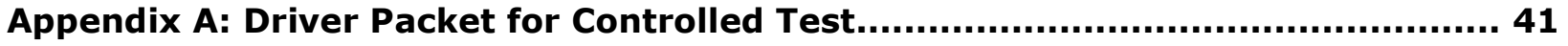

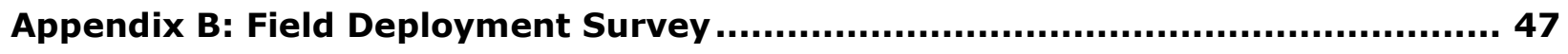




\section{List of Figures}

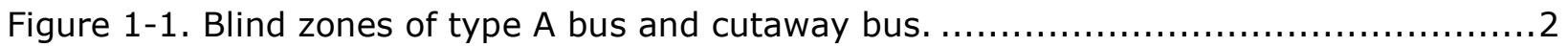

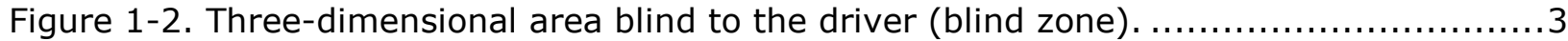

Figure $2-1$. View from $100^{\circ}$ angle lens (left) and $65^{\circ}$ angle lens (right) .......................

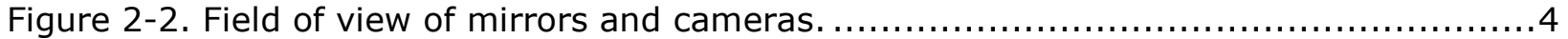

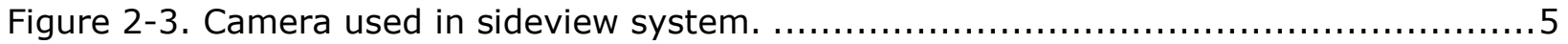

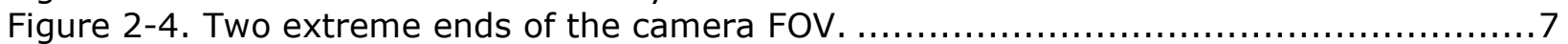

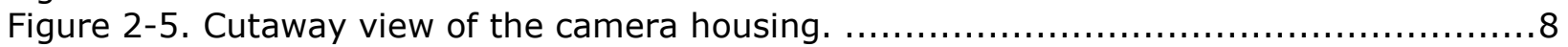

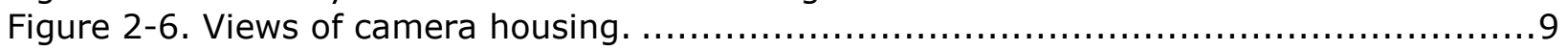

Figure 2-7. Mirror-camera system used for cutaway bus. ................................. 10

Figure 2-8. 7" (left) and 8" (right) monitors used for the sideview camera system. ..........11

Figure $3-1$. Controlled test (closed course) route............................................. 13

Figure 3-2. Layout for the object detection/recognition test (type A bus). ................. 14

Figure 3-3. Layout for the object detection/recognition test (cutaway bus) .................. 15

Figure $3-4$. Left and right side cameras on type A bus.......................................... 16

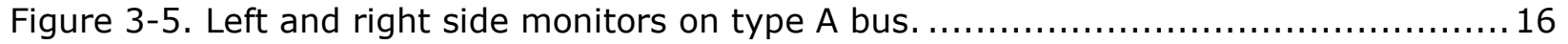

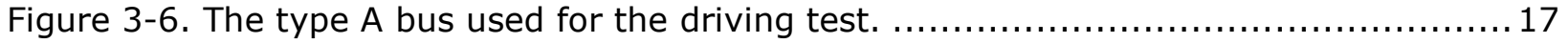

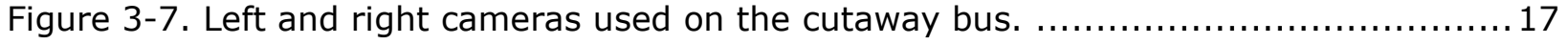

Figure 3-8. Left and right side monitors mounted on the cutaway bus....................... 18

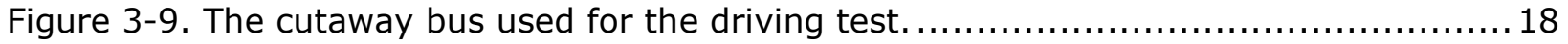

Figure 3-10. Response times as a function of baseline vs. enhancement. .................... 20

Figure 3-11. Main effect of object-location-type pair on response time......................21

Figure 3-12. Interaction of baseline vs. enhancement with object location-type pair on

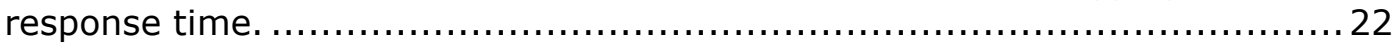

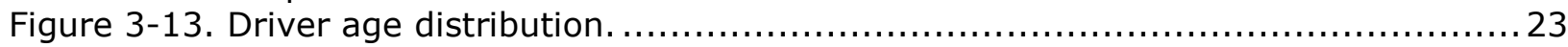

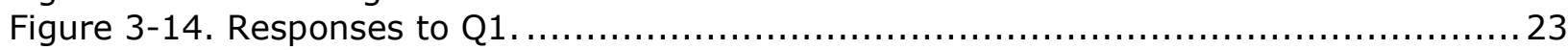

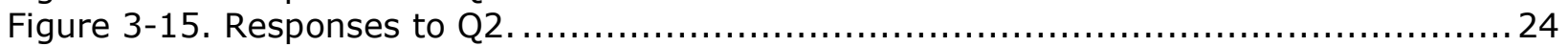

Figure 3-16. Responses to Q3 (left) asked before, and Q7 (right) asked after the test. ..... 24

Figure 3-17. Responses to Q4 (left) asked before, and Q8 (right) asked after the test. ..... 25

Figure 3-18. Responses to Q5 (left) asked before, and Q9 (right) asked after the test. ..... 25

Figure 3-19. Responses to Q6 (left) asked before, and Q7 (right) asked after the test. ..... 26

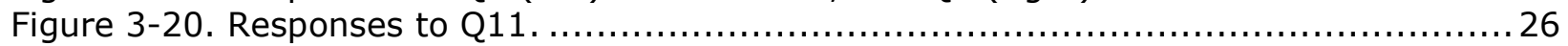

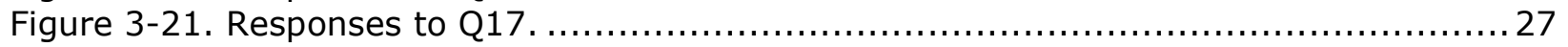

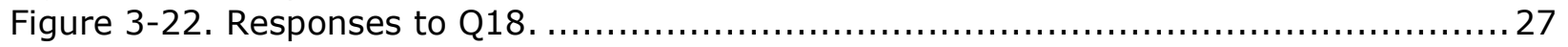

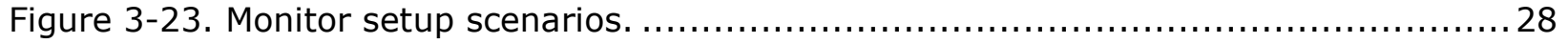

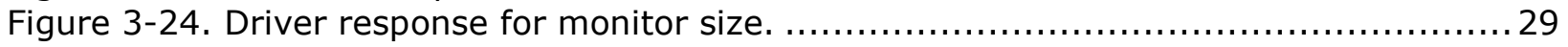

Figure $4-1$. Left side camera installed on type A bus. .......................................... 30

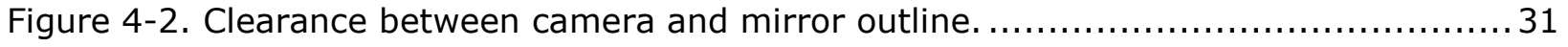

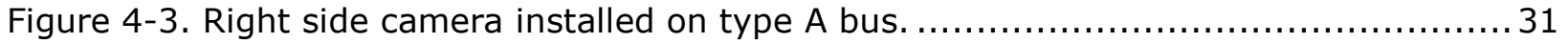

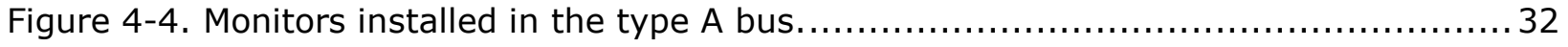

Figure 4-5. View from the monitors installed in the type A bus.............................. 32

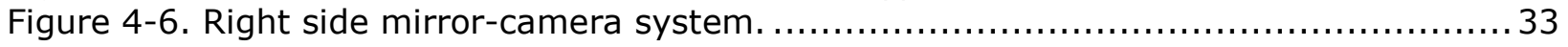

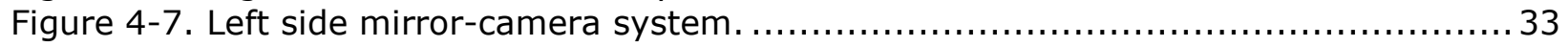

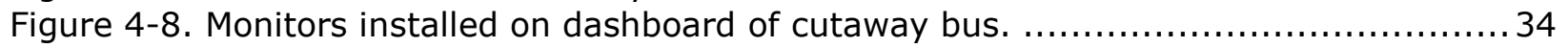

Figure $4-9$. Close-up of the camera used on the cutaway bus. .............................. 34

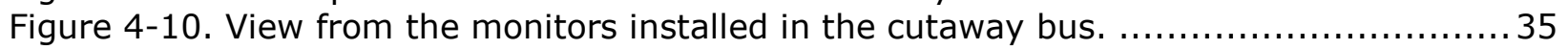

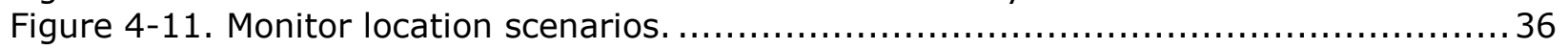




\section{List of Tables}

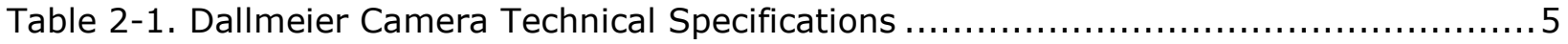

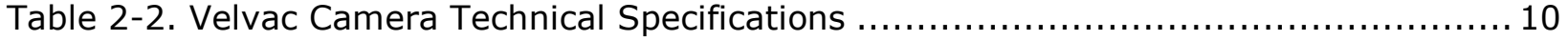

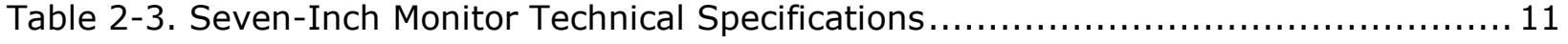

Table 2-4. Eight-Inch Monitor Technical Specifications ........................................ 12

Table 3-1. Object Presentation Scheme for the Object Detection Test .......................... 15

Table 3-2. Correctness of Location as a Function of Baseline vs. Enhancement............... 19

Table 3-3. Correctness of Location as a function of Baseline vs. Enhancement for Driver

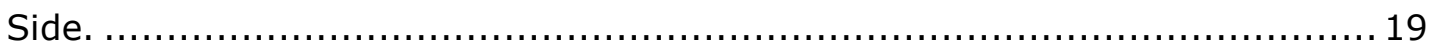

Table 3-4. Correctness of Location as a Function of Baseline vs. Enhancement for

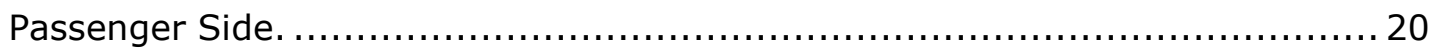

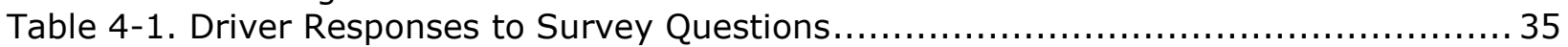




\section{Chapter 1 Introduction}

Side collisions, including sideswipe and angle crashes, make up the highest percentage of transit collisions, accounting for more than 40 percent of all crashes (Wang et al., 2003). Camera-based systems have great potential to provide drivers with views of the blind zones that exist due to the inability of mirrors to cover those zones. This side view camera system has great potential to enhance the existing mirrors and provide drivers with a clear view of the sides of the bus, especially during common lane changing maneuvers. It can eliminate the need for mirror adjustments, especially in the case of rotating drivers of an in-service bus. It can also eliminate the danger of right side bus mirrors hitting passengers waiting for the bus.

Previous research on side view camera systems includes comparisons between mirrors, sensors, and camera-based systems as collision avoidance technologies. Findings showed that the sensor-based systems were not reliable; they provided false warnings and, with time, were rendered unusable by the drivers (Dunn et al., 2007).

Aftermarket side view camera systems were studied in Phase I of this project using a controlled driving test to assess the systems' effectiveness in a controlled environment. The result of the controlled driving test showed convincing potential use of the side view camera systems to reduce transit bus side collisions. The side view camera system can reduce or eliminate blind zones. The video system provides a much better view than the mirrors under rainy conditions and at night due to the use of infrared illumination (Lin et al., 2010). The feedback received from the 28 bus drivers that participated in the controlled driving test was positive. Based on the findings from Phase I, the existing aftermarket side view camera systems used in the Phase I study can be further enhanced to achieve the best results. A field deployment with existing mirror systems and enhanced side view camera systems through local transit agencies along with a comprehensive evaluation was carried out in Phase II to evaluate its effectiveness.

\section{Research Objectives}

Available side view camera systems on the market are mostly used for commercial and recreational vehicles as supplemental tools to the existing mirror systems. The specifications of these side view camera systems vary greatly, depending on the market they are designed for. Specific research on the effectiveness of mirror systems combined with side view camera systems is still very limited. Therefore, the major purpose of the second phase of the project was to evaluate an integrated mirror and camera system for transit buses, and recommend specifications for such a system for potential widespread use in the future.

This project had four primary objectives:

1) Design and produce an appropriate integrated mirror and camera system with cooperation from manufacturers.

2) Deploy integrated mirror and camera systems at local transit agencies for a period of time to evaluate and improve the system.

3) Collect field data, analyze performance, and obtain feedback from various drivers participating in the study.

4) Develop specifications for an integrated mirror and camera system appropriate for use to enhance the safety for transit buses. 


\section{Literature Review}

The current efforts to reduce side collisions of transit buses focuses primarily on developing automatic object detection systems that can help bus drivers by detecting approaching objects as the bus is moving, and warn the driver of an eminent collision. An extensive literature review for sideview video systems was performed in Phase I (Lin et al., 2010). The system however was changed from the potential to replace the existing mirrors, to be added in addition to the mirrors, thus resulting in an integrated mirror-camera hybrid system that would better serve the drivers.

The change was decided after interviews with transit bus managers and drivers, where they shared that changing from a mirror only to a camera only system would be a significant change for the drivers to adjust to. The team therefore decided to develop a hybrid system adding cameras to the existing mirrors of buses to effectively cover the blind zones.

The available aftermarket systems used in Phase I proved that they can cover the areas around a transit bus and eliminate the blind zones that exist due to the limitation of the mirrors. Figure 1-1Figure 1-1 shows the side and rear blind zones of two types of buses. Type $A$ is the most common type of bus with a low floor for easy boarding and exiting the bus. The second is called a cutaway because of the truck body used with a passenger compartment. It is usually shorter than the first, and used primarily in smaller transit agencies, shorter or special routes, or for paratransit services.

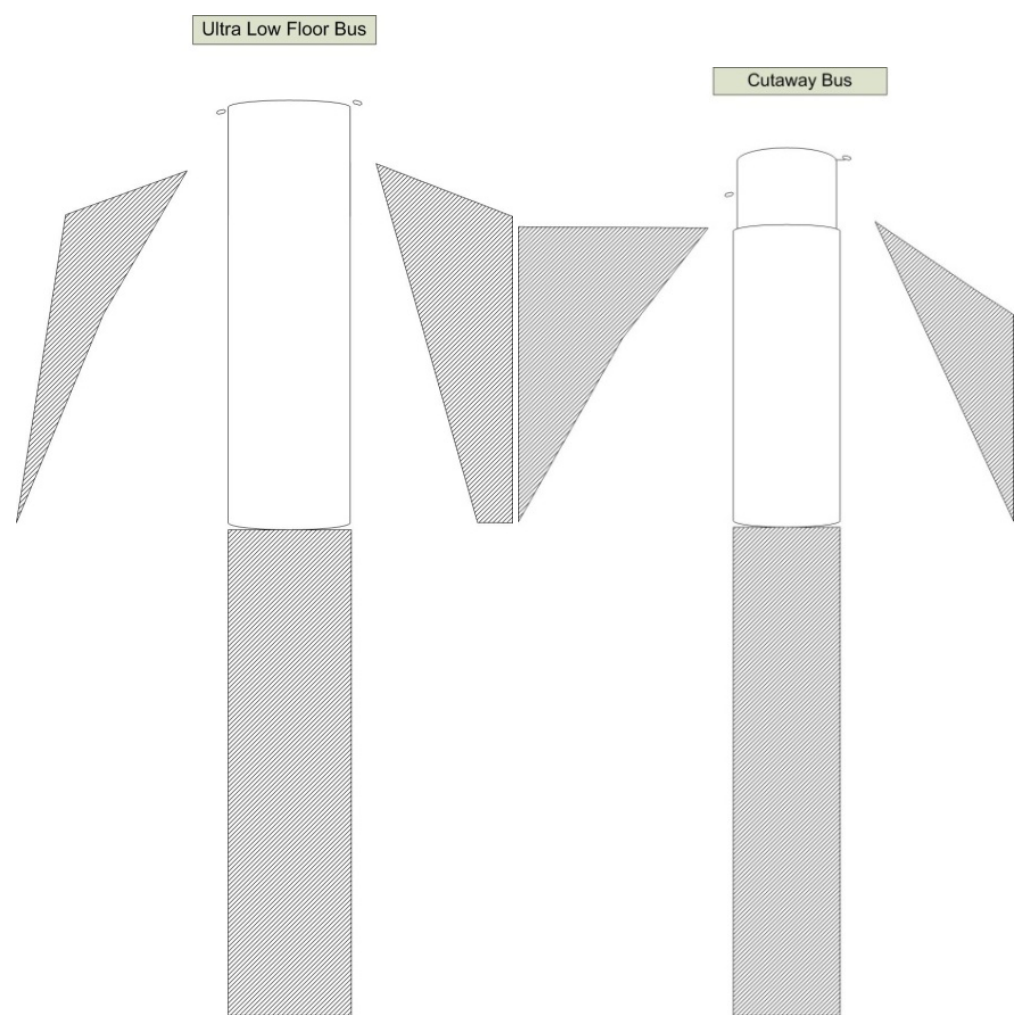

Figure 1-1. Blind zones of type $A$ bus and cutaway bus.

Figure 1-2 shows the blind zones of a transit bus in three dimensions which represents reality better than a two dimensional drawing. 


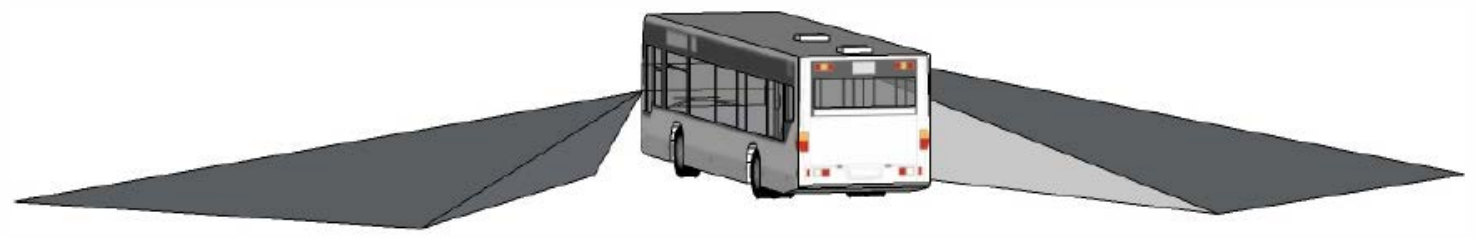

Figure 1-2, Three-dimensional area blind to the driver (blind zone). 


\section{Chapter 2 Development of Sideview Camera System}

\section{Existing Side Camera System}

During the first phase of the project, an existing aftermarket sideview video system was installed on buses and tested. Usually these cameras have a wide field of view covering up to $100^{\circ}$ horizontally. However, this wide field of view has an effect called "fish eye". Simply put, the wide lens is able to capture more of a scene, but the image is also more distorted. Figure 2-1 shows the difference of the same scene with a $100^{\circ}$ lens, versus a more normal $65^{\circ}$ lens. It is clear that more of the scene is visible in the wide angle but with more curvature at the edges (fish eye effect).
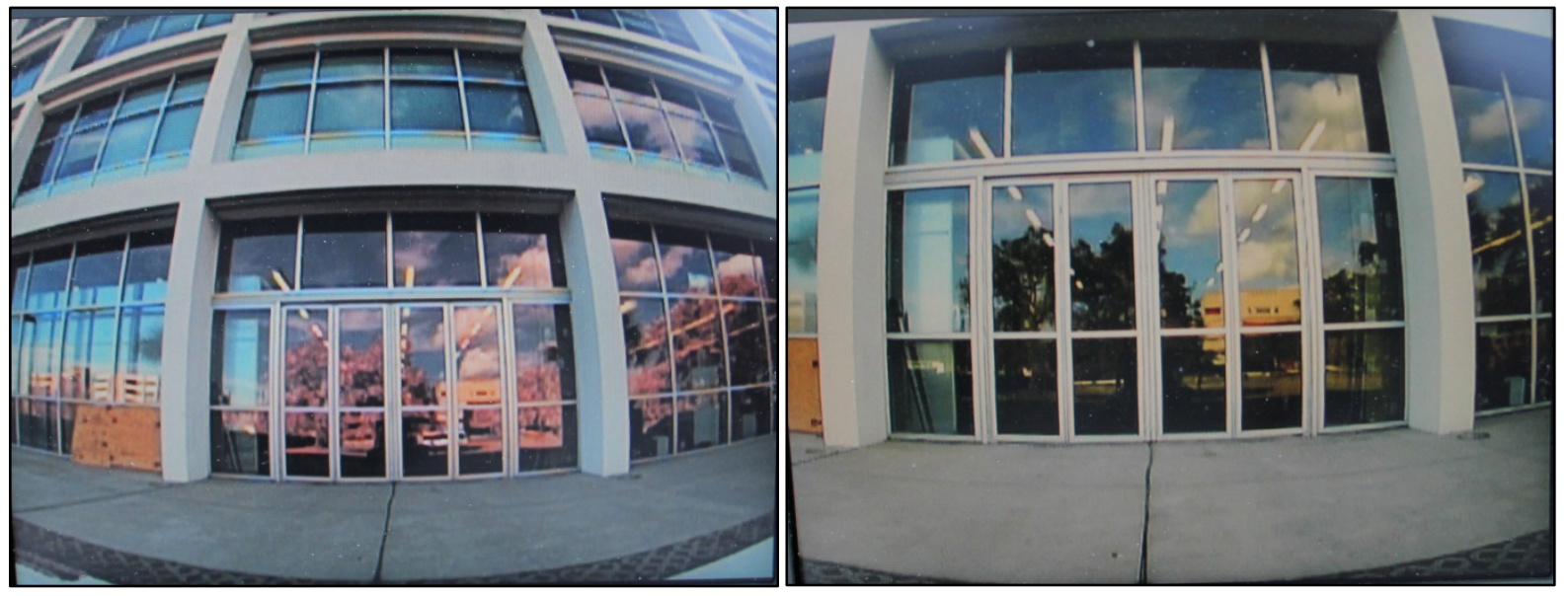

Figure 2-1. View from $100^{\circ}$ angle lens (left) and $65^{\circ}$ angle lens (right).

Figure 2-2 shows the coverage of the two mirrors that are standard on all buses, the field of view (FOV) of a regular $\left(65^{\circ}\right)$ lens camera, and the FOV of a wide angle $\left(100^{\circ}\right)$ lens camera. Convex mirror and camera fields of view cover the flat mirror FOV. Slightly wider angle lens camera than the normal lens camera is expected to cover the FOV of the convex mirror. The cameras are usually located on the side of a bus. It is apparent that these cameras have the potential to cover as much area as the mirrors do and can provide much more coverage if necessary. The cameras are installed at the same location on each side of the bus, unlike the mirrors that require different brackets for the left and right mirrors.

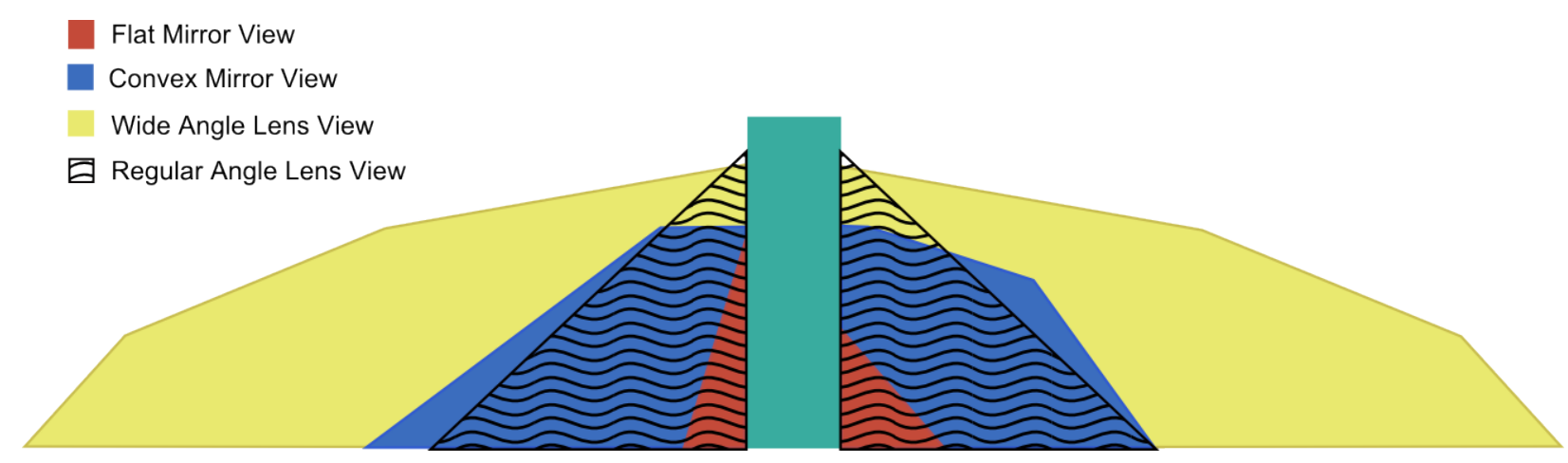

Figure 2-2. Field of view of mirrors and cameras. 


\section{Development of Camera System}

During the first phase testing, it was clear that the wide angle lens cameras were covering the required area for the blind zones, but were providing too much of an area to the drivers. Having a wide view is important but too much is not necessary and can have adverse effects on the drivers. During the first controlled driving test, some drivers commented that they could see too much on the side of the bus and sometimes could not identify which lane a vehicle was traveling next to them. Simply put, too much information cannot be projected in the same monitor unless the view becomes smaller.

The team therefore decided to test different angles that provide different views, thus providing a different representation of the scene on a monitor.

\section{Cameras}

The cameras needed to have variable zooming so that different FOV could be tested. The

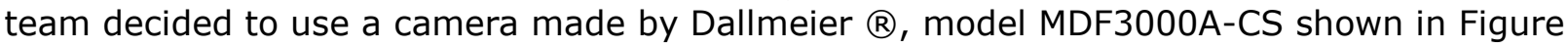
2-3. The technical specifications of this camera are shown in Table 2-1.
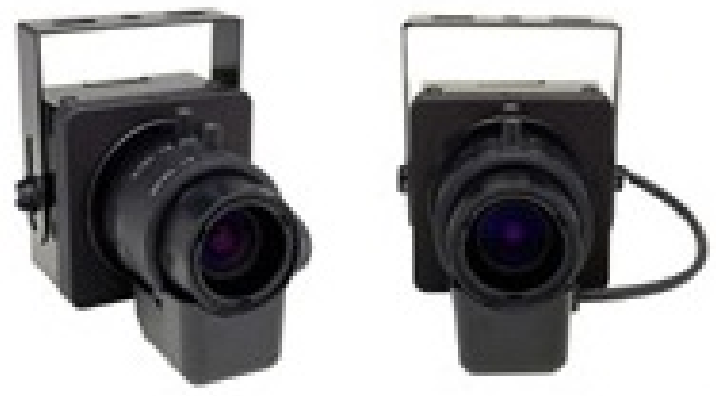

Figure 2-3. Camera used in sideview system.

Table 2-1. Dallmeier Camera Technical Specifications

\begin{tabular}{|l|l|}
\hline Dallmeier MDF3000A-CS & \\
\hline Camera & \\
\hline Sensor & $1 / 3$ " DPS CMOS \\
\hline Signal Processing & 17 -bit DSP \\
\hline Video format & NTSC / PAL \\
\hline Video capture & Progressive Scan \\
\hline Video capture rate & 30 fps (NTSC), 25 fps (PAL) \\
\hline Video transfer format & PSF (Progressive With Segmented Frames) \\
\hline Video transfer rate & 60 fields per second (NTSC), 50 fields per second (PAL) \\
\hline Number of effective pixels & 720 (H) x 540 (V) \\
\hline Horizontal resolution & 540 TV lines \\
\hline Dynamic range & 102 dB typical, 120 dB max. \\
\hline
\end{tabular}




\begin{tabular}{|c|c|}
\hline Dynamic range & $102 \mathrm{~dB}$ typical, $120 \mathrm{~dB}$ max. \\
\hline $\mathrm{B} / \mathrm{W}$ and color mode & Yes \\
\hline Signal to Noise ratio & $>48 \mathrm{~dB}$ \\
\hline Brightness adjustment & (ALC / AE) Automatic / Manual \\
\hline Adjustable white balance & ATW, AWB, MWB (2000 to $11000 \mathrm{~K}$ ) \\
\hline AGC & Brightness and gain limit adjustable, $0 \mathrm{~dB}$ to $48 \mathrm{~dB}$ \\
\hline Gamma correction & Automatic / Manual \\
\hline Synchronization & Intern \\
\hline Light sensitivity & $0.5 \operatorname{lux}(\mathrm{F} 0.95 ; 50$ IRE) \\
\hline AE Presets & 7 \\
\hline Slow Shutter & Up to $8 x$ \\
\hline Backlight compensation & Yes, with adjustable backlight zone \\
\hline Digital zoom & $4 \mathrm{x}$ \\
\hline Configuration & Outlined OSD via UTC commands \\
\hline Lens mount & CS-mount, C-mount with $5 \mathrm{~mm}$ adapter \\
\hline IR Filter & Built in IR cut filter / ND filter \\
\hline Privacy zone & via Privacy Zone Box \\
\hline Power Supply & $12 \vee \mathrm{DC} \pm 5 \%$ \\
\hline Power Consumption & $\operatorname{Max} 2 \mathrm{~W}$ \\
\hline Weight & Approx. $146 \mathrm{~g}$ \\
\hline Temperature & $-10^{\circ} \mathrm{C}-50^{\circ} \mathrm{C}, 0^{\circ}-35^{\circ} \mathrm{C}$ recommended \\
\hline \multicolumn{2}{|l|}{ Lens } \\
\hline Focal Length & $f=2.8-8 \mathrm{~mm}$ \\
\hline Zoom / Focus control & Manual \\
\hline Iris control & DC auto iris \\
\hline Iris range & F0.95 - T360 (equivalent to F360) \\
\hline Angle of view $(\mathrm{H} \times \mathrm{V})$ & $99^{\circ} \times 73^{\circ}$ (wide end), $35^{\circ} \times 26^{\circ}$ (tele end) \\
\hline Minimum object distance (M.O.D.) & $0.3 \mathrm{~m}$ \\
\hline Object dimensions at M.O.D. $(\mathrm{H} \times \mathrm{V})$ & $736 \times 459 \mathrm{~mm}$ (wide end), $196 \times 145 \mathrm{~mm}$ (tele end) \\
\hline Neutral density filter (ND filter) & Built-in \\
\hline
\end{tabular}

This camera had several features that were beneficial and necessary for a sideview video system application. These features included automatic gain control (AGC) for adjusting the image quality automatically, built-in automatic infrared (IR) filter, manually adjustable field of view (FOV) and focus, compact size, and power requirements. The cameras were calibrated by mounting them at their relative installation height and adjusting the lenses to allow for a $60^{\circ}$ FOV using calibration markers and refocusing. The camera view was adjusted manually after installation on the vehicle. The housing mounts allow for vertical 
and horizontal rotation. Figure 2-4 shows the two extremes for the FOV which represent the $99^{\circ}$ wide end and the $35^{\circ}$ tele end. The red dashed line represents the angle needed for the FOV in order to cover the blind zone and thus leave no area blind to the driver.

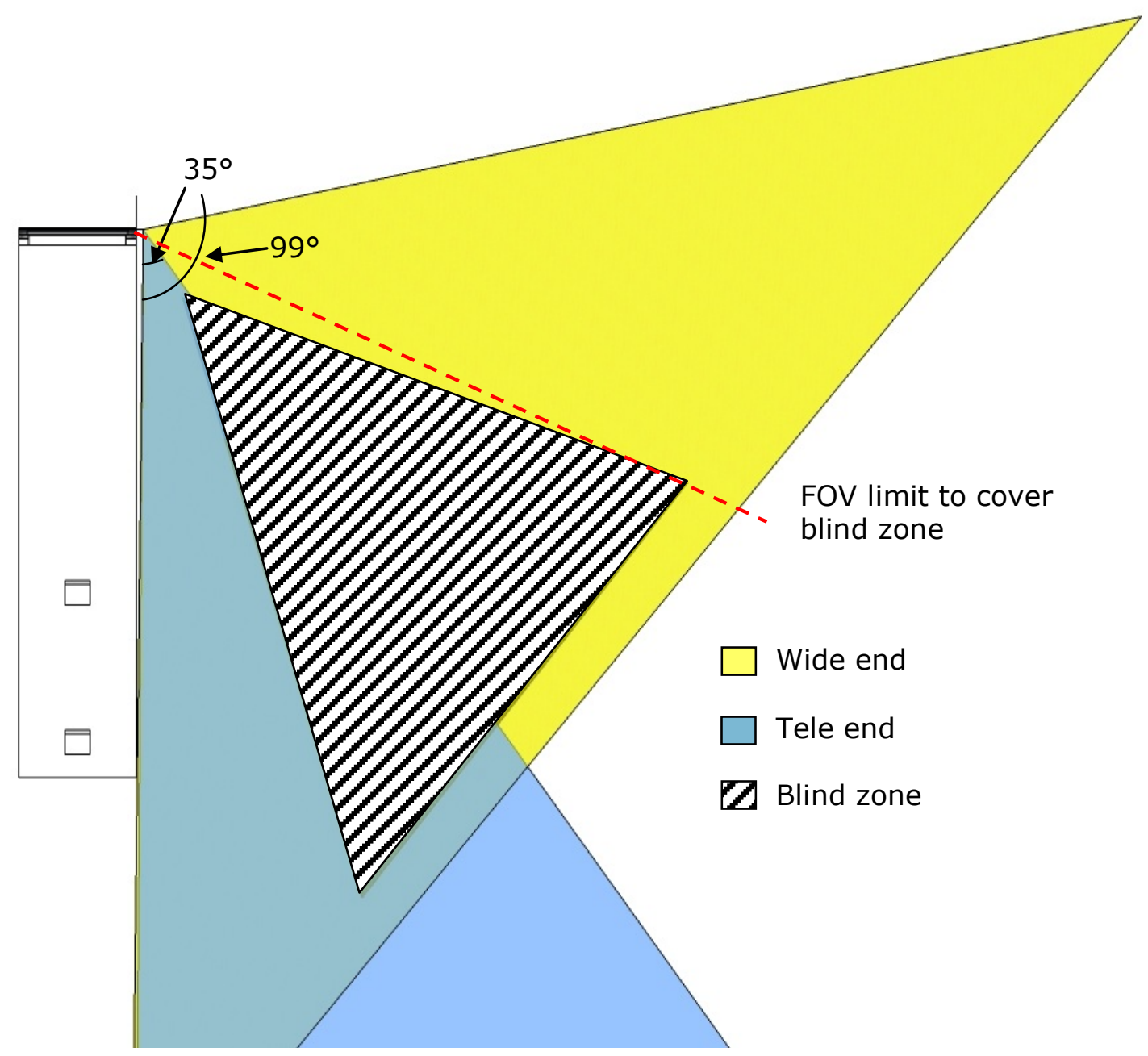

Figure 2-4. Two extreme ends of the camera FOV.

Testing the camera required obtaining the horizontal and vertical dimensions and using the help of a three dimensional software to plot the coverage area. This allowed the comparison of the FOV and testing before the installation on a bus. One of the most important questions of this study was to identify the appropriate FOV which would not be too much or too little. Based on previous work, the wide angle view could cover more than three lane widths next to the bus. Though somewhat beneficial, this was deemed to be too much information for the drivers. Thus, the decision was made to use a field of view of $60-65^{\circ}$ horizontally, since this was also the limit to which the view was covering the blind zones as seen in Figure 2-4 above.

Since the selected cameras were not primarily made for outside use, a housing needed to be fabricated for the field deployment. The camera housing used on the type $A$ bus had to be small, lightweight, waterproof, and have anti-fogging features. The decision was made to fabricate the camera housing in two parts: the main body which holds the camera and its related connector, and the glass/shade portion that would be held together with hardware 
and sealed with an O-ring gasket. Figure 2-5 shows the design of the camera housing for the Dallmeier cameras. The housing was made from PVC plastic with a glass window in the front.

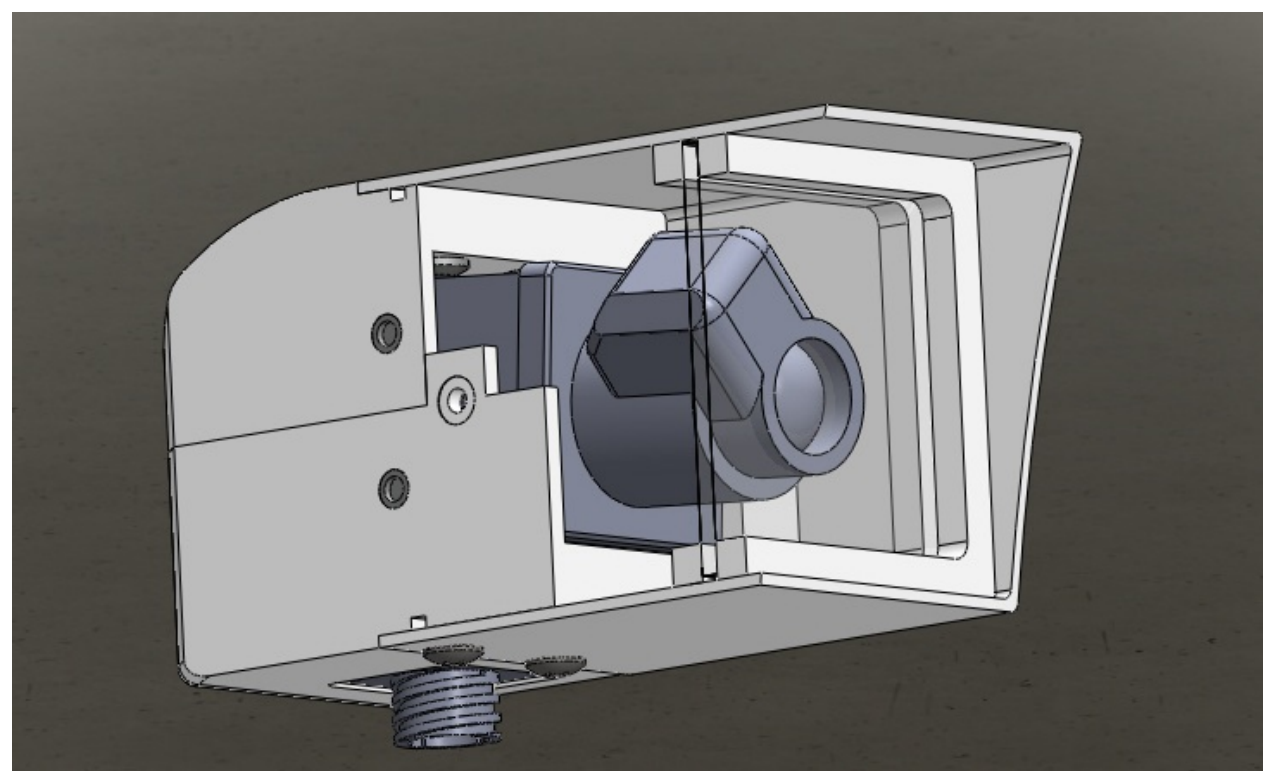

Figure 2-5. Cutaway view of the camera housing.

The main body was fabricated out of two 3 "x 1 "x $4.5^{\prime \prime}$ PVC blocks that were machined and cemented together to form a $3 " \times 3 " x 4.5^{\prime \prime}$ housing. The main body housed the attachment points for the Dallmeier MDF3000A-CS camera, electrical connector, nitrogen filling valve, and air bleeder valve. The sealing area consisted of a slot cut radially on the main body for the fitment of an O-ring gasket. Sealed threaded inserts were utilized as attachment points for the glass/shade portion of the camera housing.

The glass/shade portion was fabricated out of 3"x 3" PVC square tubing. The tubing was cut in order to have a shade integrated into the form. "Window frames" were machined out of $3 " x 3^{\prime \prime} \times 1 / 4$ " PVC and were cemented inside the square tubing. $1 / 8$ " thick glass was cut to allow a window for the camera lens without obstruction. The glass was sealed in place and secured between two window frames. Overall, great importance was given to the materials used in order to achive a lightweight, durable, and robust housing to protect the cameras. When an airtight container changes temperature, the air inside might cause the glass surface to fog from the inside (or outside) thus blocking the view to the camera. The outside is not a problem, but the inside fogging is a problem since there are no easy ways to clean the moisture unless the container is opened. A similar system used in the study by Wiereille et al. (2008) dealt with this problem by introducing pressurized nitrogen into the housing with the air-bleeder valve open to displace the air inside with nitrogen. A nitrogen filled environment does not allow for any moisture to exist. The housings were therefore filled with pressurized nitrogen gas. Another method to achieve this was to use silica gel inside the housing. One of the housings was initially filled with silica gel packets, but the quantity was not enough to absorb the moisture created inside the housing. It was later changed to nitrogen filled as well.

Figure 2-6 shows all the design views of the housing. It was designed to have some aerodynamic component and to deflect air. Also there is shade to provide some cover from the sun for the camera as seen on the right and left view. 


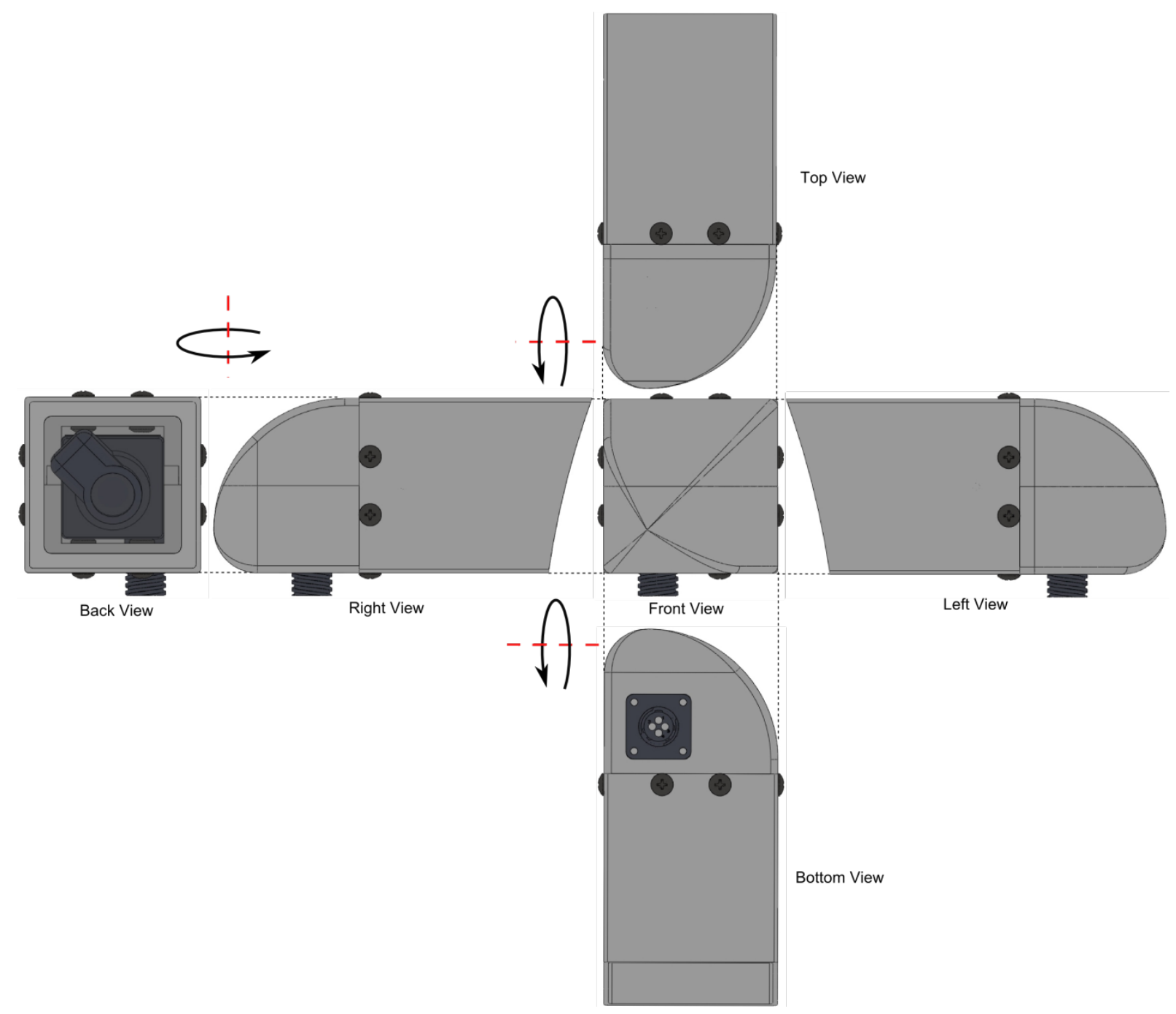

Figure 2-6. Views of camera housing.

These cameras were used only for the type A bus. For the cutaway bus, an aftermarket system by VELVAC ${ }^{\circledR}$ was used, since it was made specifically for the purpose and was meeting the requirements chosen by the team. The camera used in this system has similar characteristics with the Dallmeier, and provides a similar view. It is also manufactured in combination with a flat-convex mirror for cutaway buses. The technical specifications of the camera are shown in Table 2-2. The camera was installed in a custom housing underneath the mirror housing shown in Figure 2-7. The camera was angled downward at $17^{\circ}$ and can be adjusted for left or right alignment after installation so that it can provide the optimum visibility to the driver. 
Table 2-2. Velvac Camera Technical Specifications

\begin{tabular}{|l|l|}
\hline Weight & $0.33 \mathrm{Ib}$ \\
\hline Camera Type & CMOS \\
\hline B/W or Color & Color and B/W (IR) \\
\hline Power System & 12 V DC \\
\hline Waterproof & Yes IPX7 \\
\hline Viewing Angle (degree) & $65^{\circ}$ Horizontal \\
\hline IR LED Low Light Enhancement & Yes \\
\hline Built-in Microphone & No \\
\hline Video Output Signal Format & NTSC \\
\hline Sensor (Inches) & $1 / 4$ \\
\hline Shutter & Electronic Iris \\
\hline Image Orientation & Mirror (Reversed) \\
\hline Impact Resistant Plastic Housing & Yes \\
\hline Machined Aluminum Body & Yes \\
\hline
\end{tabular}

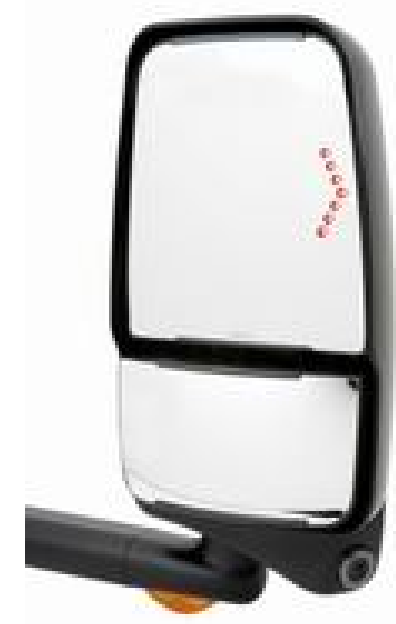

Figure 2-7. Mirror-camera system used for cutaway bus.

Monitors

The monitors used in this study were chosen for their features and size. For the type $A$ bus system in conjunction with the Dallmeier cameras, one Voyager 7" LCD monitor, and one Accelevision 8" LCD monitor were used. For the cutaway bus, two Voyager 7" LCD monitors were used since the space is limited on the driver dashboard. Figure 2-8 shows the 7" monitor and the $8^{\prime \prime}$ monitor used in combination with the cameras to complete the sideview video system. The specifications of the 7" monitor and 8" monitor used in the systems are shown in Table 2-3 and Table 2-4. The right monitor for the type A bus was chosen to be $8^{\prime \prime}$ because of feedback received from drivers during Phase I. The drivers reported that they wanted the right monitor to be larger than the 7" used.

The monitors were robust and tested for commercial use in order to withstand the harsh environment of transit buses. 

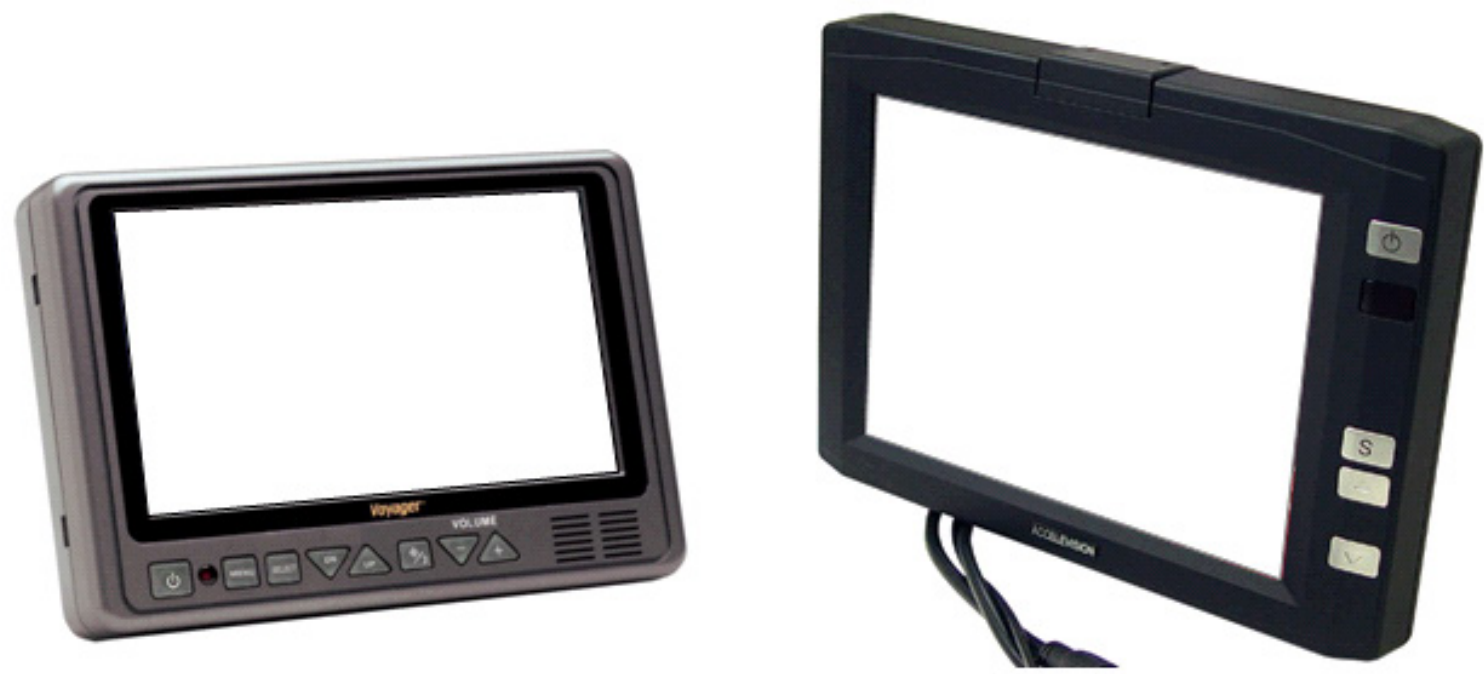

Figure 2-8. 7" (left) and 8" (right) monitors used for the sideview camera system.

Table 2-3. Seven-Inch Monitor Technical Specifications

\begin{tabular}{|c|c|c|}
\hline \multicolumn{3}{|l|}{ Voyager AOM-711 } \\
\hline Size/Type & \multicolumn{2}{|c|}{ 7" (Diagonal) TFT-LCD } \\
\hline Brightness & \multicolumn{2}{|l|}{$500 \mathrm{~cd} / \mathrm{m}^{2(\max )}$} \\
\hline Contrast Ratio & \multicolumn{2}{|l|}{$300(\max )$} \\
\hline View Angles & Top (12 o'clock) & $50^{\circ}(\min )$ \\
\hline \multirow[t]{2}{*}{ (@CR $\geq 10)$} & Bottom (6 o'clock) & $70^{\circ}(\mathrm{min})$ \\
\hline & Horizontal & $\pm 70^{\circ}(\min )$ \\
\hline \multirow{2}{*}{ Response Time } & \multicolumn{2}{|c|}{ Rise: 12 ms (typ); 24 ms (max) } \\
\hline & \multicolumn{2}{|c|}{ Fall: 18 ms (typ); 36 ms (max) } \\
\hline Back Light Life & \multicolumn{2}{|l|}{$10,000 \mathrm{hr}(\mathrm{min})$} \\
\hline Operation Temperature Range & \multicolumn{2}{|l|}{$-20{ }^{\circ} \mathrm{C}$ to $+65^{\circ} \mathrm{C}$} \\
\hline Storage Temperature Range & \multicolumn{2}{|l|}{$-35^{\circ} \mathrm{C}$ to $+85^{\circ} \mathrm{C}$} \\
\hline Operation Voltage Range & \multicolumn{2}{|l|}{$\mathrm{DC} 10.5 \mathrm{~V}$ to $32 \mathrm{~V}$} \\
\hline Current Draw (typical) & \multicolumn{2}{|l|}{$15 \mathrm{~W}(\max )$} \\
\hline Signal System & $\begin{array}{l}\text { NTSC or PAL (Auto } \\
\text { detection) }\end{array}$ & \\
\hline \multirow{2}{*}{ Video } & Aspect Ratio & $16: 9$ \\
\hline & Input Level & $1 \mathrm{Vp}-\mathrm{p} 75 \Omega$ \\
\hline Audio & Input Level & Max $0.2 \mathrm{~W}-150 \mathrm{mV}$ \\
\hline Product Weight & \multicolumn{2}{|l|}{$1.43 \mathrm{lb} / 650 \mathrm{~g}$} \\
\hline Product Dimensions & \multicolumn{2}{|c|}{$7.75 " \mathrm{~W} \times 5.25 " \mathrm{H} \times 1.25 " \mathrm{D}$} \\
\hline
\end{tabular}


Table 2-4. Eight-Inch Monitor Technical Specifications

\begin{tabular}{|c|c|c|}
\hline \multicolumn{3}{|l|}{ Accelevision LCDP8SVGA } \\
\hline Size/Type & \multicolumn{2}{|l|}{ 8" (Diagonal) TFT-LCD } \\
\hline Brightness & \multicolumn{2}{|l|}{$220 \mathrm{~cd} / \mathrm{m}^{2(\max )}$} \\
\hline Resolution & \multicolumn{2}{|l|}{$800 \times 600$} \\
\hline \multirow{3}{*}{ View Angles } & Top (12 o'clock) & $40^{\circ}$ (min) \\
\hline & Bottom (6 o'clock) & $65^{\circ}(\min )$ \\
\hline & Horizontal & $\pm 65^{\circ}(\min )$ \\
\hline Back Light Type & \multicolumn{2}{|l|}{ CCFL } \\
\hline Operation Temperature Range & \multicolumn{2}{|l|}{$-0{ }^{\circ} \mathrm{C}$ to $+50^{\circ} \mathrm{C}$} \\
\hline Storage Temperature Range & \multicolumn{2}{|l|}{$-30{ }^{\circ} \mathrm{C}$ to $+60{ }^{\circ} \mathrm{C}$} \\
\hline Operation Voltage Range & \multicolumn{2}{|l|}{$\mathrm{DC} 12 \mathrm{~V} \pm 15 \%$} \\
\hline Current Draw (typical) & \multicolumn{2}{|l|}{$950 \mathrm{~mA}$} \\
\hline Signal System & NTSC, PAL, VGA(SVGA) & \\
\hline Video & Input Level & $1 \vee p-p 75 \Omega$ \\
\hline Product Weight & \multicolumn{2}{|l|}{$1.47 \mathrm{lb} / 670 \mathrm{~g}$} \\
\hline Product Dimensions & \multicolumn{2}{|c|}{ 8.6250"W x 6.4375"H x 1.4375"D } \\
\hline
\end{tabular}




\section{Chapter 3 Controlled Driving Test}

One of the methods used to evaluate a safety enhancement device is to perform a driving test under controlled conditions. The driving test can collect certain data pertaining to the use of the system by drivers and its effectiveness on the safety aspect tested. A driver test requires drivers from the relevant population, in this case, transit bus drivers, driving a bus equipped with the safety enhancement device, in this case, the sideview video system, performing certain maneuvers designed to test different aspects of the system.

The purpose of the controlled driving test was to measure how fast and accurate, transit drivers could identify an object using the mirrors only, or using the combination of cameramirror system. In addition, the test was used to obtain feedback from the drivers on the system's effectiveness to aid the driver in identifying potentially hazardous situations they cannot identify with the mirrors.

\section{Test Design}

The test consisted of two parts:

1. Driving the bus to get familiar with the system.

2. Object detection/recognition test.

The driving test was performed on May 8-9, 2012 at the StarMetro Transit Agency in Tallahassee, FL. The bus parking lot was utilized for the closed course since the test could not be conducted on public roads. Figure 3-1 shows the location and route the drivers took to complete the first part of the test. The parking lot was empty at the time since almost all buses were in service.

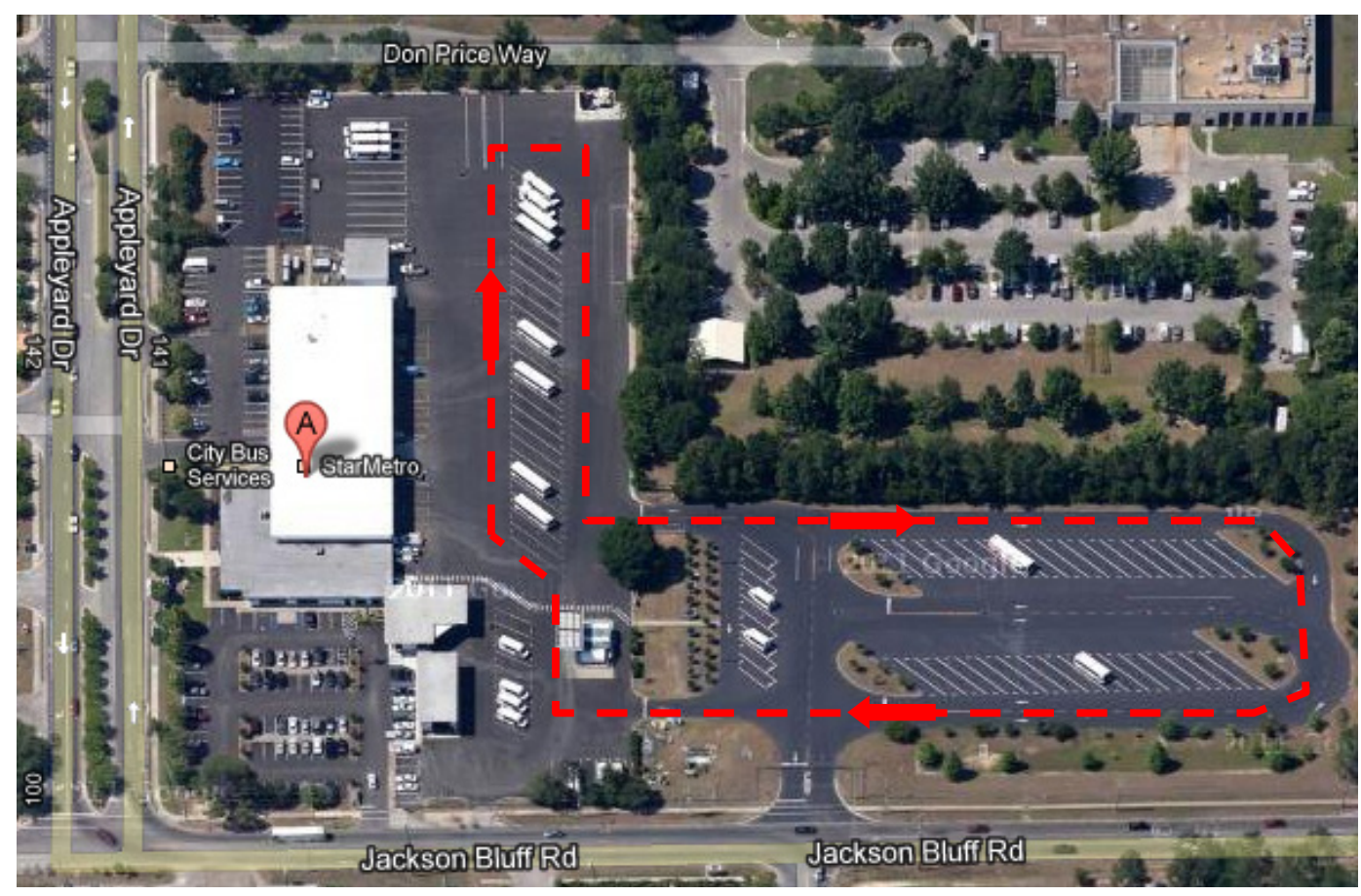

Figure 3-1. Controlled test (closed course) route. 
A closed loop driving course was designed. Drivers were provided with a limited time to experience the sideview video system and use it before they performed the object detection test. This allowed for some learning and exposure time. The course consisted of left and right turns.

Before the drivers drove the course, they were advised to use the sideview video system as they would have used their side mirrors in order to follow the course. After the drivers drove the bus around the closed course twice, they proceeded to perform the next part of the test, unless they felt they needed more time to get familiar with the system.

The second part was designed to measure if the drivers could identify an object (traffic cone) and a person placed at different places around the bus while the bus was static. The test was performed twice: once using the mirrors only and once with the mirror-camera combination. This allowed the measurement of the effectiveness of the camera system in aiding the drivers to identify the objects correctly, and quickly. The test included both types of buses, equipped with the systems described in Chapter 2. The cameras were not placed in their final housing at that time. Predetermined random locations were chosen for both the traffic cone and the person. Figure 3-2 shows the position/order where the cone (ㅇ) and the person $(0)$ were placed in the order shown in increasing numbers $(1,2,3 \ldots)$ at random order for each driver. Each driver was given a 35-dollar incentive for participating in the test. This was a volunteer participation and approved (USF IRB \#00006235). The materials given to the drivers can be found in Appendix A.

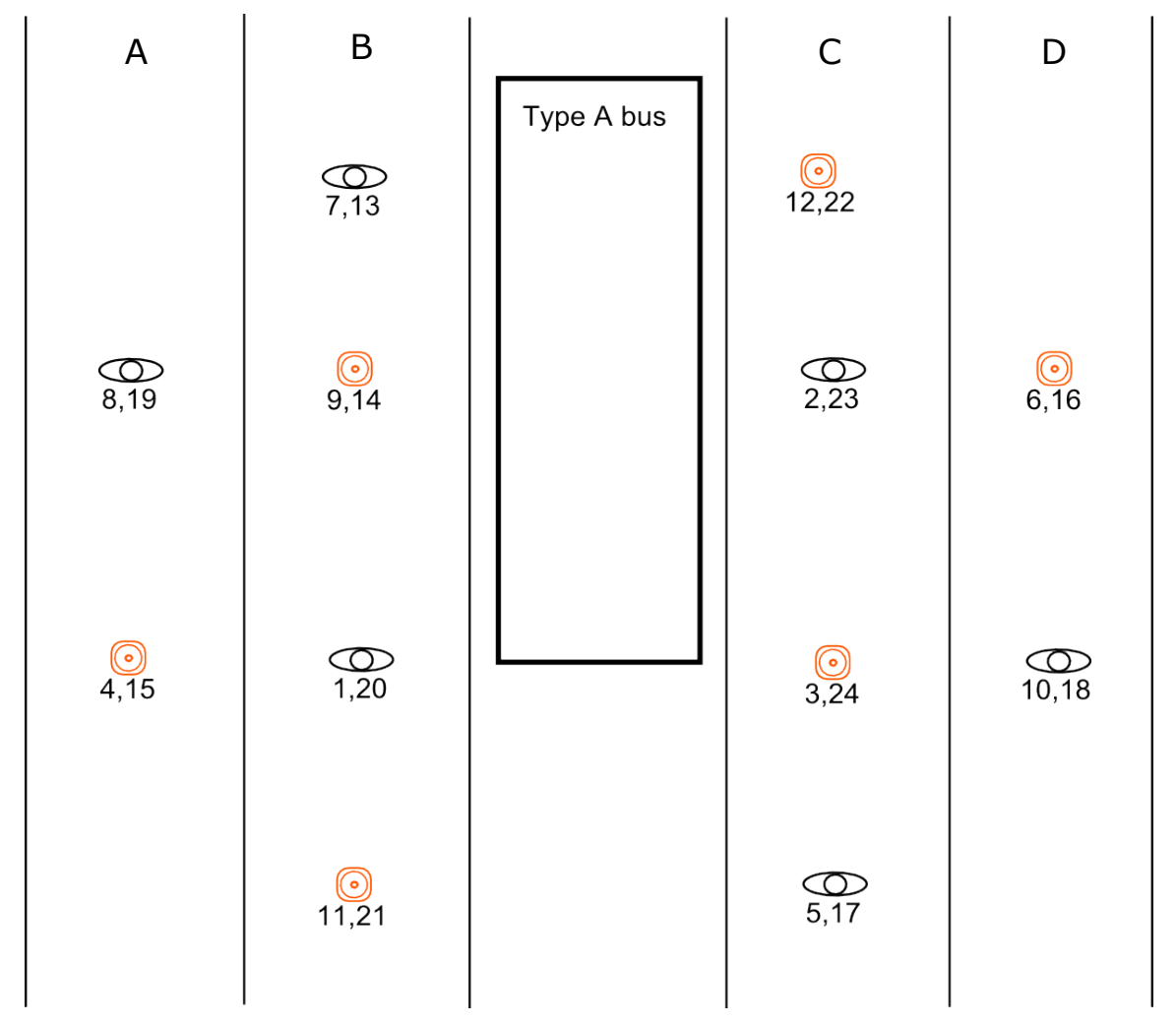

Figure 3-2. Layout for the object detection/recognition test (type A bus). 


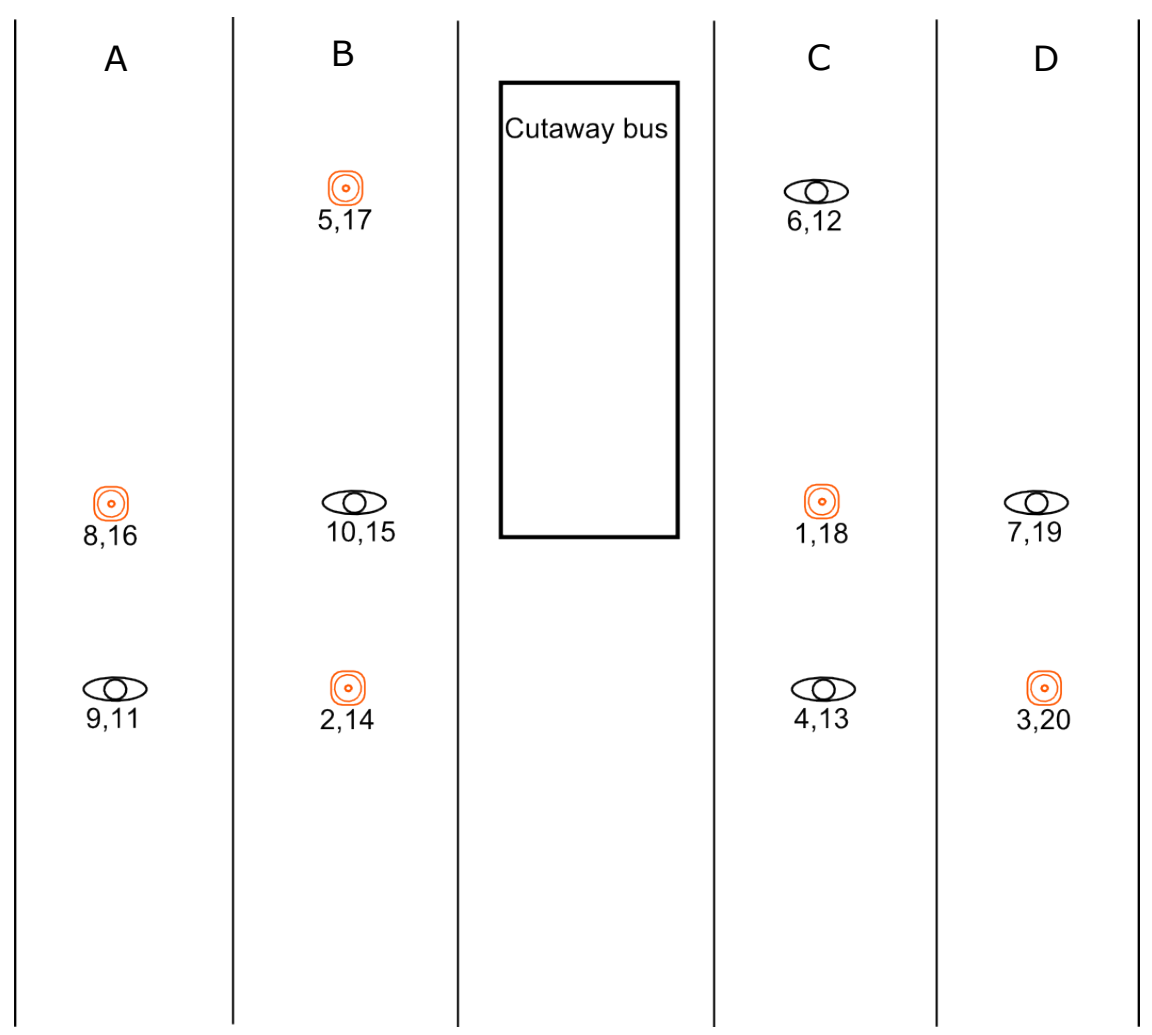

Figure 3-3. Layout for the object detection/recognition test (cutaway bus).

Subjects were instructed that on a few of the tasks there might not be an object present. This helped to prevent guessing. The drivers were asked to report "undetectable" when they could not see an object, and it was considered the appropriate response, so subjects were discouraged from guessing. This allowed comparison of the number of undetectable responses with and without the camera system. Results were scored in terms of correctness of object location, correctness of object location and identification (combined), and response time. A maximum time was selected as 30 seconds because objects were not always detectable regardless of time allowed. However, there were no cases where response time exceeded 30 seconds. Drivers who could not find an object simply said it was undetectable. This always occurred in less than 30 seconds, so selection of the value became irrelevant.

Table 3-1. Object Presentation Scheme for the Object Detection Test

\begin{tabular}{|l|l|l|}
\hline Bus Type & \multicolumn{1}{|c|}{ With Camera } & Without Camera (mirror only) \\
\hline Type A & $1,4,5,7,10,12,15,17,19,20,23,24$ & $2,3,6,9,8,11,13,14,16,18,21,22$ \\
\hline Cutaway & $3,4,5,6,9,11,13,15,17,19$ & $1,2,7,8,10,12,14,16,18,20$ \\
\hline
\end{tabular}

The steps taken to conduct this test were as follows:

1. The driver was asked to park the bus at the predetermined location.

2. The driver was instructed to look down, and wait until the test administrator instructed him/her to look up and scan mirrors and monitors (if they were on) and identify if, what, and where they could see the object.

3. The test administrator was outside communicating with a two way radio and randomly putting the cone or themselves in the predetermined position.

4. When the driver reported what they could see and where, the administrator would also record the time it took the driver to scan, identify, and report. 
5. The test was completed when all combinations of locations/objects were performed.

The cameras and monitors were temporarily installed on the buses using suction cups on the type A bus shown in Figure 3-4. The monitors were installed at the A-pillar for the left, and above the GPS travel logger screen next to the driver, as shown in Figure 3-5.
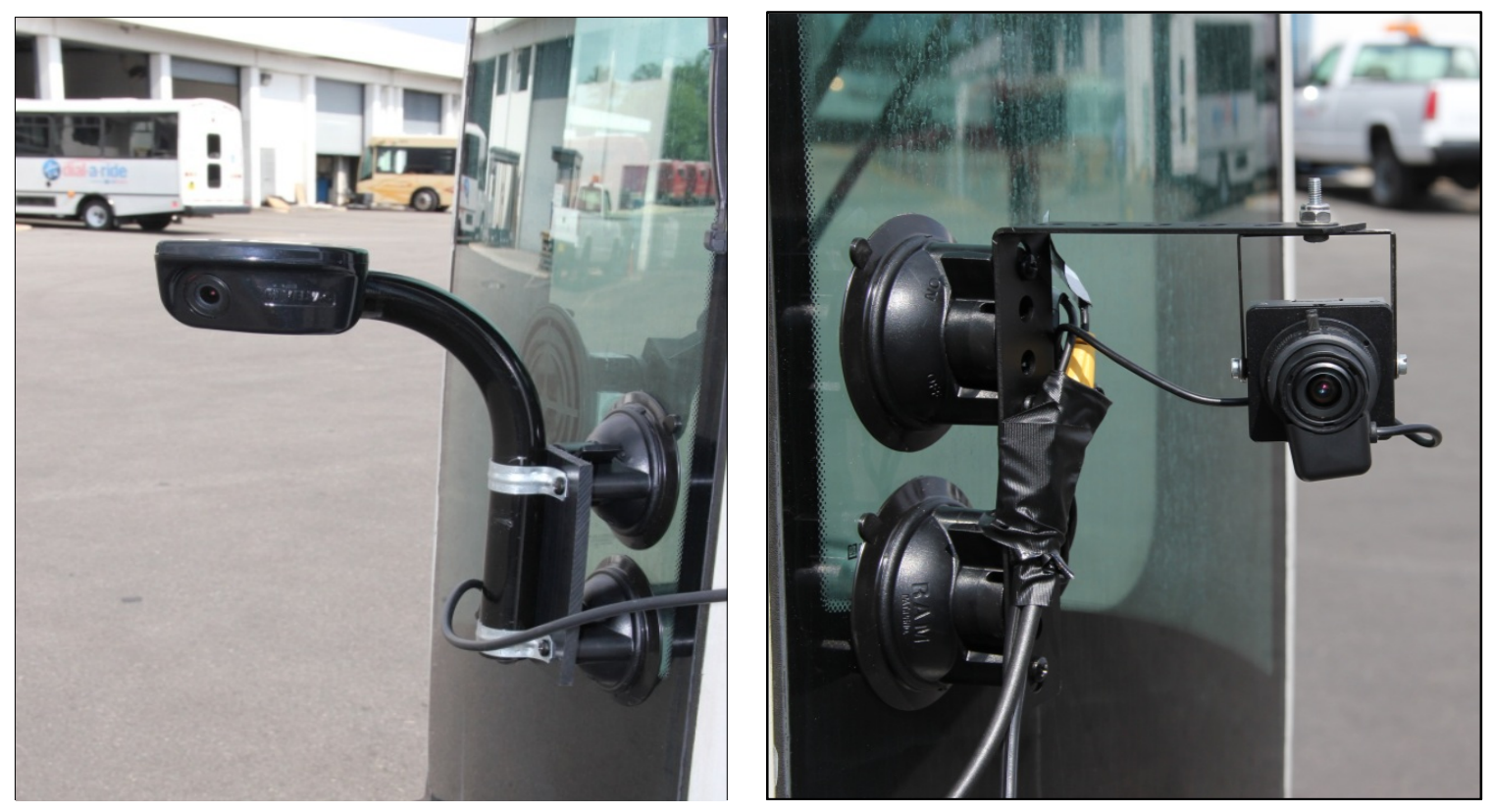

Figure 3-4. Left and right side cameras on type $A$ bus.

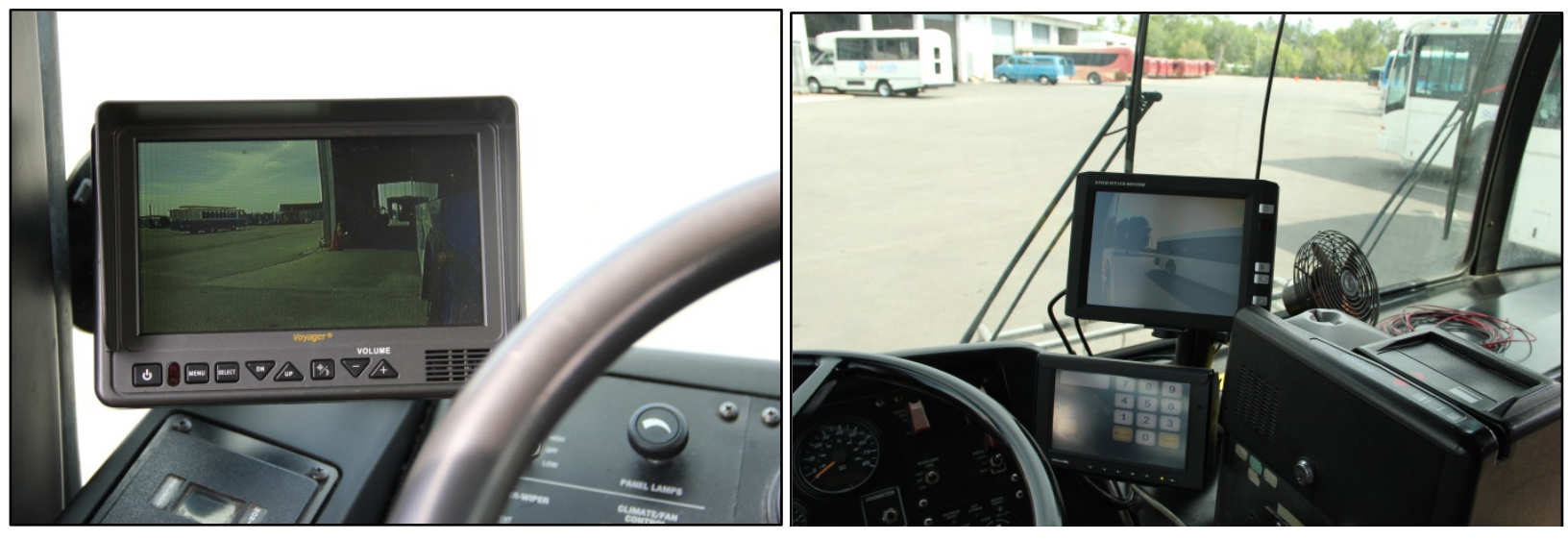

Figure 3-5. Left and right side monitors on type A bus. 


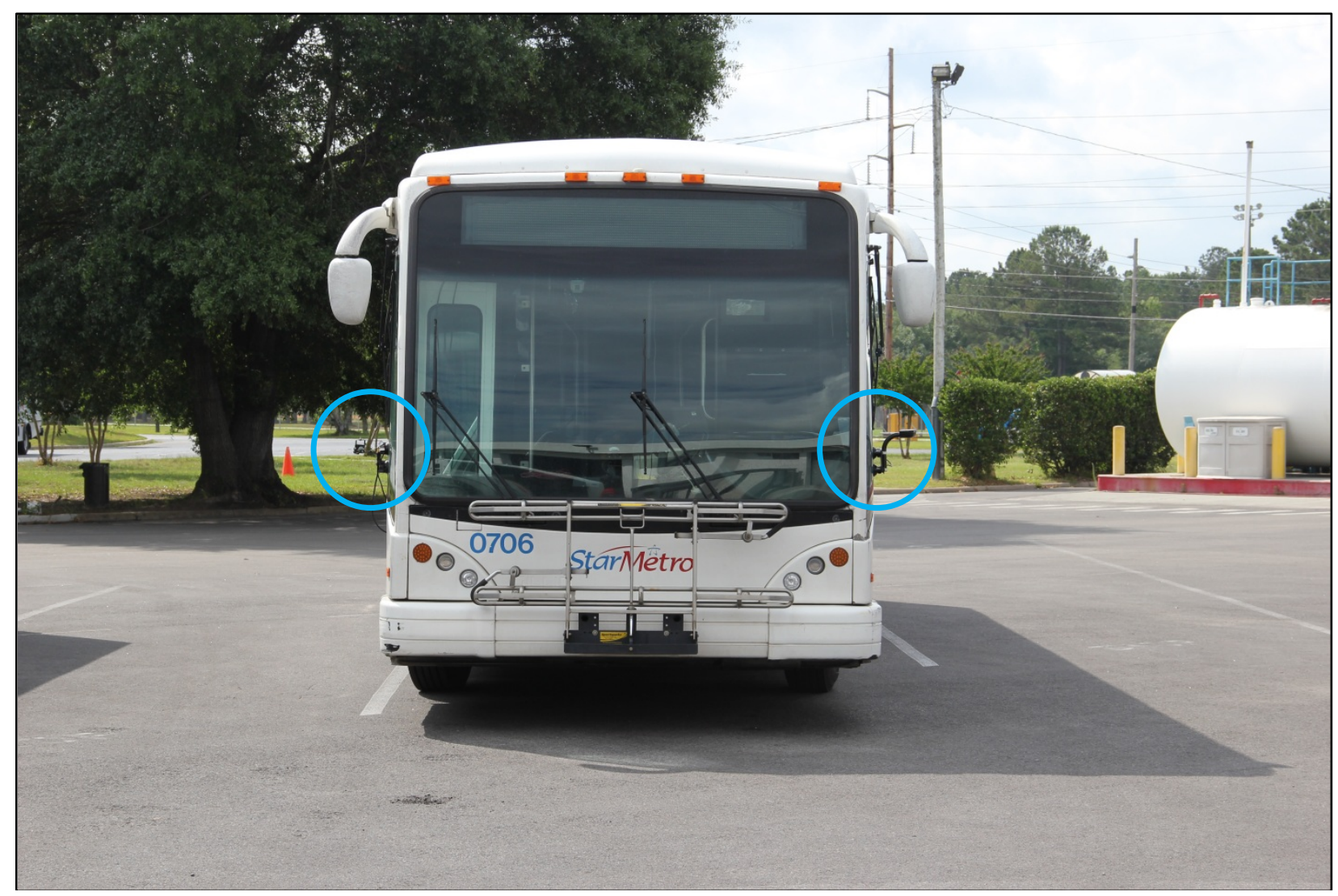

Figure 3-6. The type A bus used for the driving test.

On the cutaway bus, since space was an issue, two 7" monitors were used. The cameras used were mounted on the mirror arms since this was the best location identified to achieve the required view. The cameras were angled so that the drivers could see the edge of the bus on the edge of the monitor, just like a mirror would be adjusted for optimum viewing.
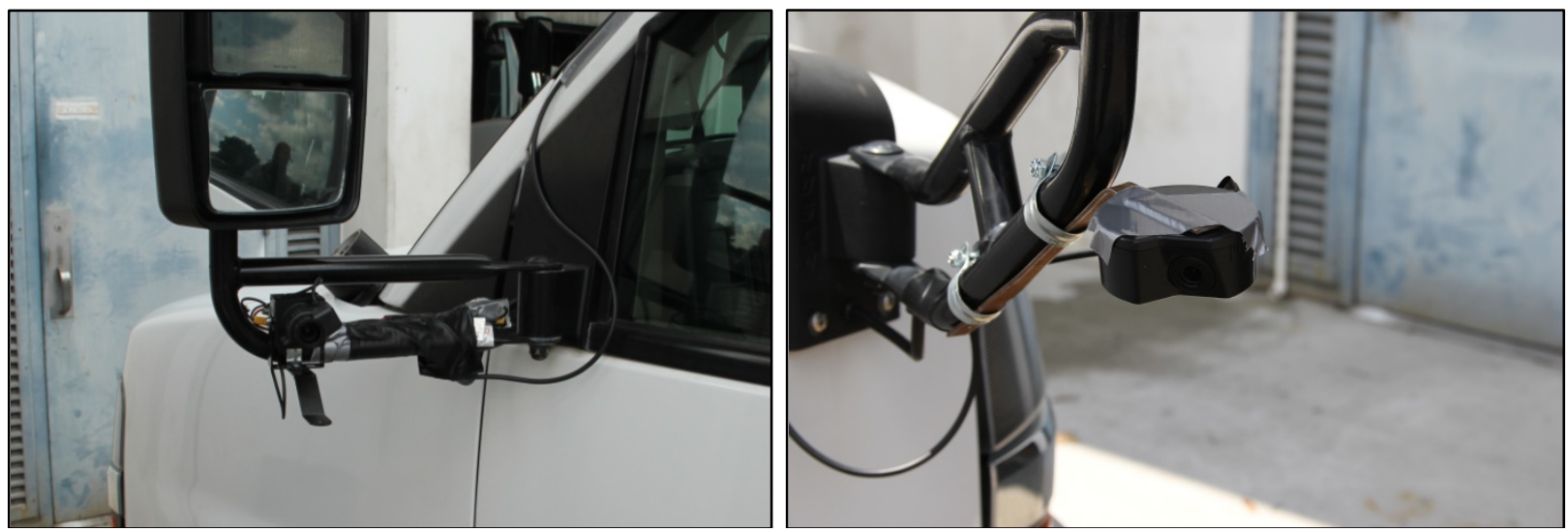

Figure 3-7. Left and right cameras used on the cutaway bus. 


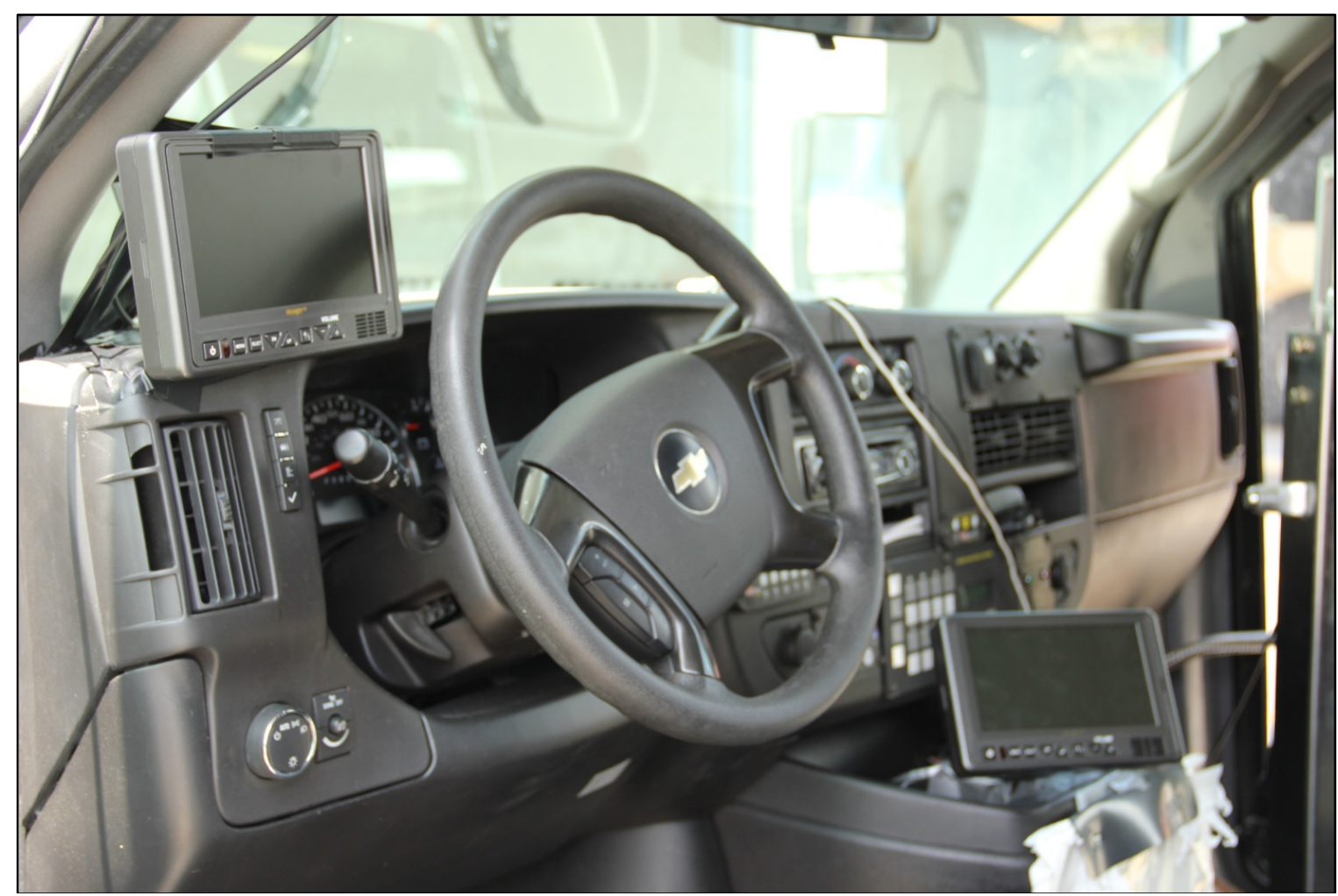

Figure 3-8. Left and right side monitors mounted on the cutaway bus.

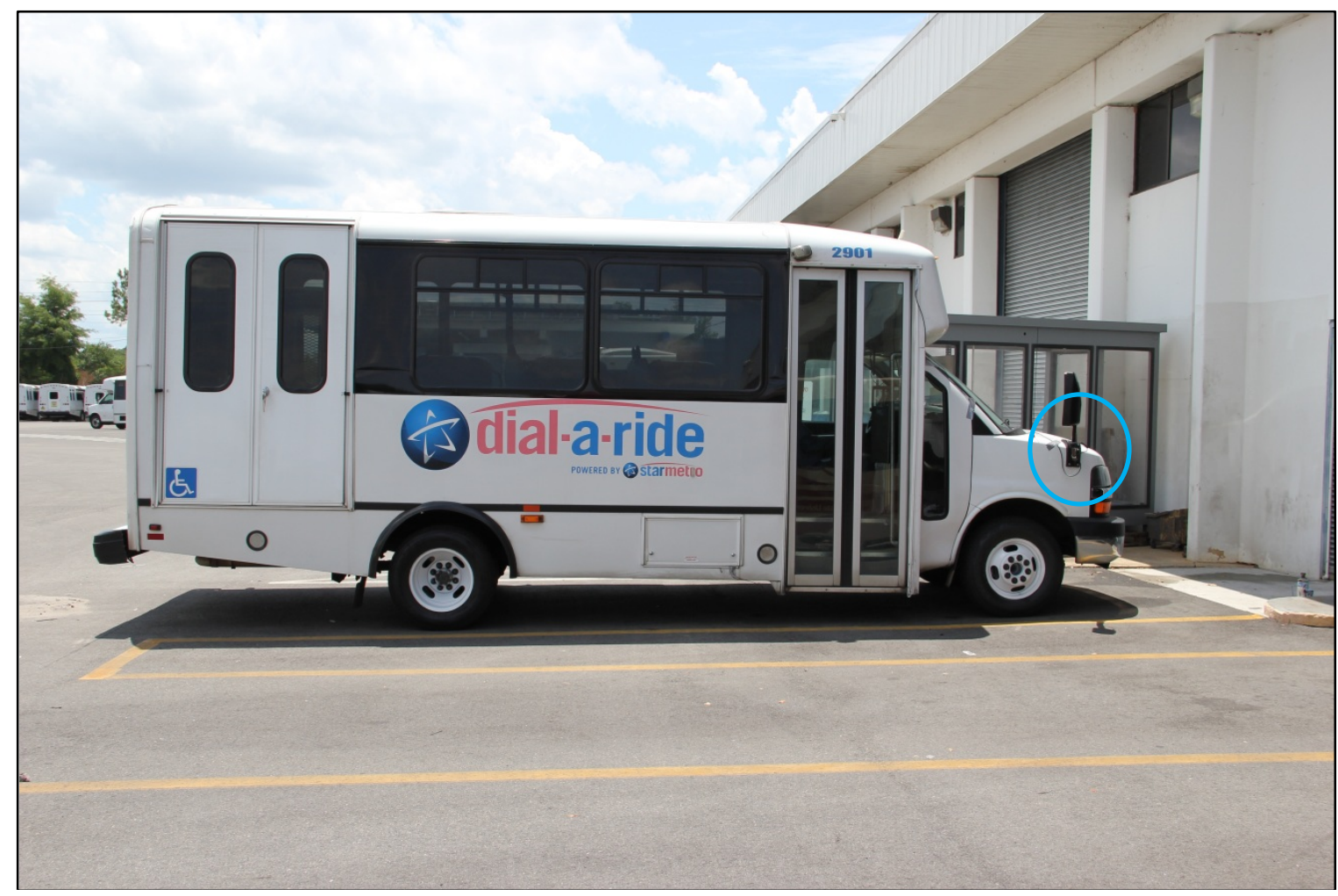

Figure 3-9. The cutaway bus used for the driving test. 


\section{Results of the Controlled Driving Test}

During testing on the type $A$ bus, it became clear from the first couple of tries that the pairs $(7,13)$ and $(12,22)$ from the testing sequence found in Figure 3-2 were not beneficial because they were placed too close to the driver on the left and in the direct field of view from the passenger door on the right. The drivers could see the cone and the person too easily so the decision was made to remove the two locations and four points from the testing. The remaining data provided 20 data points, or 10 pairs for each of the buses.

A total of 29 drivers participated in the driving test. Sixteen drivers drove the type A bus, and 13 drivers drove the cutaway. The drivers were separated because each driver drives only one of the two types of buses regularly. In other words, a driver that drives the cutaway bus does not drive the type A bus and vice versa. The first analysis was directed at correctness of object location. Table 3-2 shows the results. There were 10 pairs for each of the 29 total subjects, resulting in a total of 290 trials for mirror (baseline) and 290 trials for the camera system (enhancement).

Table 3-2. Correctness of Location as a Function of Baseline vs. Enhancement

\begin{tabular}{|l|c|c|}
\hline & Correct & Incorrect \\
\hline Mirror (baseline) & 202 & 96 \\
\hline Camera (enhancement) & 279 & 12 \\
\hline
\end{tabular}

A chi-square analysis demonstrated a significant difference between the baseline and enhancement conditions: $x^{2}(1)=65.675, p<0.0001$. This result shows that object location determination was significantly better with the enhancement than with baseline. In terms of comparison, subjects provided the correct location of objects 96.2 percent of the time with the enhancement operating and 69.7 percent of the time with baseline. The correctness of identification was 100 percent accurate for all drivers since there were only two objects and easily identified. All tests were performed during daylight conditions.

Driver Side Analysis

Subsets of the data were also examined by side of the bus. These data were intended to determine if the enhancement was helpful, depending on the general location of the object, that is, to which side. In regard to the driver side, all pairs appearing in columns $A$ and $B$ in Figures 3-2 and 3-3 were included. There were 10 pairs on the driver side, as the figure shows. Data for these 10 pairs were extracted and analyzed. The chi-square test showed that there was a significantly better location determination with the enhancement than with baseline conditions: $x^{2}(1)=23.179, p<0.0001$. Shown in Table 3-3, 96.9 percent of drivers correctly identified the location with enhancement vs. 79.1 percent in the baseline condition.

Table 3-3. Correctness of Location as a function of Baseline vs. Enhancement for Driver Side.

\begin{tabular}{|l|c|c|}
\hline & Correct & Incorrect \\
\hline Mirror (baseline) & 102 & 27 \\
\hline Camera (enhancement) & 156 & 5 \\
\hline
\end{tabular}


Passenger Side Analysis

This analysis was carried out in a manner similar to the driver side analysis, except that pairs in columns $C \& D$ were used. In this case there were, again, 10 pairs. The data were again analyzed statistically and were found to result in significance using a chi-square test: $x^{2}(1)=4.094, p<0.0001$. Table 3-4 shows that the subjects correctly located objects on the passenger side with the enhancement 98.4 percent of the time, whereas only 70.2 percent of the time in the baseline condition.

Table 3-4. Correctness of Location as a Function of Baseline vs. Enhancement for Passenger Side.

\begin{tabular}{|l|c|c|}
\hline & Correct & Incorrect \\
\hline Mirror (baseline) & 113 & 48 \\
\hline Camera (enhancement) & 127 & 2 \\
\hline
\end{tabular}

\section{Response Time}

In these analyses, response times were analyzed regardless of correctness. In other words, this analysis was simply response time from the cue to begin the search until the subject responded with a location, whether correct or incorrect. In each case, a two (baseline versus Enhancement) by 10 (Object location-Type) within-subject ANOVA was performed, using the data from the 29 subjects. The baseline versus enhancement main effect was significant, $F(1,28)=7.972, p<0.001$. The main effect of object location-type was significant, $\mathrm{F}(9,261)=62.434, p<0.0001$.

The main effect of baseline versus enhancement on response time, regardless of correctness, is shown in Figure 3-10. Surprisingly, the results show that times to find objects were faster for the enhancement condition than for the baseline condition, even though there were more sources to scan with the enhancement condition. It can be said that the enhancement did not add to response time, which is an important finding.

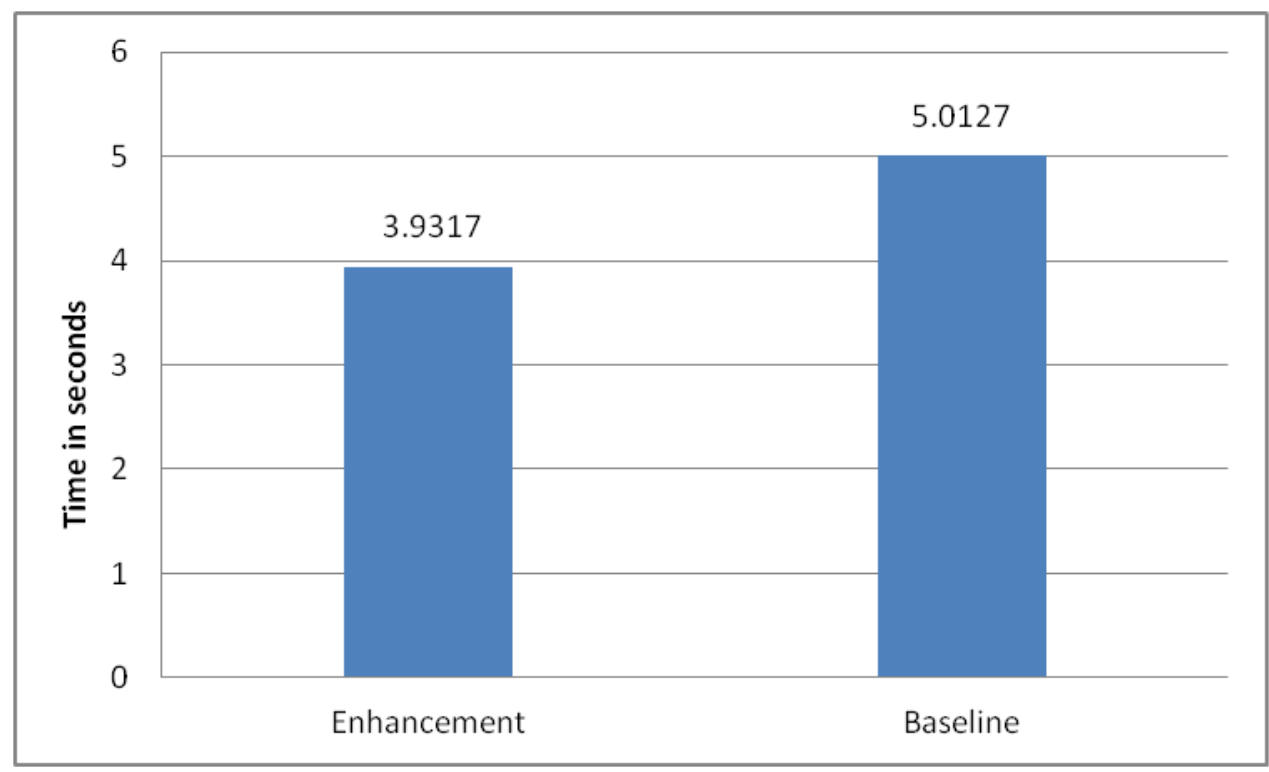

Figure 3-10. Response times as a function of baseline vs. enhancement. 
The main effect of object location-type for responses regardless of correctness is shown in Figure 3-11. Here, the response times, regardless of correctness, have been put in ascending order. Analysis showed that the outward location-objects (Figure 3-2 and Figure 3-3), took longer to detect except the pair $(9,11)$ for the cutaway and $(4,15)$ for the type A. Also note that attention should be paid to pairs $(7,19)$ and $(6,16)$ which have the highest response time. These pairs were admittedly on the right side blind zone and drivers had to move their head using the mirrors to finally identify the object.

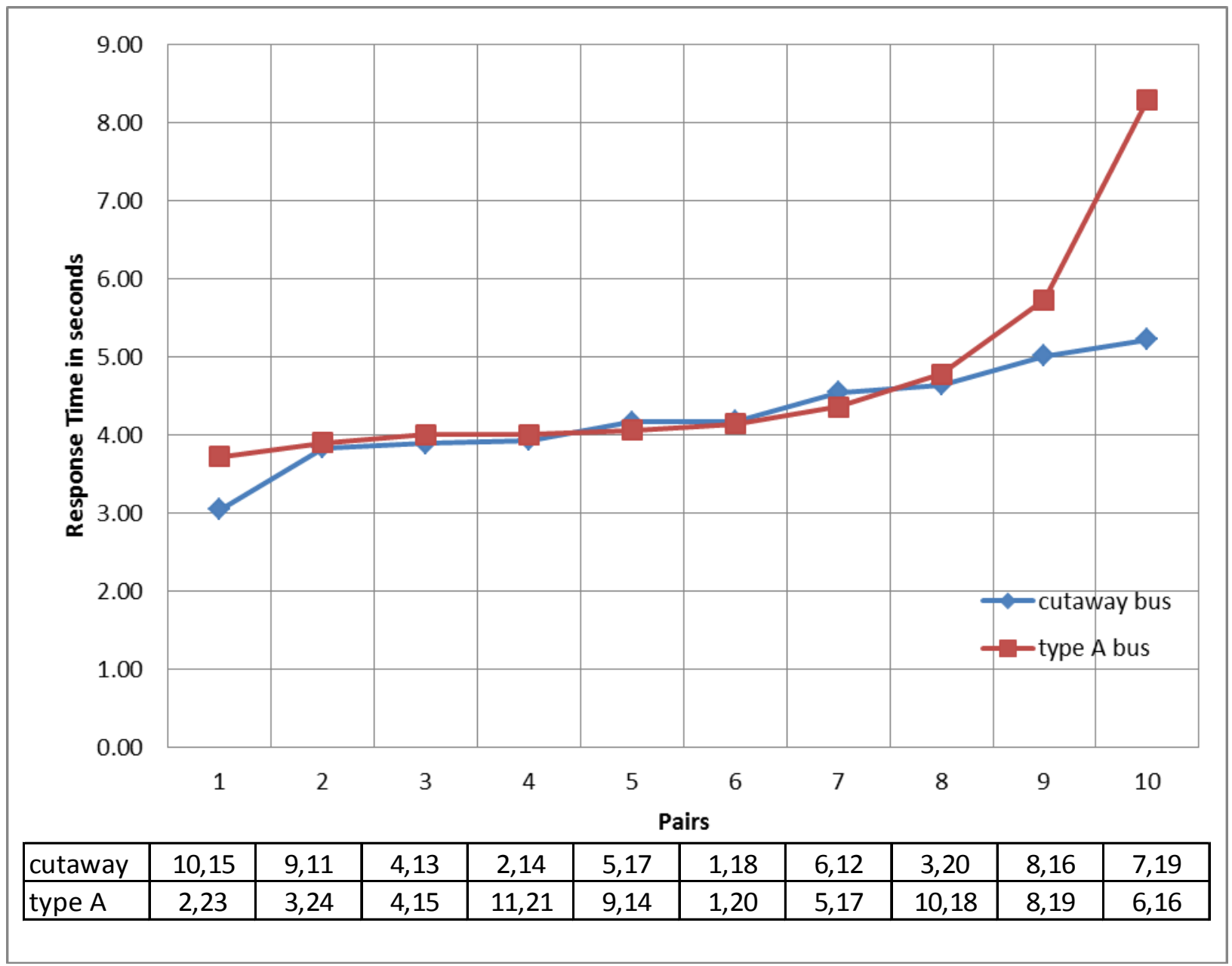

Figure 3-11. Main effect of object-location-type pair on response time.

The interactive effect is shown in Figure 3-12 which includes only the pairs from both buses that had one trial the baseline, and the other trial the enhancement. The figure shows that in both types of buses, several of the very long response time pairs were substantially improved (shortened) by the presence of the enhanced condition except in one case, pair $(3,20)$ in the cutaway bus. As shown in Figure $3-3$, this pair was at the right side at the farthest location possible from the driver and therefore could be in the edges of the visible view from both mirror and camera.

Taken together, the results suggest that the enhancement is effective in reducing the search times and also in improving the accuracy of object location and type detection. Results demonstrate statistically significant improvements on the passenger side as well as improvements in general. 


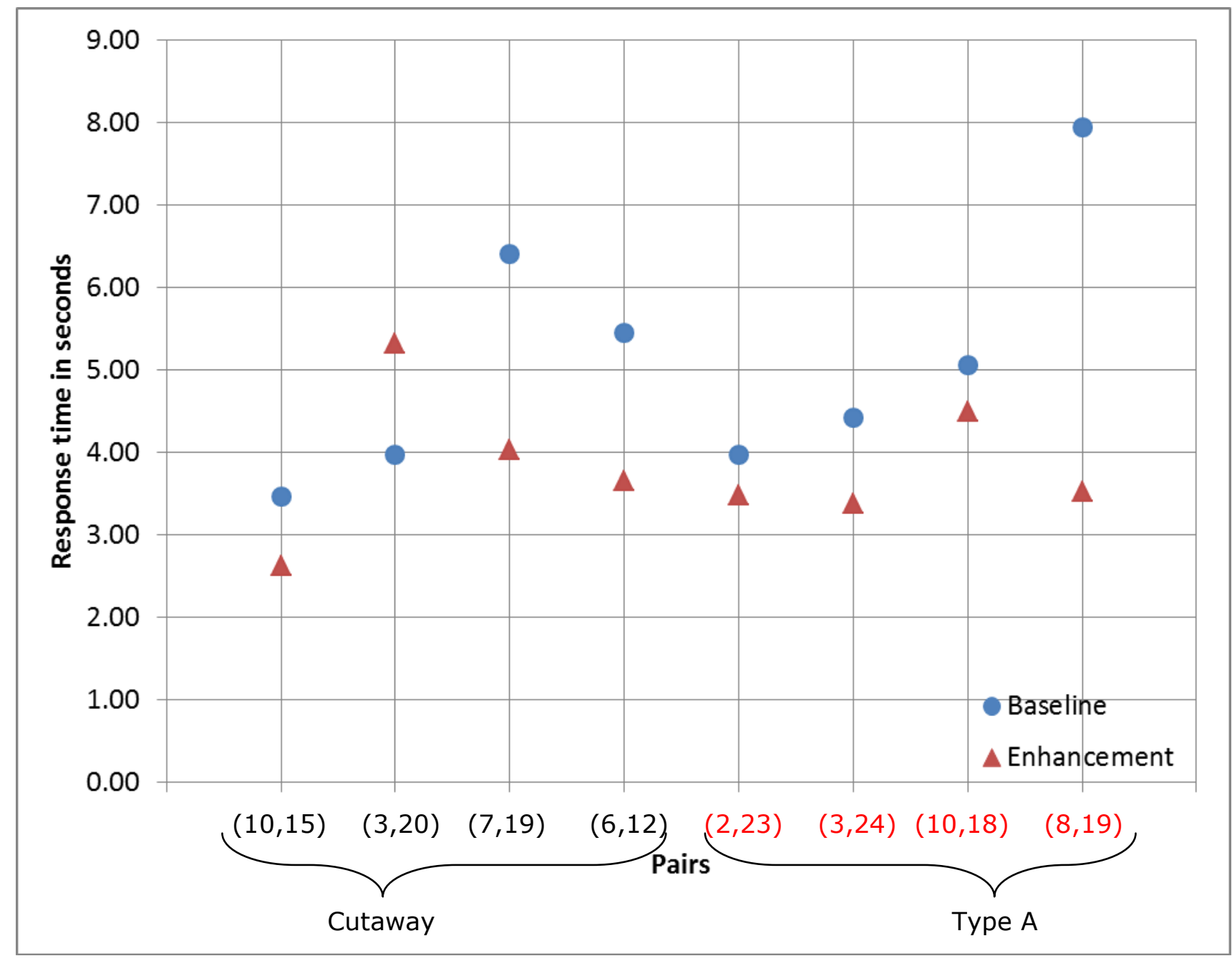

Figure 3-12. Interaction of baseline vs. enhancement with object location-type pair on response time.

\section{Driver Survey}

Drivers participating in the controlled test were asked to provide feedback with a series of questions shown in Appendix A. Questions 1-6 were asked before the drivers drove the equipped bus. After they experienced the system, and completed the object detection test, they finished answering the rest of the questions. Some questions were the same from before and after so a comparison and potential shift in opinion could be captured.

\section{Driver Demographics}

The 29 participating drivers had the age distribution shown in Figure 3-13 and an average of 7.88 years of driving experience with 1 year minimum and 30 maximum. Twenty percent had previous experience with a camera aid system and 43.3 percent had a previous side crash while driving a bus. 


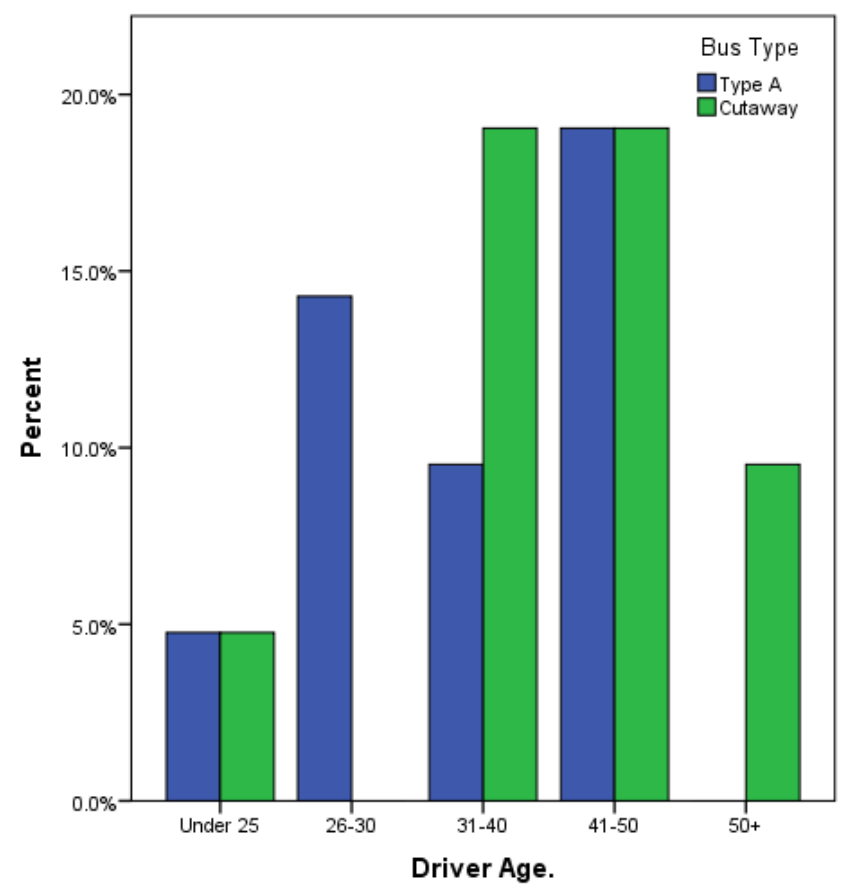

Figure 3-13. Driver age distribution.

Responses to Questions

Approximately 86 percent of drivers of both buses agreed that the mirrors become less effective when it is raining.

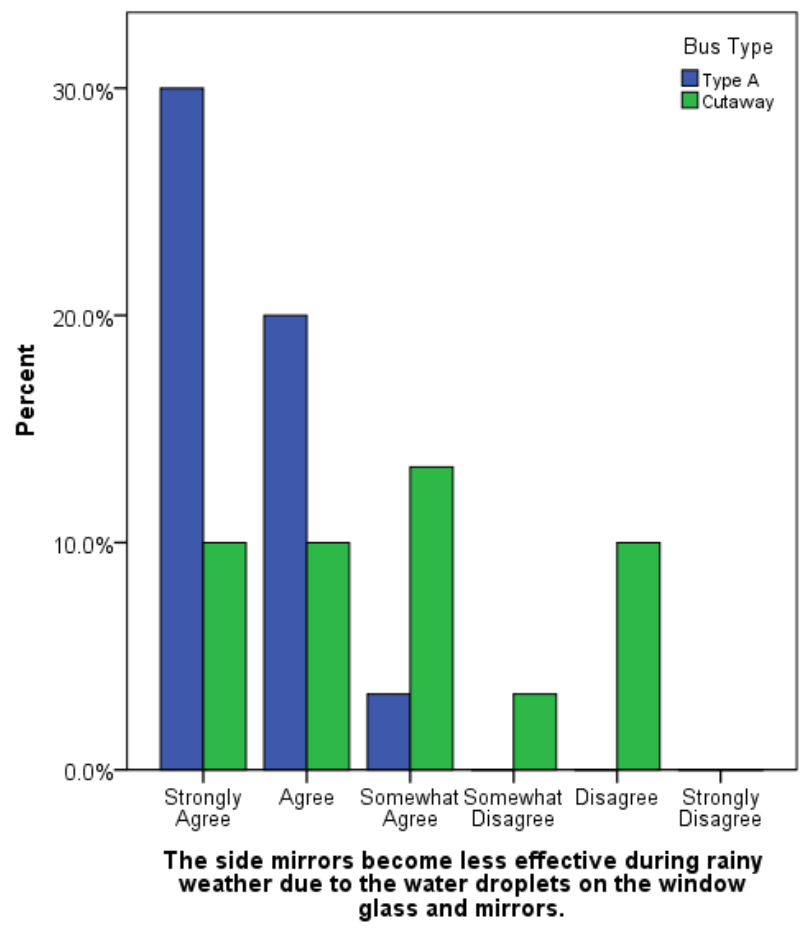

Figure 3-14. Responses to Q1. 


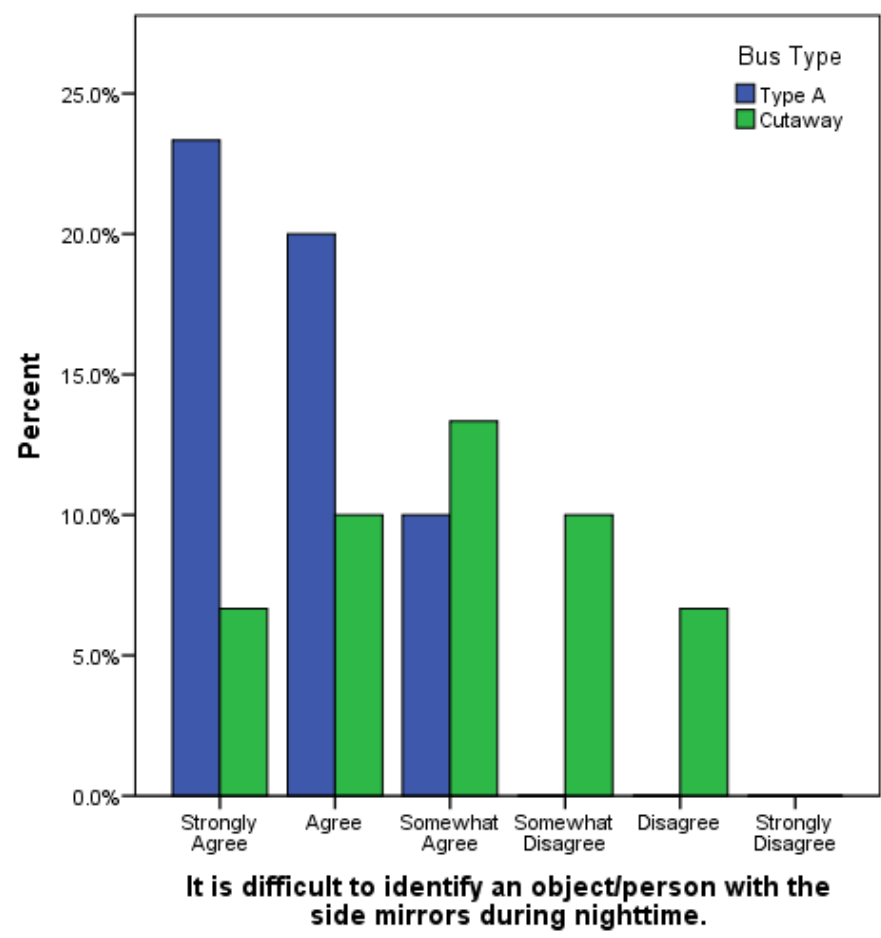

Figure 3-15. Responses to Q2.

An opinion shift was recorded towards more agreement with the statement asked in Q3 and Q7. Drivers that replied they completely agree increased from 27 percent to 40 percent for the type $A$ bus and from 18 percent to 20 percent after taking the test.
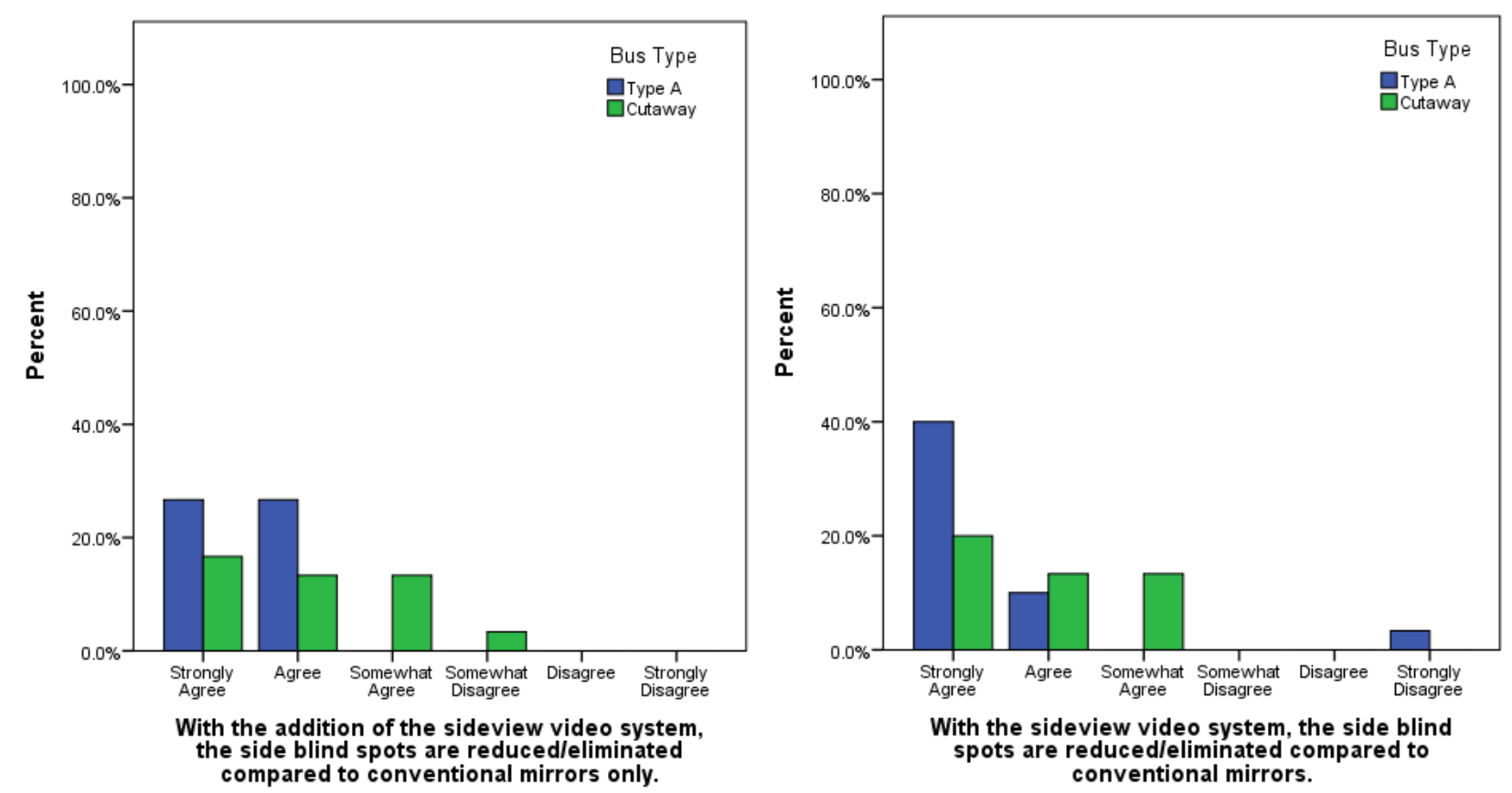

Figure 3-16. Responses to Q3 (left) asked before, and Q7 (right) asked after the test. 


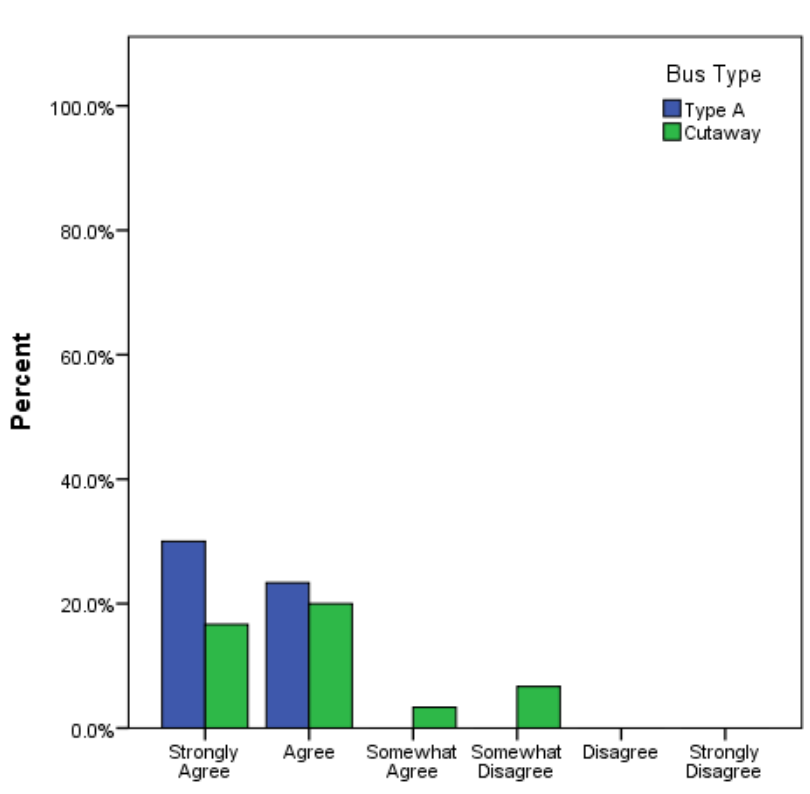

The sideview video system can help drivers reduce side crashes (sideswipe, turns, angle crashes) by providing a better view.

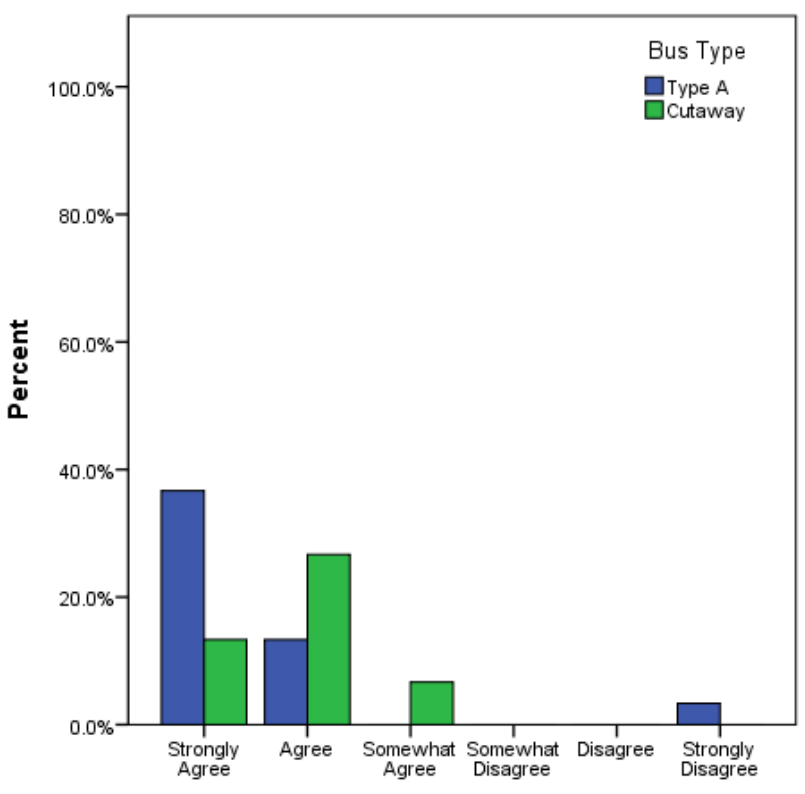

The sideview video system can help drivers to reduce side crashes (sideswipe, turns, angle crashes) by providing a better view.

Figure 3-17. Responses to Q4 (left) asked before, and Q8 (right) asked after the test.
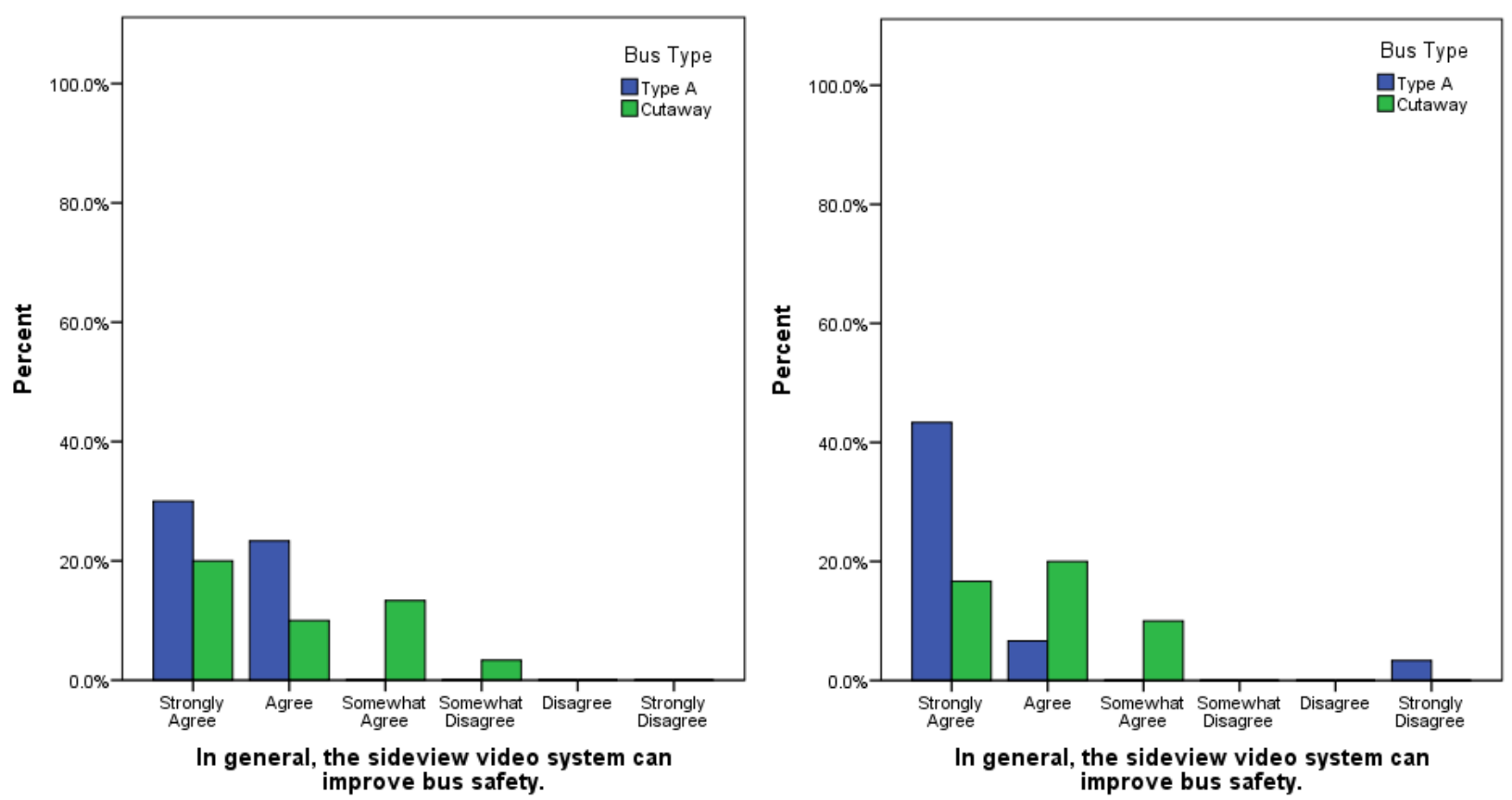

Figure 3-18. Responses to Q5 (left) asked before, and Q9 (right) asked after the test. 

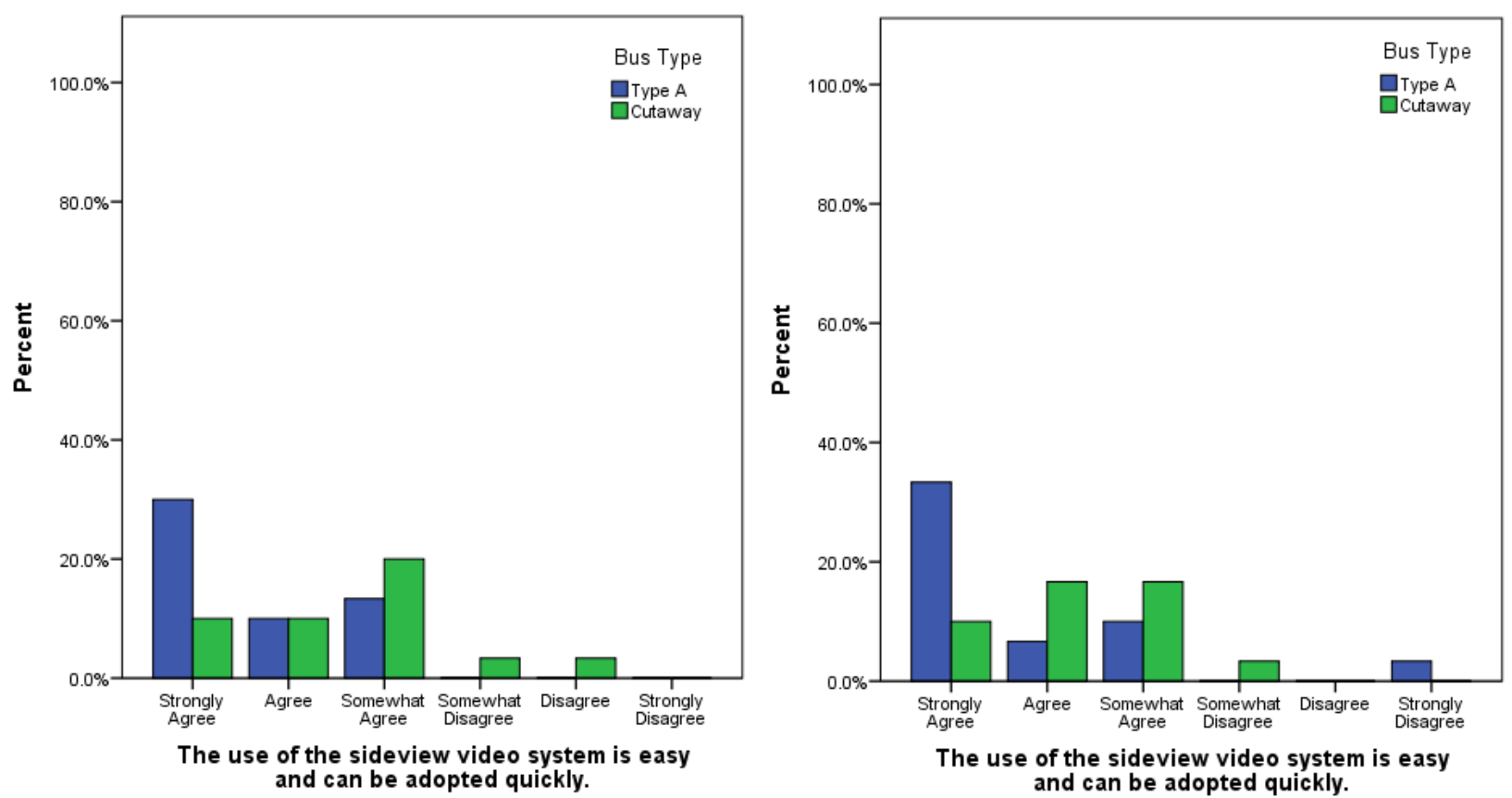

Figure 3-19. Responses to Q6 (left) asked before, and Q7 (right) asked after the test.

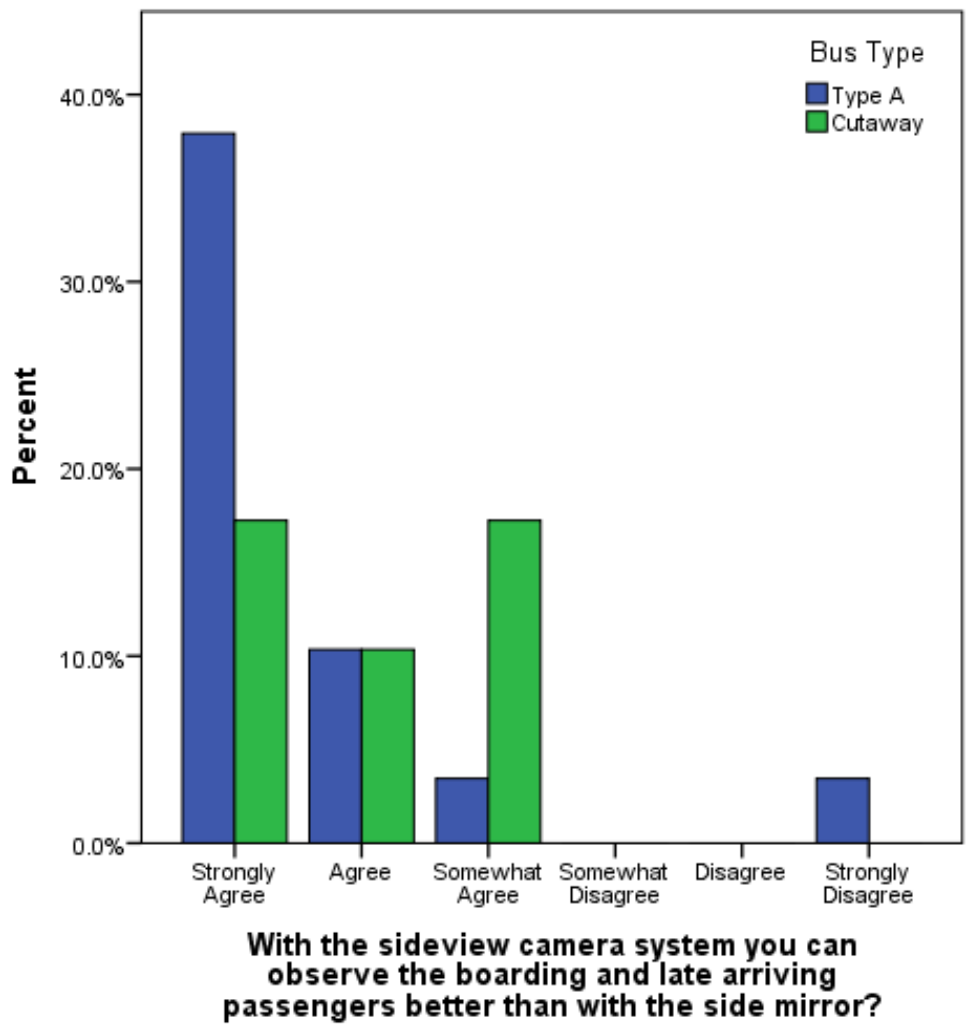

Figure 3-20. Responses to Q11. 


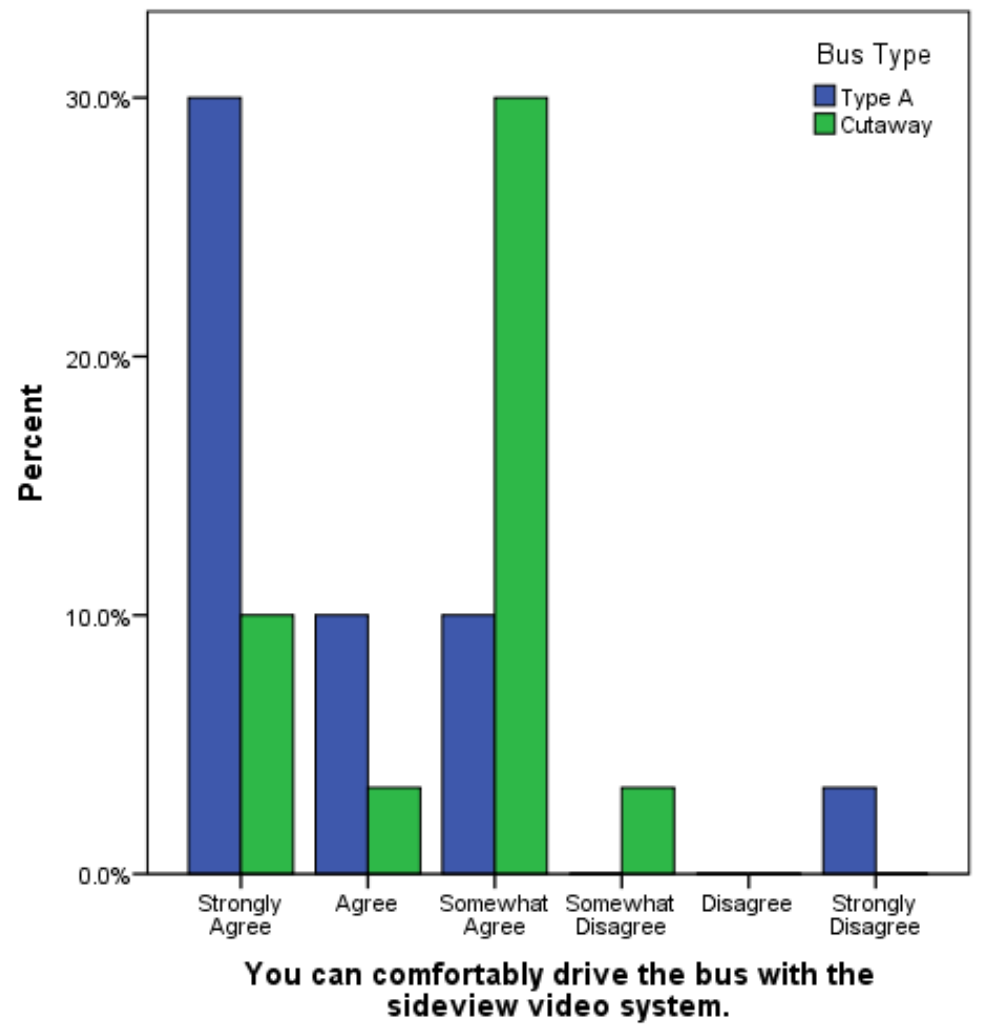

Figure 3-21. Responses to Q17.

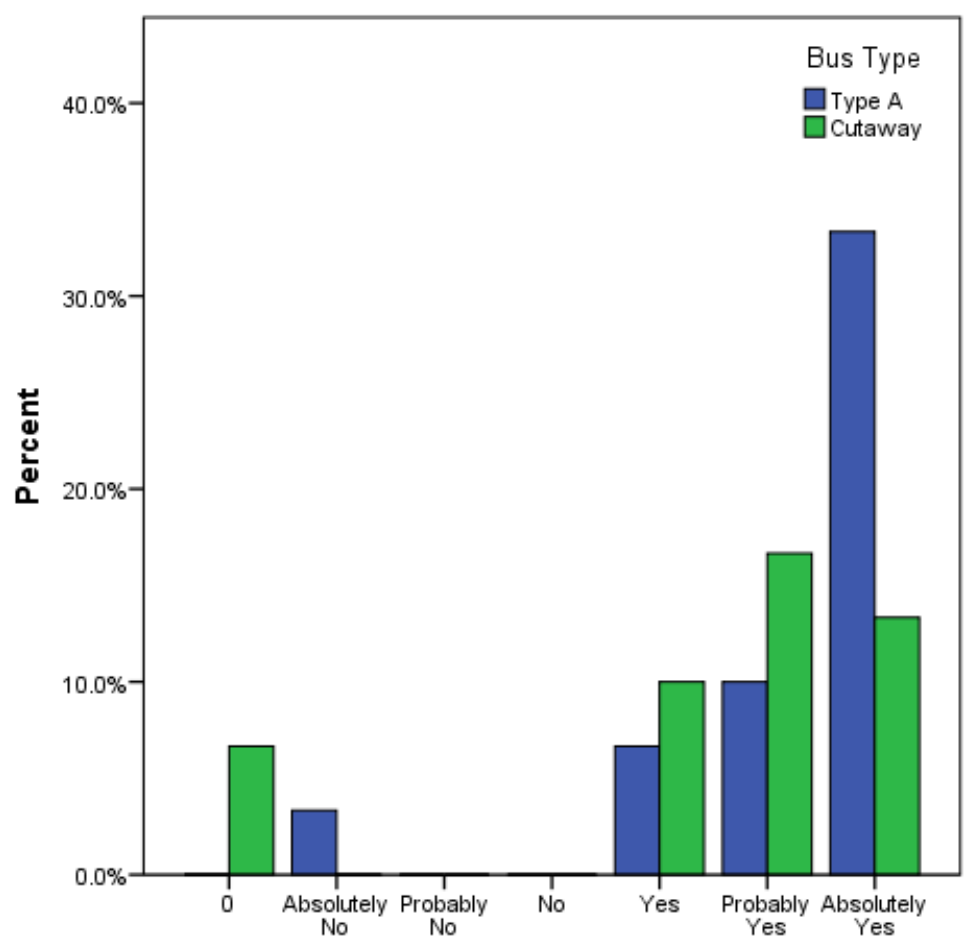

Would you like to have a sideview video system in the bus you drive every day?

Figure 3-22. Responses to Q18. 


\section{System Setup}

The drivers were also asked questions pertaining to the monitor location and size combination. The setup was slightly different for the two buses: type A had a scenario more like setup 2 but the right monitor was in the center console; the cutaway bus was exactly like setup 2. The percent replies can be seen in Figure 3-23. They were combined for the two bus types.
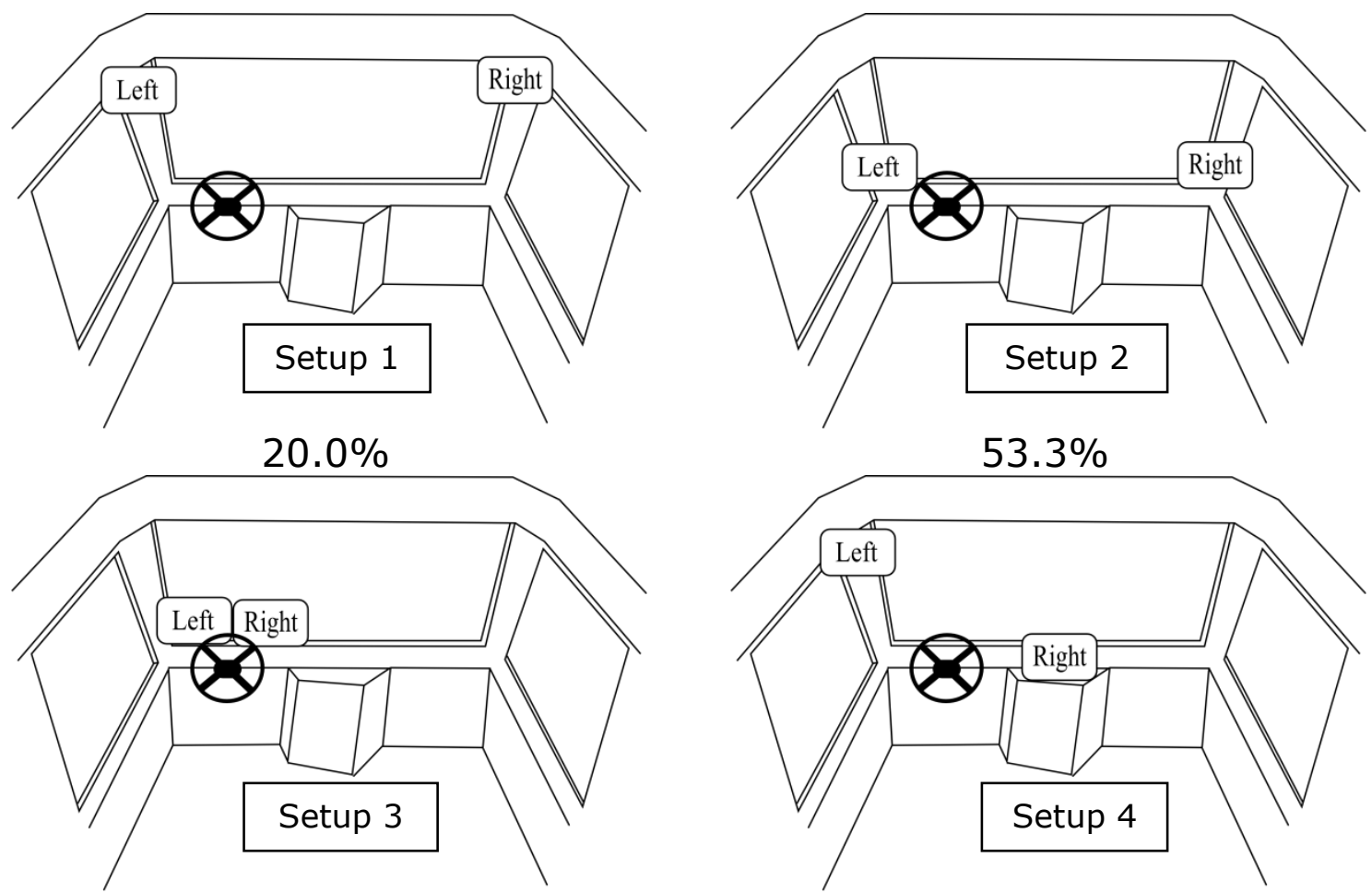

$6.7 \%$

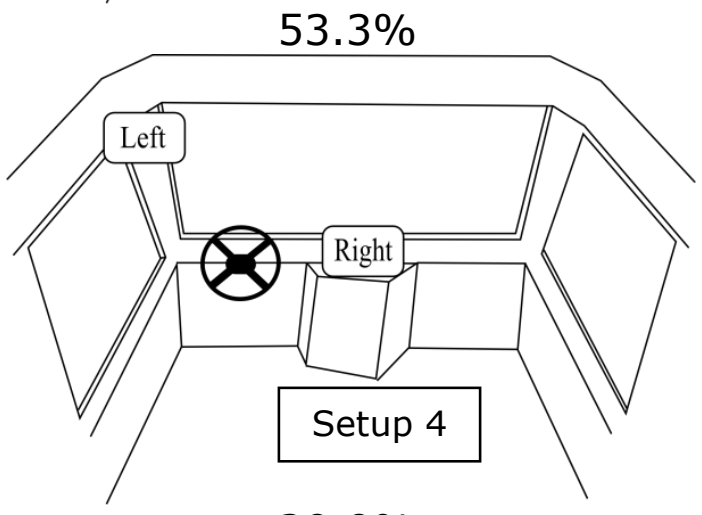

$20.0 \%$

Figure 3-23. Monitor setup scenarios.

The drivers were also asked to comment on the monitor size. Not surprisingly, cutaway drivers would like the 7 inch monitors, whereas with the type A bus, since it is larger and has more space, drivers shifted toward the bigger sizes. Note that the actual sizes used were 7-inch monitors for the cutaway bus and a 7-inch left and 8-inch right for the type A bus. The question however asked 7, 9 or 10-inch on purpose to understand if drivers preferred a bigger monitor. 


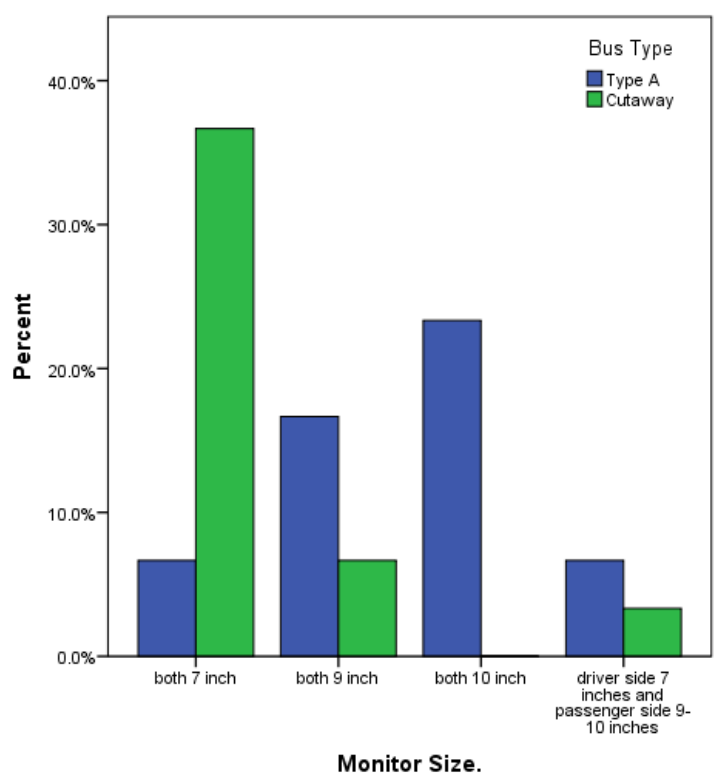

Figure 3-24. Driver response for monitor size.

General comments from the drivers included the following:

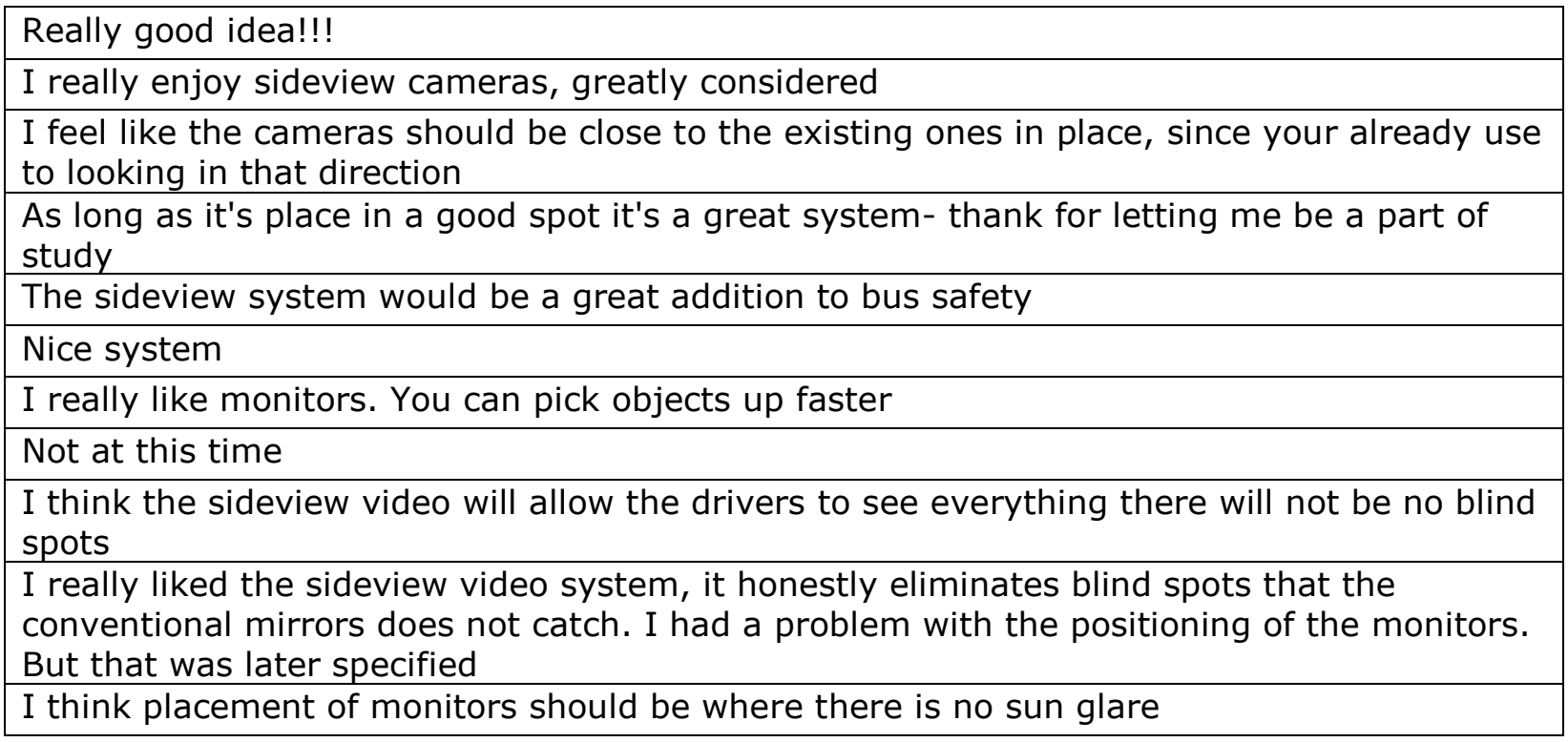




\section{Chapter 4 Field Deployment}

After the controlled driving test, the systems needed to be tested on actual transit routes. This would allow the drivers to offer feedback on the system based on driving in their everyday environment. For the type A bus, the camera system described in Chapter 2 was used. The cameras were mounted on the mirror brackets with stainless steel rings to prevent rust. They were adjusted to have a $65^{\circ}$ horizontal view, and aimed so that the driver could see the edge of the bus in the monitors. On the left side, a 7-inch monitor was installed at the vehicle's left A-pillar. On the right side, a 8-inch monitor was installed to the right of the driver console. They were wired so that they were engaged once the ignition was switched on.

LeeTran in Ft. Myers, FL, agreed to help with the deployment of the camera systems on two of their buses. The system on the type A bus was installed on July 1, 2012, and results were obtained continuously until November 7, 2012. The cutaway bus was equipped on October 11, 2012, and data were obtained until November 15, 2012.

Figure 4-1 shows the camera installed on the left side mirror. The camera was installed in such a way so that it did not extend beyond the mirror, as illustrated in Figure 4-2.

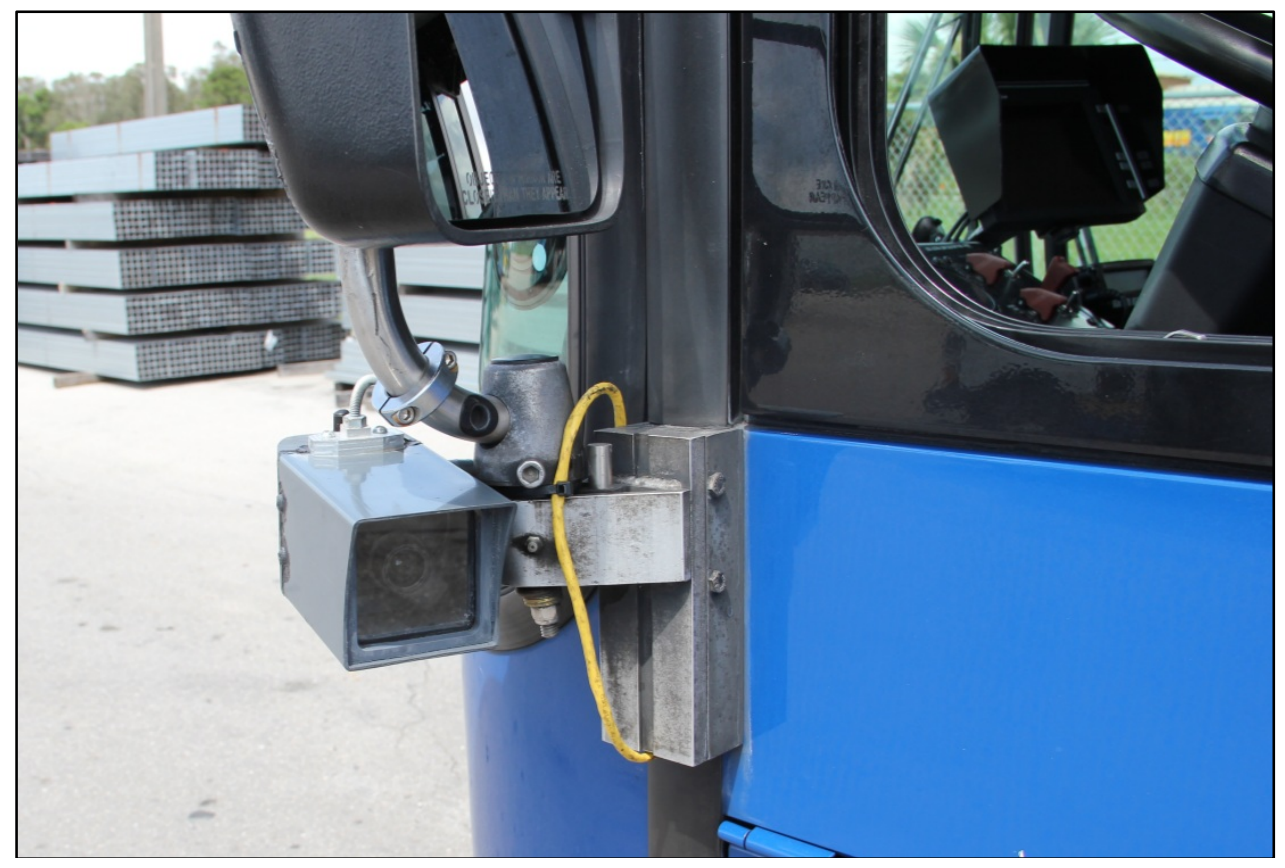

Figure 4-1. Left side camera installed on type A bus. 


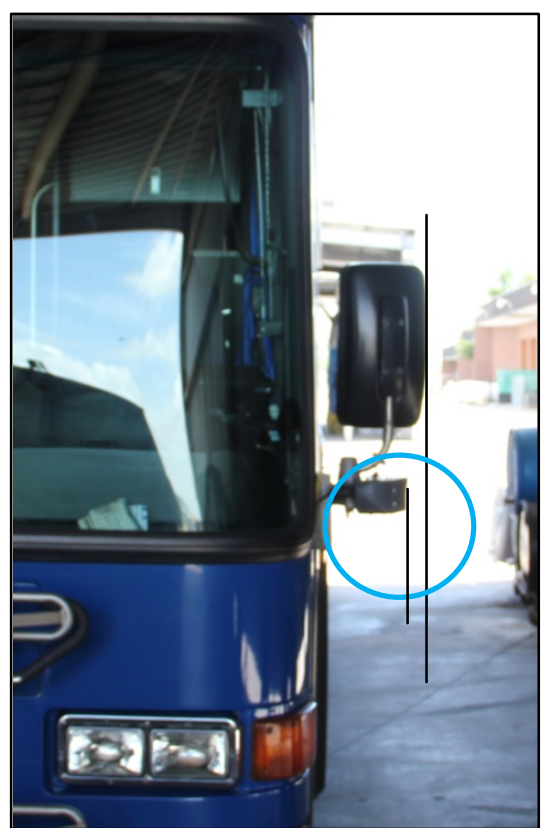

Figure 4-2. Clearance between camera and mirror outline.

The right side camera was installed on the bracket of the right mirror. Shown in Figure 4-3, the mirror on the right side was mounted at highest point of the bus and not in the middle of the height as on the driver side. Careful placement was achieved on this side as well so that there was clearance between the camera and the outline of the mirror similar to the driver side.

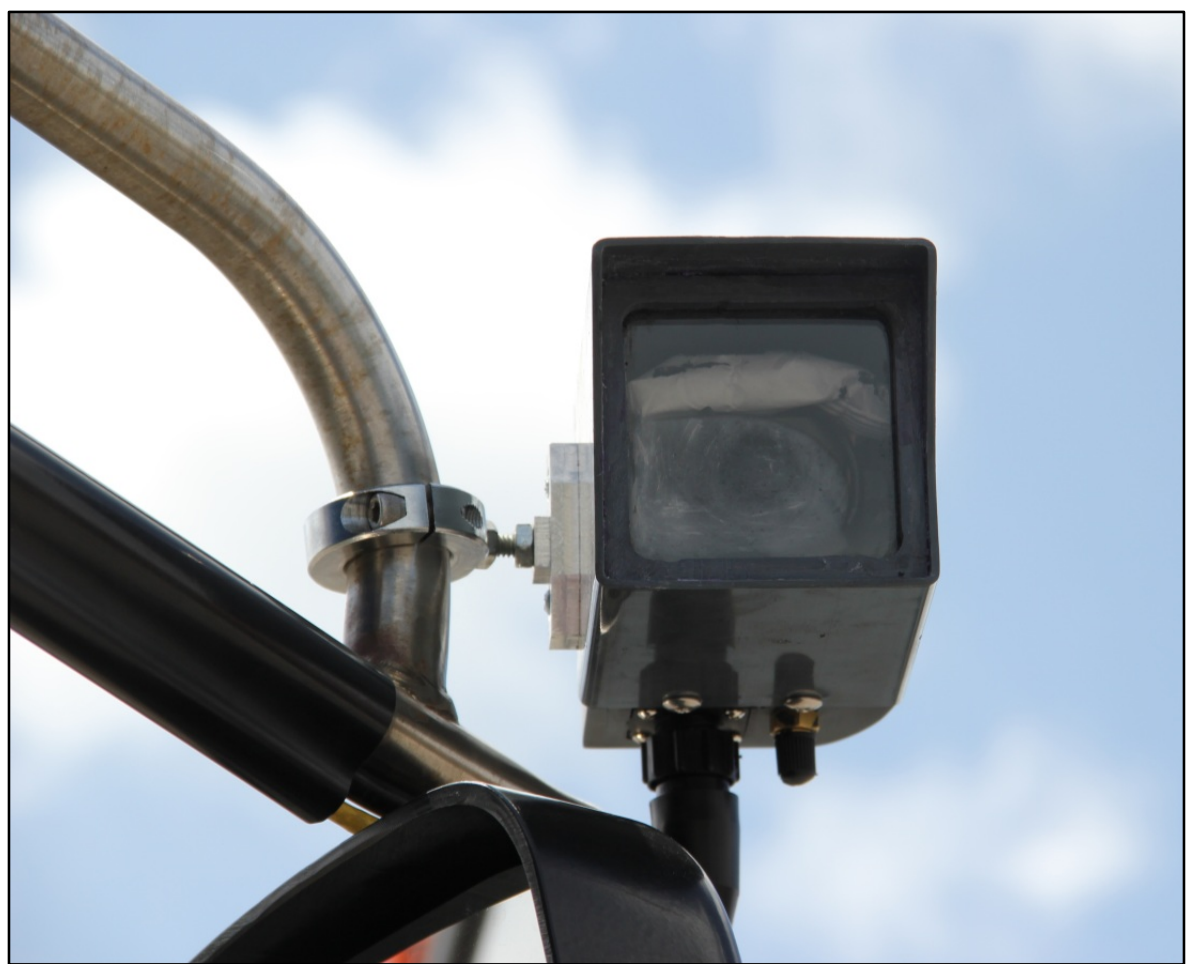

Figure 4-3. Right side camera installed on type A bus. 
The monitors were installed as shown in Figure 4-4. Sun visors were also used on the monitors to reduce glare from the sun light. The monitor views can be seen in Figure 4-5.

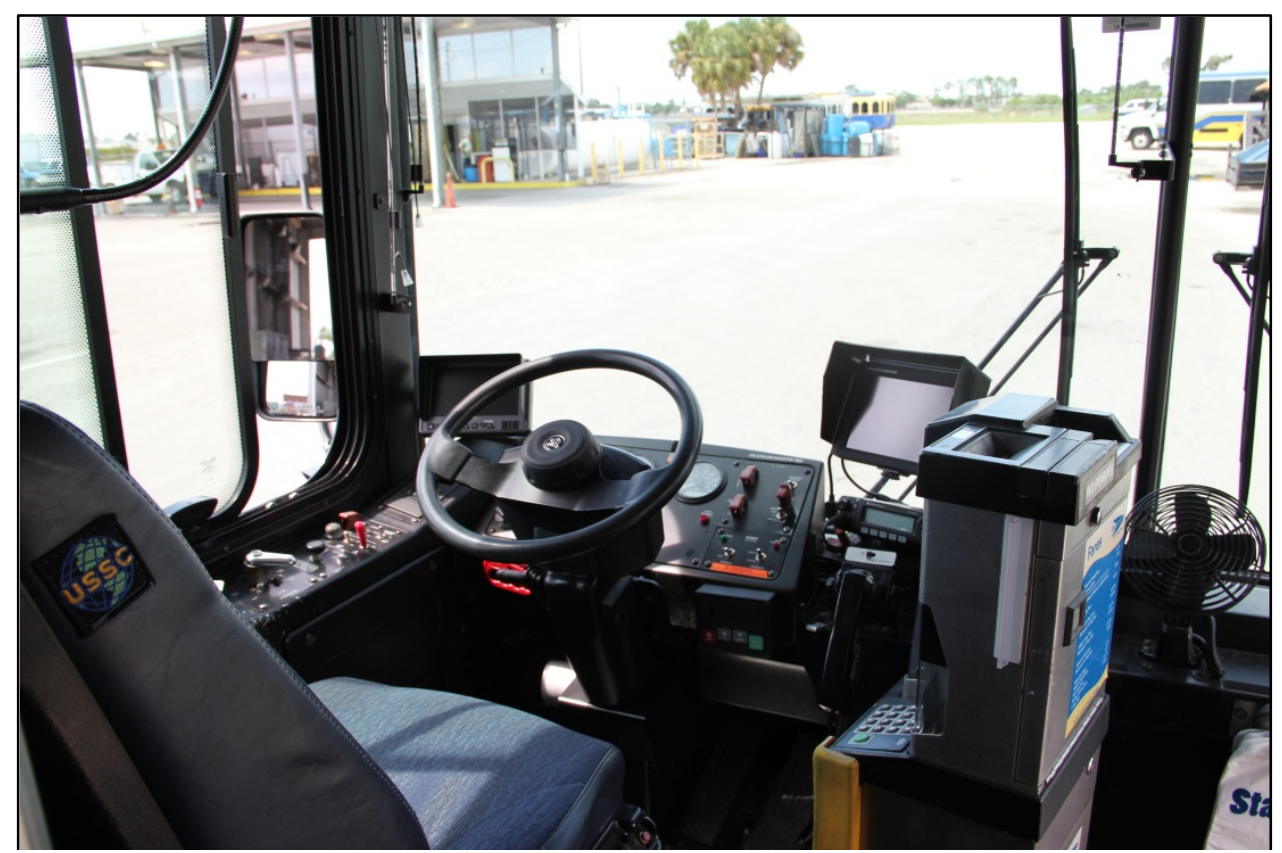

Figure 4-4. Monitors installed in the type A bus.

The operations manager was advised to instruct the drivers on how to use the system and collect their feedback. An online survey was set up so that the drivers could take the survey once every week. The survey questions can be found in Appendix B. The operations manager was also instructed to rotate as many drivers as feasible on the bus equipped with the system.

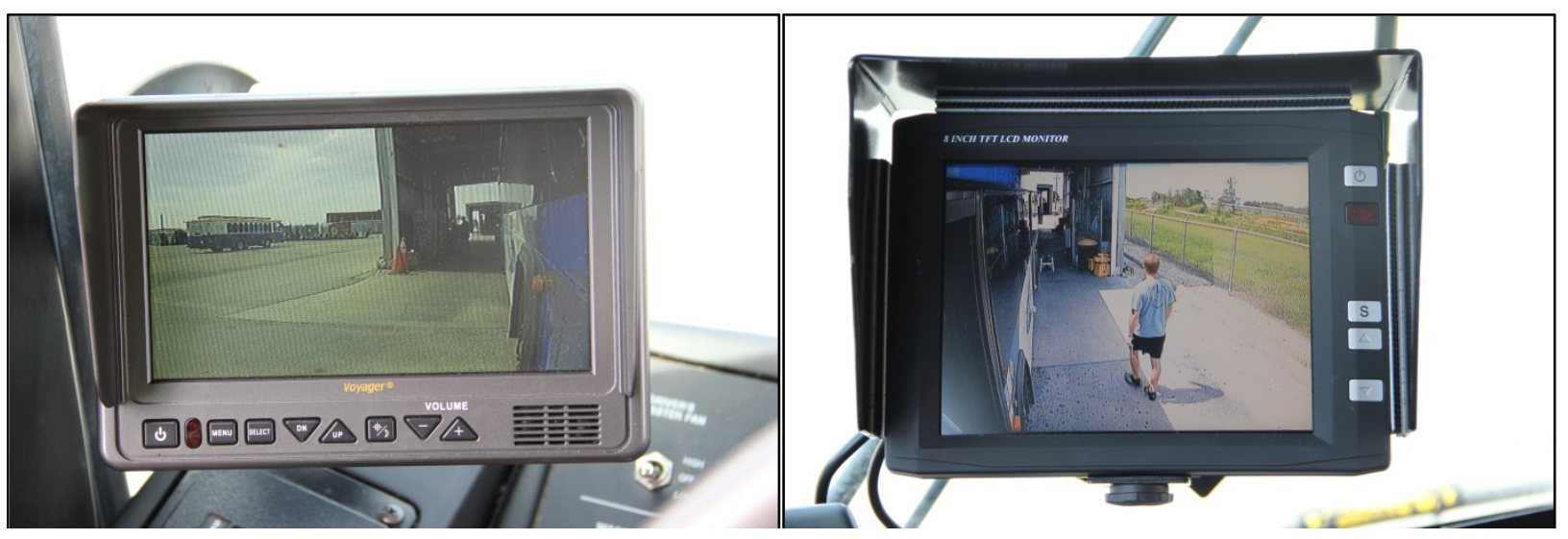

Figure 4-5. View from the monitors installed in the type A bus.

For the cutaway bus, the decision was made to use the system designed and developed by Velvac $®$ as described in Chapter 2. The complete system included the mirrors with brackets, and cameras installed on the same housing. Figure 4-6 shows the right side hybrid camera system, and Figure 4-7 shows the left side hybrid system installed on the cutaway bus. 


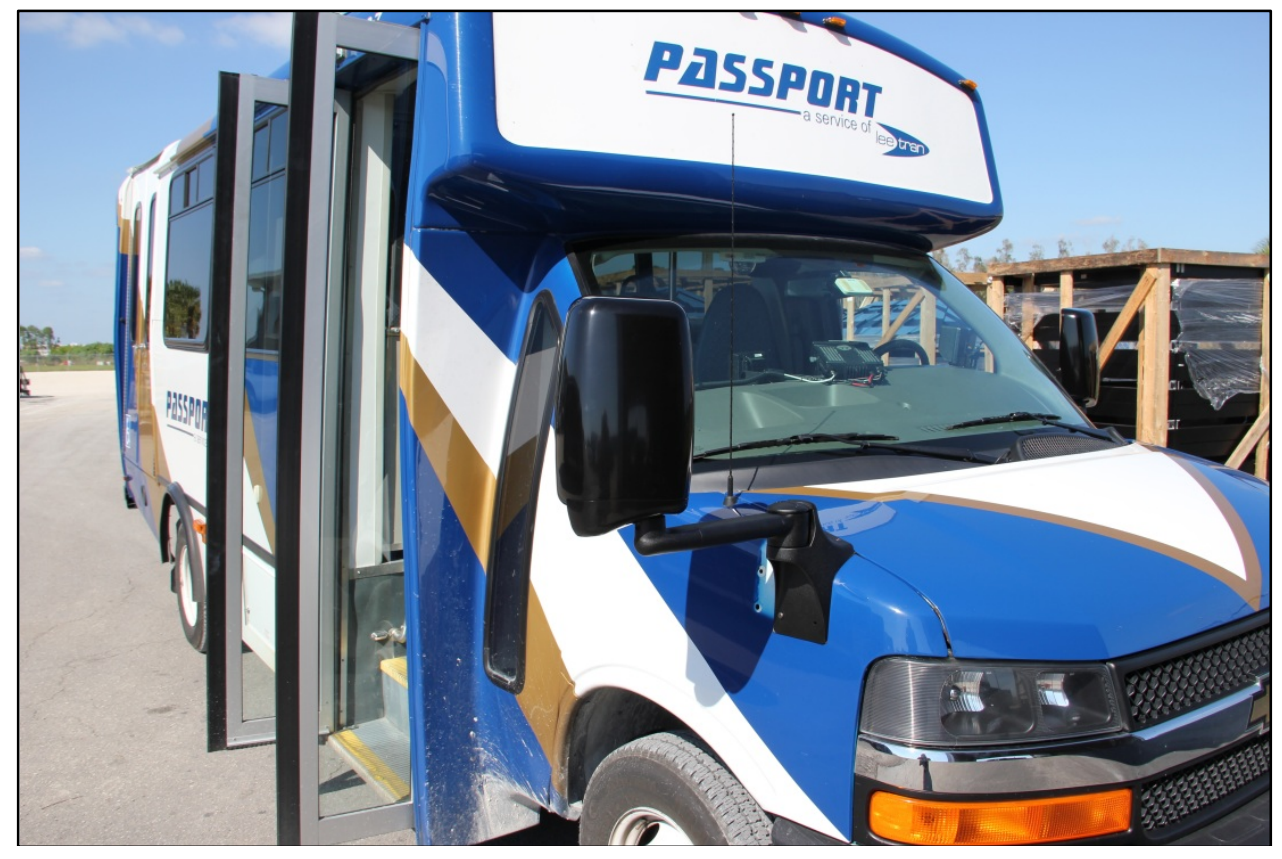

Figure 4-6. Right side mirror-camera system.

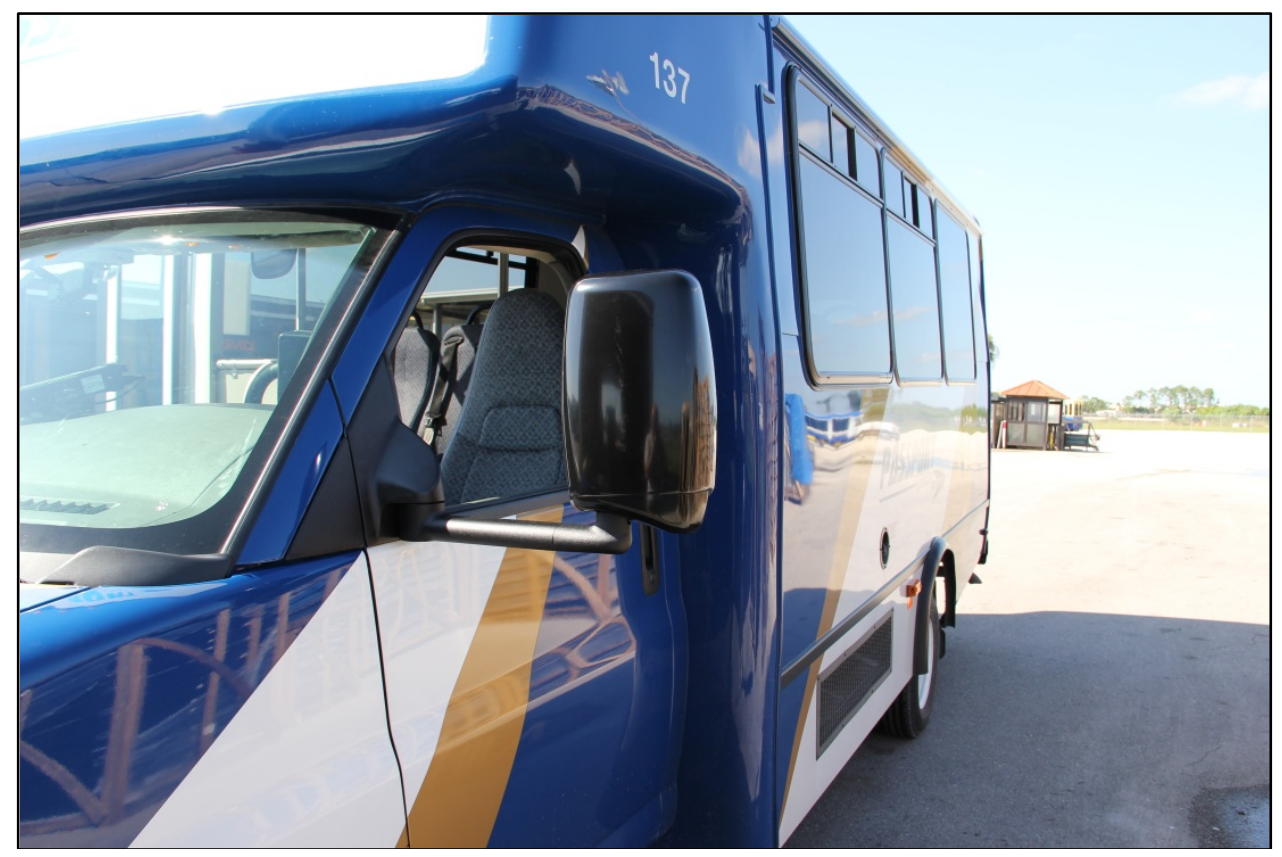

Figure 4-7. Left side mirror-camera system.

The two monitors were installed on the dashboard as shown in Figure 4-8. The left side monitor was installed in the corner of the left A-pillar. The right side monitor was also installed on the right A-pillar. This change was decided because of feedback from the controlled driving test. Drivers felt that the monitor which was installed by the cup holders, was too out of the way of the driver's eye sight and thus not beneficial. Raising it up and in the middle of the dashboard similar to the type A bus was not possible because the dashboard of these buses is high (like a passenger car) and installing the monitor there 
would block the driver's view. After consideration of all the factors, the decision was made to install it to the right A-pillar even if the view would be slightly farther from the driver.

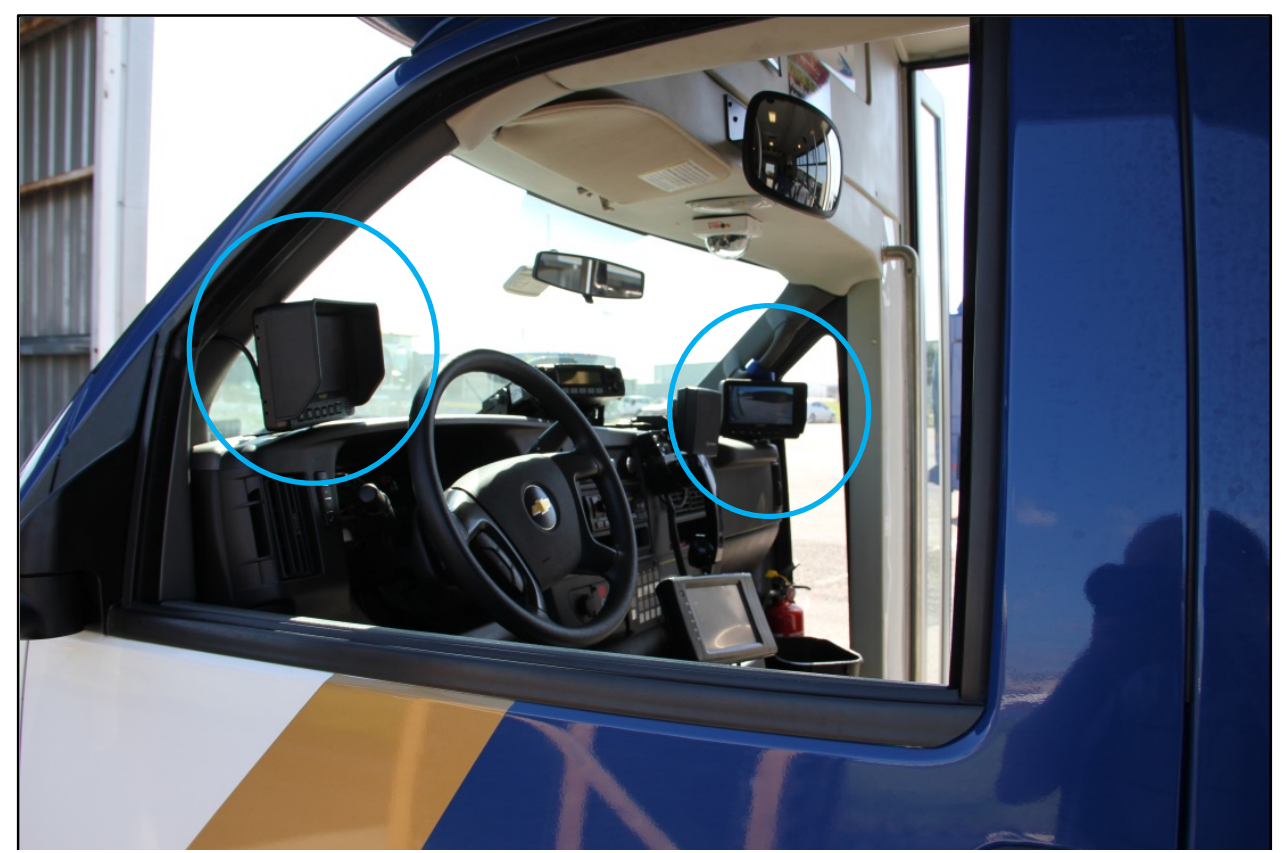

Figure 4-8. Monitors installed on dashboard of cutaway bus.

A close-up of the camera is shown in Figure 4-9. The major difference of this camera from the cameras used in the type A bus was that these were equipped with infrared illumination, capable of providing light to the camera even in complete darkness.

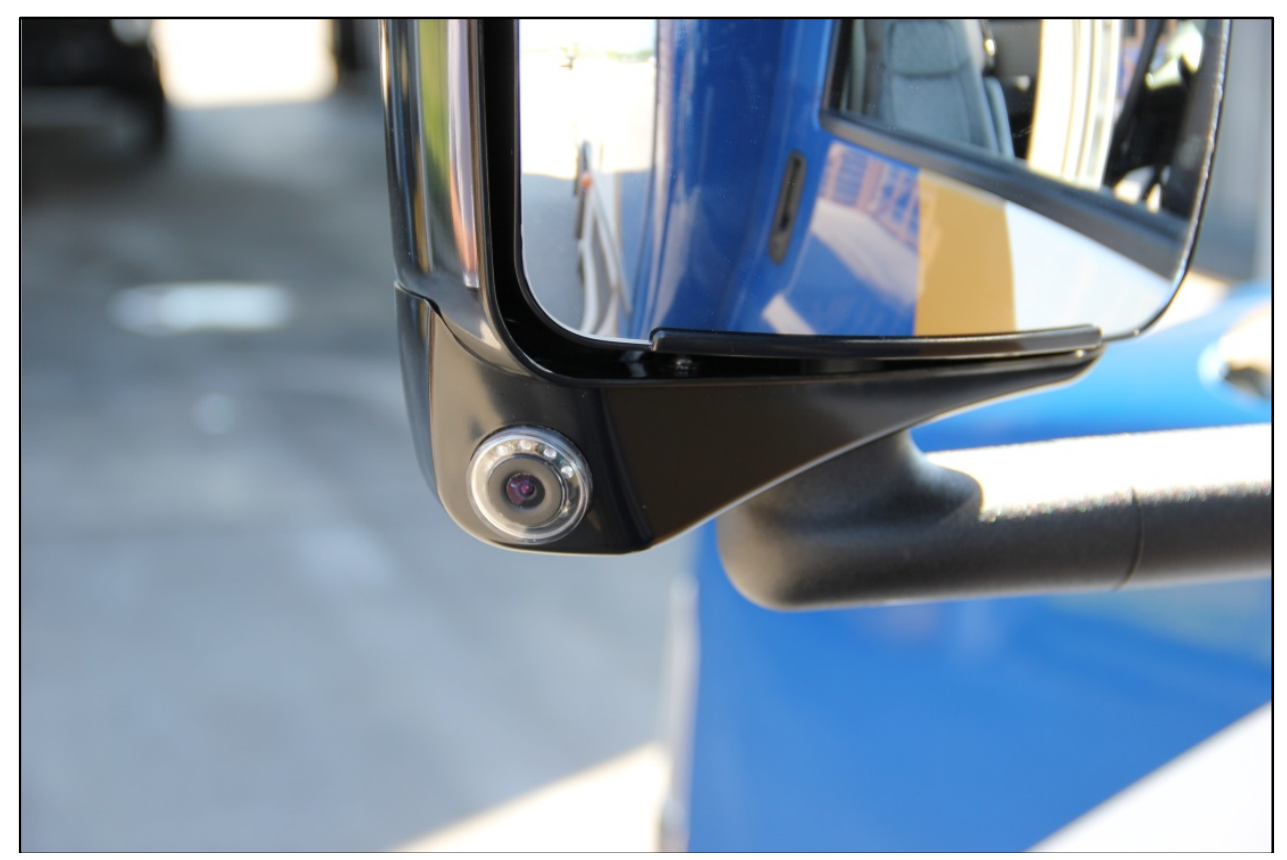

Figure 4-9. Close-up of the camera used on the cutaway bus. 
The view from the monitors installed in the cutaway bus is shown in Figure 4-10. The system was connected in such a way that it would engage when the ignition was switched on, similarly to the type A bus. The drivers had the option to switch the system off manually if they deemed it too distracting for safety reasons.

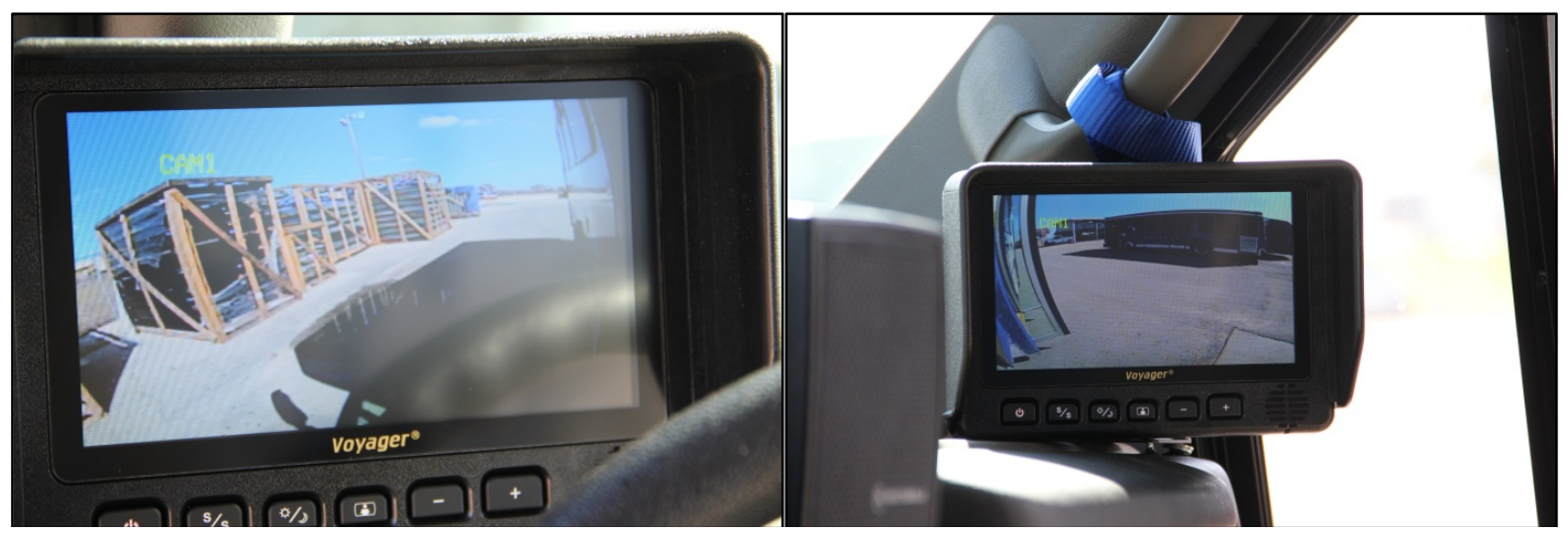

Figure 4-10. View from the monitors installed in the cutaway bus.

\section{Results of the Field Deployment}

The respondent drivers were all male, 50 percent in the $41-50$ year old group and 50 percent in the $50+$ age group. The drivers had an average of 14.5 years of driving experience ( $2 \mathrm{yr}$ min, $40 \mathrm{yr}$ max). One driver had a previous side crash. Thirty seven percent of drivers had previous experience with a camera system (any aid system). Table 4-1 summarizes the responses received from the questions found in Appendix B. Even though more options were given in the form of a scale, the results are summarized in two categories: agree, disagree. For example, if one driver answered strongly agree and one driver somewhat agree, then both drivers essentially agree on the statement. The numbers correspond to the question order on the survey.

\section{Table 4-1. Driver Responses to Survey Questions}

\begin{tabular}{|l|c|c|}
\hline \multicolumn{1}{|c|}{ Question } & Agree & Disagree \\
\hline $\begin{array}{l}\text { 8. With the addition of the sideview video system, the blind spots are } \\
\text { reduced/eliminated compared to conventional mirrors only. }\end{array}$ & $100.0 \%$ & $0.0 \%$ \\
\hline $\begin{array}{l}\text { 9. The sideview video system can help drivers reduce side crashes (sideswipe, } \\
\text { turns, angle crashes) by providing a better view. }\end{array}$ & $100.0 \%$ & $0.0 \%$ \\
\hline 10. The sideview video system provides better view than the mirrors. & $62.5 \%$ & $37.5 \%$ \\
\hline 11. The use of the sideview video system is easy and can be adopted quickly. & $75.0 \%$ & $25.0 \%$ \\
\hline $\begin{array}{l}\text { 12. You can comfortably drive the bus using the sideview system. } \\
\text { 13. With the sideview camera system you can observe the boarding and late } \\
\text { arriving passengers better than the side mirror. }\end{array}$ & $62.5 \%$ & $37.5 \%$ \\
\hline 15. You can use the cameras even when it is raining. & $62.5 \%$ & $0.0 \%$ \\
\hline $\begin{array}{l}\text { 16. The sideview system was effective while driving at night. } \\
\text { 17. The glare from the vehicle headlights/taillights makes the monitors } \\
\text { unusable or not needed during night driving. }\end{array}$ & $37.5 \%$ & $50.0 \%$ \\
\hline 18. The monitor(s) image(s) were clear enough to be able to identify vehicles. & $75.0 \%$ & $12.5 \%$ \\
\hline
\end{tabular}


When asked if they would like to have the sideview video system in the bus they drive every day, 50 percent of drivers responded yes, and 50 percent said no. Some of the comments were that they would like to have control of the adjustments, or the view of the cameras were too distracting, especially at night because of the headlights from passing cars on the left.

The drivers were also asked to comment about the monitor locations. When asked to place the monitors using the following image they reported the numbers shown in parentheses. The options given were 1-2 for the left side, and 4-6 for the right side. As a reminder, the monitors were installed in location 1 and location 5.

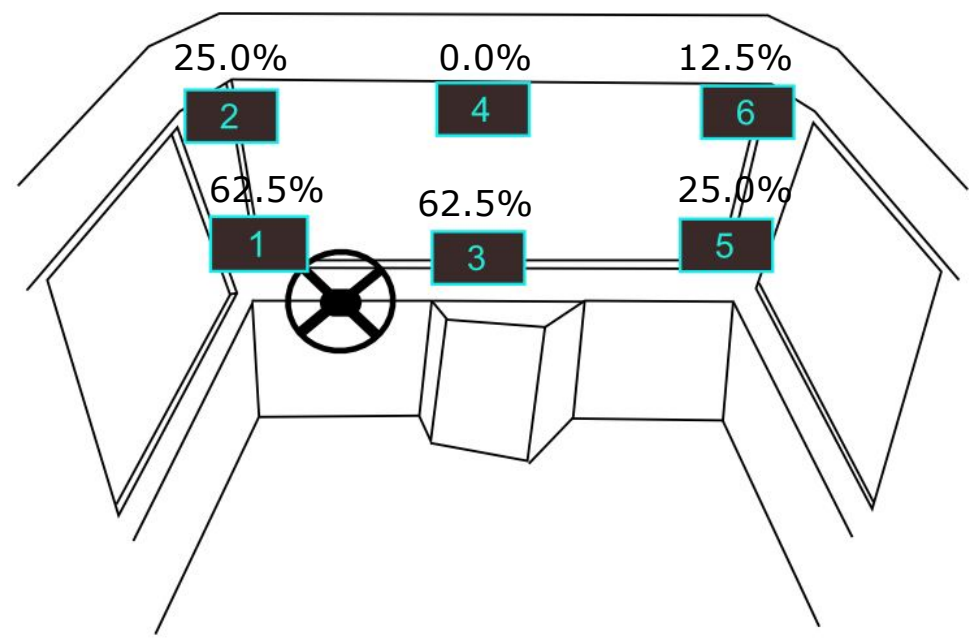

Figure 4-11. Monitor location scenarios.

Finally the drivers were asked to comment on the size of the monitors and what they would prefer. The responses are shown below.

\begin{tabular}{lccc}
\hline Answer Options & Smaller & $\begin{array}{c}\text { Same as in the } \\
\text { bus now }\end{array}$ & Bigger \\
\hline Left monitor & $62.5 \%$ & $37.5 \%$ & $0.0 \%$ \\
Right monitor & $0.0 \%$ & $100.0 \%$ & $0.0 \%$ \\
\hline
\end{tabular}




\section{Chapter 5 Recommendation for Specifications}

\section{General Requirements}

A camera system used as an imaging enhancement is a system composed of cameras and monitors where the monitor provides a real-time visual image of the scene captured by the cameras. Such systems can provide views to the drivers that are otherwise blind (blind zones) to the side of the bus. These systems can be used as enhancements to the existing mirror system to improve the safety of the vehicle. They can only be used for driving related activities and not for entertainment because of their driver distraction potential.

An enhancement system should provide a comprehensive view of the desired scene with minimum distortion. Since it is supposed to deliver a real time image, there should be littleto-no delay and provide a faithful reproduction to the driver. The field of view should not be too narrow as it will not provide all the information, but also not too wide because it can result in unnecessary image distortion and size compression (changing scale) as well as distraction to the driver.

\section{Monitors}

Monitors for enhancements should not encroach on the direct forward or side scenes of the driver's position. Doing so would result in unnecessary tradeoff between increased blind spots and the enhanced visibility provided by the enhancement. Monitors should be mounted in positions such as side headers, pillars, the dash, doors, top of dash but out of direct FOV. The A-pillars are a good location but monitors need to be small enough so that they do not obstruct the view of the driver to the outside.

\section{Cameras}

Camera FOV must be chosen to provide coverage of the defined scene, but must not be too wide. In addition, cameras should have adequate resolution, sensitivity range, and focus range to perform their required functions over the operating environment. Cameras should operate over the widest practical range of encountered light levels and other environmental conditions so that full advantage is taken of the visibility that can be achieved with the enhancement system.

In camera selection, particular attention should be paid to the camera having immunity from bright light sources in the field. These include headlights, streetlights, and possibly direct sunlight. Cameras should suppress bleed-through and blooming, and should have rapid recovery from direct glare of any kind. Color should be used to improve detection and identification capabilities. Research shows that drivers strongly prefer color over black and white images because it helps to identify objects. When infrared illumination is used, monochrome usually provides higher resolution, but drivers prefer color when available. Color rendition is also important because drivers use it as one form of identifiers, particularly of other vehicles around them.

Cameras and their mountings must be rugged in construction. Since the environment of the transit buses is severe, cameras must withstand the conditions they are meant for. Camera housings should be weatherproof with provisions for removal of interior condensation. They must be designed to avoid collection of dust, snow, ice, and other debris. The housing can be designed to provide turbulence, thus repelling debris. Vibration is also a major problem depending on the mounting position. Both camera and brackets must be able to withstand 
vibration, to avoid camera shaking. This can cause the view to change FOV rapidly, rendering it unusable.

\title{
Side Mirror-Camera Enhancement Recommended Specifications
}

\author{
Application: Transit Bus; Type A, Cutaway
}

Purpose: To reduce side blind spots caused by mirror geometry on both type A and cutaway buses by utilizing the camera field of view to provide coverage of said areas.

Camera Location, angle of coverage, aim direction, and focus range:

Type A: Cameras mounted on left and right side mirror posts utilizing stand-alone housings and positioned within the mirror extension. Camera field of view $60^{\circ}-65^{\circ}$, with one edge of each view defined by the side of the bus.

Cutaway: Cameras mounted in integrated mirror/camera housing due to mirror design limitations. Camera field of view $60^{\circ}-65^{\circ}$, with one edge of each view defined by the side of the bus.

Monitor location and approximate size:

Type A: Viewing area for left camera at base of left A-pillar with the 7" monitor. (Note: Alternative locations are the upper portion of the left A-pillar.) Viewing area for right camera on top center of dash with 8" monitor. (Note: Alternative locations are the top center of windshield and upper and lower positions on right A-pillar shown in the figure in Appendix B.)

Cutaway: Viewing area for left camera mounted at base of left A-pillar with the 7" monitor. (Note: Alternative locations are the upper portion of the left A-pillar.) Viewing area for right camera at the base of the right A-pillar with 7" monitor. (Note: Alternative locations are top center of dash, top center of windshield, and upper portion of right A-pillar shown in the figure in Appendix B.)

Image presentation: Reversed image to match images in mirrors.

Activation/Deactivation: Activation with ignition in the on/run position. Deactivation with ignition off or off button on monitor depressed by user.

Backup: Not required. 


\section{Chapter 6 Conclusions}

During this second phase of the project, a side camera system was designed to perform better than the available aftermarket sideview camera systems used in Phase I. A controlled test was performed to optimize locations of cameras and monitors, as well as design characteristics of the system. A total of 29 transit bus drivers participated in the controlled driving test which showed that the addition of the camera system to the mirrors is a great benefit to the drivers; it reduced the time it took to identify an object located around the vehicle, and improved the accuracy of correctly identifying the object. The test was conducted using two types of buses: a common type A transit bus used for fixed routes and a cutaway (shuttle) bus used for paratransit services. The two buses are different in design and present different challenges to overcome.

Based on the controlled driving test, the enhancement (i.e., integrated mirror-camera system) aided drivers in correctly identifying objects around the bus in the majority of cases, and it reduced the time it took a driver to scan mirrors and monitors to identify the object, even though there were more locations for the drivers to search. The driver feedback was generally optimistic, with the majority of drivers agreeing that the camera system eliminated blind zones, reduced the risk of side collisions, and made for better bus safety. Drivers also commented on the size and location of the monitors, which helped the setup of the field deployment that followed.

A camera housing was developed and manufactured as a prototype to be tested during a field deployment. The housing was made of plastic and sealed to weatherproof the camera. This camera system was used on the type A bus, whereas an aftermarket system developed

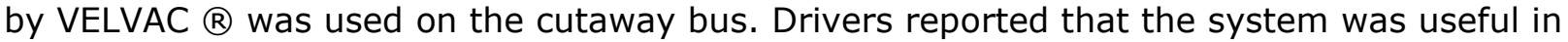
eliminating the blind zones, thus increasing safety of transit buses. The drivers had a problem with nighttime use since the glare of the headlights in the monitor did seem to be distracting.

The field deployment showed that the camera system must meet stringent criteria to be used in the field. Drivers were overall positive about the experience even though there were initial problems with fogging that were overcome. The majority of drivers agreed that the camera system reduces or eliminates the blind zones and is effective in reducing side crashes. One of the reported problems of the system is that during nighttime driving, the headlights of passing vehicles tend to be distracting. This particular issue was not investigated further, even though the cameras were chosen because they reduce blooming and light bleed-through, and they recover relatively fast from this effect. Further research might shed light on this problem, because if it is not addressed, the system can become potentially hazardous in extreme cases.

The camera system used in the project was successful, and recommendations for specifications for these systems to be used widely were put forth. The specifications are primarily in unison with specifications provided by Wiereille et al (2008) for use on heavy trucks. 


\section{References}

1. Rephlo, J., S. Miller, R. Haas, H. Saporta, D. Stock, D. Miller, L. Feast, and B. Brown. Side Object Detection System Evaluation: Final Evaluation Report. Contract DTFH6102-C-00061. ITS Joint Program Office, U.S. Department of Transportation, Washington D.C., 2008.

2. Dunn, T., R. Laver, D. Skorupski, and D. Zyrowski. Assessing the Business Case for Integrated Collision Avoidance Systems on Transit Buses. Publication FTA-OMB No. 0704-0188. FTA, U.S. Department of Transportation, Washington D.C., 2007.

3. Lin, P-S., Lee, C., Kourtellis A., Saxena M. Evaluation of Camera-Based Systems to reduce Transit Bus Side Collisions-Phase I.(Florida Department of Transportation Report BDK85 977-08). Tampa, FL: National Center for Transit Research, 2010.

4. Wiereille W., Schaudt W., Gupta S., Spaulding J., Hanowski R. Development of a Performance Specification for Camera/Video Imaging Systems on Heavy Vehicles. NHTSA, Report DOT HS 810 958, Washington D.C., 2008. 


\title{
Appendix A: Driver Packet for Controlled Test
}

\author{
Controlled driving test for sideview video system
}

Driver Packet:

- Survey Before Test

- Survey After Test
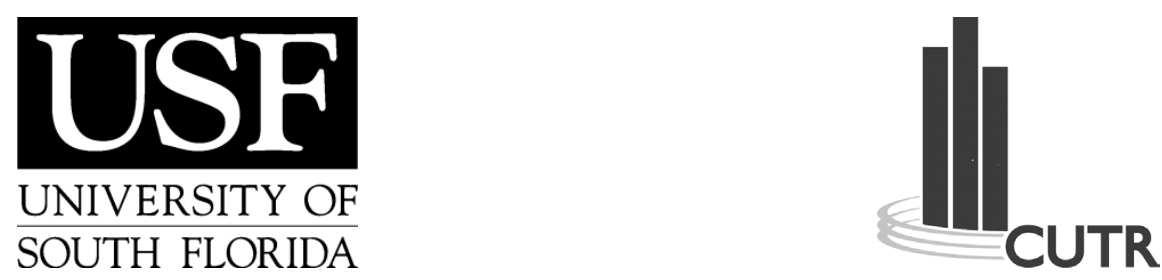


\section{Sideview Video System}

This system has two cameras and two monitors; one for each side of the bus. The sideview video system will be used as a supplement to the side mirrors, providing side view. The monitors will be mounted as shown below:

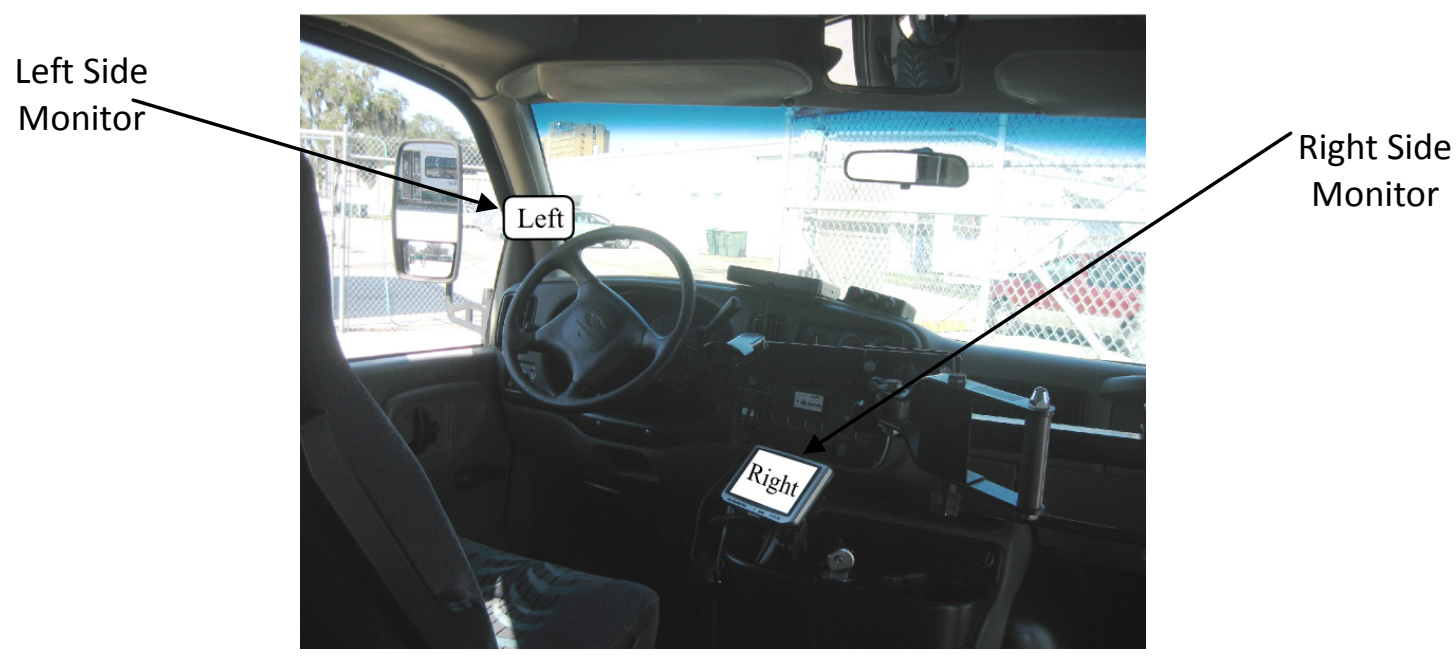

The diagram below shows the Field of View of the mirrors and camera system:

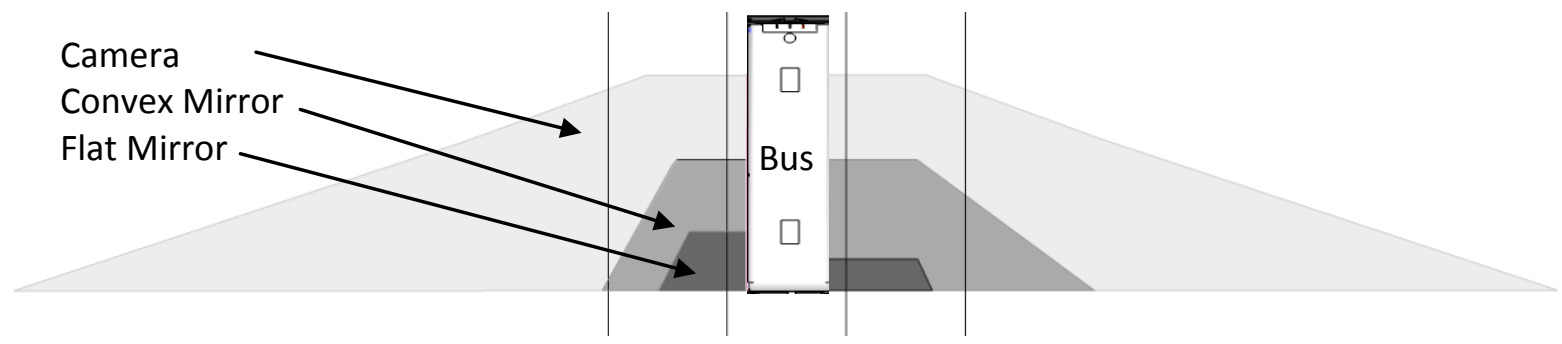

Based on your perception for the system, please fill out the before test survey. 


\section{Before Test Survey}

1. The side mirrors become less effective during rainy weather due to the water droplets on the window glass and mirrors.

\begin{tabular}{|c|c|c|c|c|c|}
1 & 2 & 3 & 4 & 5 & 6 \\
\hline $\begin{array}{c}\text { Strongly } \\
\text { Agree }\end{array}$ & Agree & $\begin{array}{c}\text { Somewhat } \\
\text { Agree }\end{array}$ & $\begin{array}{c}\text { Somewhat } \\
\text { Disagree }\end{array}$ & Disagree & $\begin{array}{c}\text { Strongly } \\
\text { Disagree }\end{array}$
\end{tabular}

2. It is difficult to identify an object/person with the side mirrors during nighttime.

\begin{tabular}{|c|c|c|c|c|c|}
1 & 2 & 3 & 4 & 5 & 6 \\
\hline $\begin{array}{c}\text { Strongly } \\
\text { Agree }\end{array}$ & Agree & $\begin{array}{c}\text { Somewhat } \\
\text { Agree }\end{array}$ & $\begin{array}{c}\text { Somewhat } \\
\text { Disagree }\end{array}$ & Disagree & $\begin{array}{c}\text { Strongly } \\
\text { Disagree }\end{array}$
\end{tabular}

3. With the addition of the sideview video system, the side blind spots are reduced/eliminated compared to conventional mirrors only.

\begin{tabular}{|c|c|c|c|c|c|}
1 & 2 & 3 & 4 & 5 & 6 \\
\hline $\begin{array}{c}\text { Strongly } \\
\text { Agree }\end{array}$ & Agree & $\begin{array}{c}\text { Somewhat } \\
\text { Agree }\end{array}$ & $\begin{array}{c}\text { Somewhat } \\
\text { Disagree }\end{array}$ & Disagree & $\begin{array}{c}\text { Strongly } \\
\text { Disagree }\end{array}$
\end{tabular}

4. The sideview video system can help drivers reduce side crashes (sideswipe, turns, angle crashes) by providing a better view.

\begin{tabular}{|c|c|c|c|c|c|}
1 & 2 & 3 & 4 & 5 & 6 \\
\hline $\begin{array}{c}\text { Strongly } \\
\text { Agree }\end{array}$ & Agree & $\begin{array}{c}\text { Somewhat } \\
\text { Agree }\end{array}$ & $\begin{array}{c}\text { Somewhat } \\
\text { Disagree }\end{array}$ & Disagree & $\begin{array}{c}\text { Strongly } \\
\text { Disagree }\end{array}$
\end{tabular}

5. In general, the sideview video system can improve bus safety.

\begin{tabular}{|c|c|c|c|c|c|}
1 & 2 & 3 & 4 & 5 & 6 \\
\hline $\begin{array}{c}\text { Strongly } \\
\text { Agree }\end{array}$ & Agree & $\begin{array}{c}\text { Somewhat } \\
\text { Agree }\end{array}$ & $\begin{array}{c}\text { Somewhat } \\
\text { Disagree }\end{array}$ & Disagree & $\begin{array}{c}\text { Strongly } \\
\text { Disagree }\end{array}$
\end{tabular}

6. The use of the sideview video system is easy and can be adopted quickly.

\begin{tabular}{|c|c|c|c|c|c|}
1 & 2 & 3 & 4 & 5 & 6 \\
\hline $\begin{array}{c}\text { Strongly } \\
\text { Agree }\end{array}$ & Agree & $\begin{array}{c}\text { Somewhat } \\
\text { Agree }\end{array}$ & $\begin{array}{c}\text { Somewhat } \\
\text { Disagree }\end{array}$ & Disagree & $\begin{array}{c}\text { Strongly } \\
\text { Disagree }\end{array}$
\end{tabular}

\section{Driving Test Procedure}

You will now go over the test with one of the test administrators. First you will go through a course using the camera system ON to get familiar with the system. 


\section{After Test Survey}

7. With the sideview video system, the side blind spots are reduced/eliminated compared to conventional mirrors.

\begin{tabular}{|c|c|c|c|c|c|}
1 & 2 & 3 & 4 & 5 & 6 \\
\hline $\begin{array}{c}\text { Strongly } \\
\text { Agree }\end{array}$ & Agree & $\begin{array}{c}\text { Somewhat } \\
\text { Agree }\end{array}$ & $\begin{array}{c}\text { Somewhat } \\
\text { Disagree }\end{array}$ & Disagree & $\begin{array}{c}\text { Strongly } \\
\text { Disagree }\end{array}$
\end{tabular}

8. The sideview video system can help drivers to reduce side crashes (sideswipe, turns, angle crashes) by providing a better view.

\begin{tabular}{|c|c|c|c|c|c|}
1 & 2 & 3 & 4 & 5 & 6 \\
\hline $\begin{array}{c}\text { Strongly } \\
\text { Agree }\end{array}$ & Agree & $\begin{array}{c}\text { Somewhat } \\
\text { Agree }\end{array}$ & $\begin{array}{c}\text { Somewhat } \\
\text { Disagree }\end{array}$ & Disagree & $\begin{array}{c}\text { Strongly } \\
\text { Disagree }\end{array}$
\end{tabular}

9. In general, the sideview video system can improve bus safety.

\begin{tabular}{|c|c|c|c|c|c|}
1 & 2 & 3 & 4 & 5 & 6 \\
\hline $\begin{array}{c}\text { Strongly } \\
\text { Agree }\end{array}$ & Agree & $\begin{array}{c}\text { Somewhat } \\
\text { Agree }\end{array}$ & $\begin{array}{c}\text { Somewhat } \\
\text { Disagree }\end{array}$ & Disagree & $\begin{array}{c}\text { Strongly } \\
\text { Disagree }\end{array}$
\end{tabular}

10. The use of the sideview video system is easy and can be adopted quickly.

\begin{tabular}{|c|c|c|c|c|c|}
1 & 2 & 3 & 4 & 5 & 6 \\
\hline $\begin{array}{c}\text { Strongly } \\
\text { Agree }\end{array}$ & Agree & $\begin{array}{c}\text { Somewhat } \\
\text { Agree }\end{array}$ & $\begin{array}{c}\text { Somewhat } \\
\text { Disagree }\end{array}$ & Disagree & $\begin{array}{c}\text { Strongly } \\
\text { Disagree }\end{array}$
\end{tabular}

11. With the sideview camera system you can observe the boarding and late arriving passengers better than with the side mirror?

\begin{tabular}{|c|c|c|c|c|c|}
1 & 2 & 3 & 4 & 5 & 6 \\
\hline $\begin{array}{c}\text { Strongly } \\
\text { Agree }\end{array}$ & Agree & $\begin{array}{c}\text { Somewhat } \\
\text { Agree }\end{array}$ & $\begin{array}{c}\text { Somewhat } \\
\text { Disagree }\end{array}$ & Disagree & $\begin{array}{c}\text { Strongly } \\
\text { Disagree }\end{array}$
\end{tabular}
12. Your Age:
A) Under 25
B) $26-30$
C) 31 to 40
D) 41 to 50
E) $50+$

13. Years of driving experience:

14. Previous experience with any camera aid systems (backup, rear view, side or otherwise)?
A) YES
B) $\quad \mathrm{NO}$

a. If YES above, duration of experience with any camera system:
A) 1 week
B) 1-2 weeks
C) 3-4 weeks
D) 1-2 months
E) 3-4 months
F) Never

15. Ever had side crashes during bus driving? YES NO 
16. The sideview video system provides a better side view than the mirrors.

\begin{tabular}{|c|c|c|c|c|c|}
1 & 2 & 3 & 4 & 5 & 6 \\
\hline $\begin{array}{c}\text { Strongly } \\
\text { Agree }\end{array}$ & Agree & $\begin{array}{c}\text { Somewhat } \\
\text { Agree }\end{array}$ & $\begin{array}{c}\text { Somewhat } \\
\text { Disagree }\end{array}$ & Disagree & $\begin{array}{c}\text { Strongly } \\
\text { Disagree }\end{array}$
\end{tabular}

17. You can comfortably drive the bus with the sideview video system?

\begin{tabular}{|c|c|c|c|c|c|}
1 & 2 & 3 & 4 & 5 & 6 \\
\hline $\begin{array}{c}\text { Strongly } \\
\text { Agree }\end{array}$ & Agree & $\begin{array}{c}\text { Somewhat } \\
\text { Agree }\end{array}$ & $\begin{array}{c}\text { Somewhat } \\
\text { Disagree }\end{array}$ & Disagree & $\begin{array}{c}\text { Strongly } \\
\text { Disagree }\end{array}$
\end{tabular}

18. Would you like to have a sideview video system in the bus you drive every day?

\begin{tabular}{|c|c|c|c|c|c|}
1 & 2 & 3 & 4 & 5 & 6 \\
\hline $\begin{array}{c}\text { Absolutely } \\
\text { No }\end{array}$ & Probably No & No & Yes & $\begin{array}{c}\text { Probably } \\
\text { Yes }\end{array}$ & $\begin{array}{c}\text { Absolutely } \\
\text { Yes }\end{array}$
\end{tabular}

If you answered NO above, please indicate why not.

19. With the sideview video, you felt comfortable performing a lane change maneuver.

\begin{tabular}{|c|c|c|c|c|c|}
1 & 2 & 3 & 4 & 5 & 6 \\
\hline $\begin{array}{c}\text { Strongly } \\
\text { Agree }\end{array}$ & Agree & $\begin{array}{c}\text { Somewhat } \\
\text { Agree }\end{array}$ & $\begin{array}{c}\text { Somewhat } \\
\text { Disagree }\end{array}$ & Disagree & $\begin{array}{c}\text { Strongly } \\
\text { Disagree }\end{array}$
\end{tabular}

20. The sideview video system has the potential to help reduce side crashes during a lane change maneuver.

\begin{tabular}{|c|c|c|c|c|c|}
1 & 2 & 3 & 4 & 5 & 6 \\
\hline $\begin{array}{c}\text { Strongly } \\
\text { Agree }\end{array}$ & Agree & $\begin{array}{c}\text { Somewhat } \\
\text { Agree }\end{array}$ & $\begin{array}{c}\text { Somewhat } \\
\text { Disagree }\end{array}$ & Disagree & $\begin{array}{c}\text { Strongly } \\
\text { Disagree }\end{array}$
\end{tabular}

21. The sideview video system can minimize or eliminate the side blind spots of the bus.

\begin{tabular}{|c|c|c|c|c|c|}
1 & 2 & 3 & 4 & 5 & 6 \\
\hline $\begin{array}{c}\text { Strongly } \\
\text { Agree }\end{array}$ & Agree & $\begin{array}{c}\text { Somewhat } \\
\text { Agree }\end{array}$ & $\begin{array}{c}\text { Somewhat } \\
\text { Disagree }\end{array}$ & Disagree & $\begin{array}{c}\text { Strongly } \\
\text { Disagree }\end{array}$
\end{tabular}


22. Considering the same monitors present during the experiment, where would you place the monitors of the sideview camera system? Please indicate by selecting one of the 4 setup scenarios.
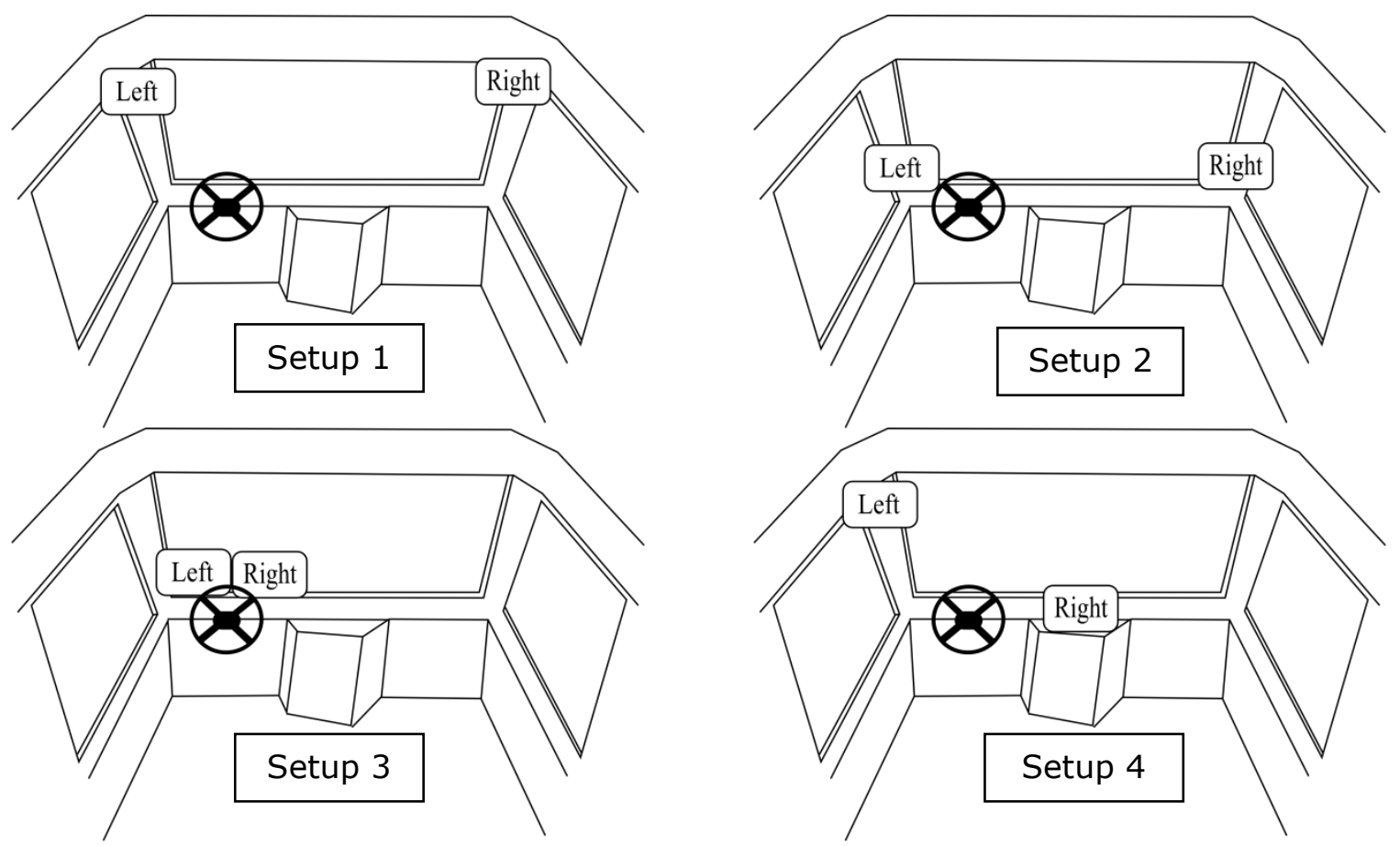

23. Considering the same monitor location as during the experiment, which size of monitor would you prefer for left and right side?
A) Both 7 inch monitors
B) Both 9 inch monitors (same size as mirrors).
C) Both 10 inch monitors.
D) Driver side monitor 7 inches and passenger side monitor bigger (9-10 inches).
E) Other:

\section{Additional Comments}

Are there any additional comments or recommendations you would like to make regarding the sideview video system? (likes, dislikes, monitor-camera locations, system configuration, etc.) 


\section{Appendix B: Field Deployment Survey}

1. What kind of bus do you drive?

Answer Options:

-Type A (low floor) bus

-Cutaway bus

2. What is your age:

- Under 25

- 26-30

- $31-40$

- 41-50

- $50+$

3. What is your gender?

- Female

- Male

4. Years of bus driving experience:

5. Have you ever had side crashes during bus driving?

- Yes

- No

- If yes please explain what happened

6. Do you wear eye sight correction glasses (other than sunglasses) while driving?

- Yes

- No

7. Do you have previous experience with any camera aid systems (backup, rearview, side-view or otherwise)?

- Yes

- No

- If yes please explain

8. With the addition of the sideview video system, the blind spots are reduced/eliminated compared to conventional mirrors only.

- Strongly Agree

- Agree

- Somewhat Agree

- Somewhat Disagree

- Disagree

- Strongly Disagree

9. The sideview video system can help drivers reduce side crashes (sideswipe, turns, angle crashes) by providing a better view.

- Strongly Agree

- Agree

- Somewhat Agree

- Somewhat Disagree

- Disagree

- Strongly Disagree 
10. The sideview video system provides better view than the mirrors.

- Strongly Agree

- Agree

- Somewhat Agree

- Somewhat Disagree

- Disagree

- Strongly Disagree

11. The use of the sideview video system is easy and can be adopted quickly.

- Strongly Agree

- Agree

- Somewhat Agree

- Somewhat Disagree

- Disagree

- Strongly Disagree

12. You can comfortably drive the bus using the sideview camera system.

- Strongly Agree

- Agree

- Somewhat Agree

- Somewhat Disagree

- Disagree

- Strongly Disagree

13. With the sideview camera system you can observe the boarding and late arriving passengers better than the side mirror.

- Strongly Agree

- Agree

- Somewhat Agree

- Somewhat Disagree

- Disagree

- Strongly Disagree

14. Would you like to have a sideview video system in the bus you drive every day?

- Yes

- No

- If no please explain

15. You can use the cameras even when it's raining.

- Strongly Agree

- Agree

- Somewhat Agree

- Somewhat Disagree

- Disagree

- Strongly Disagree 
16. The sideview system was effective while driving at night.

- Strongly Agree

- Agree

- Somewhat Agree

- Somewhat Disagree

- Disagree

- Strongly Disagree

17. The glare from the vehicle headlights/taillights makes the monitors unusable or not needed during night driving.

- Strongly Agree

- Agree

- Somewhat Agree

- Somewhat Disagree

- Disagree

- Strongly Disagree

18. The monitor(s) image(s) were clear enough to be able to identify vehicles.

- Strongly Agree

- Agree

- Somewhat Agree

- Somewhat Disagree

- Disagree

- Strongly Disagree

19. For the picture below what monitor placement combination do you prefer for the left and right sides of the bus?

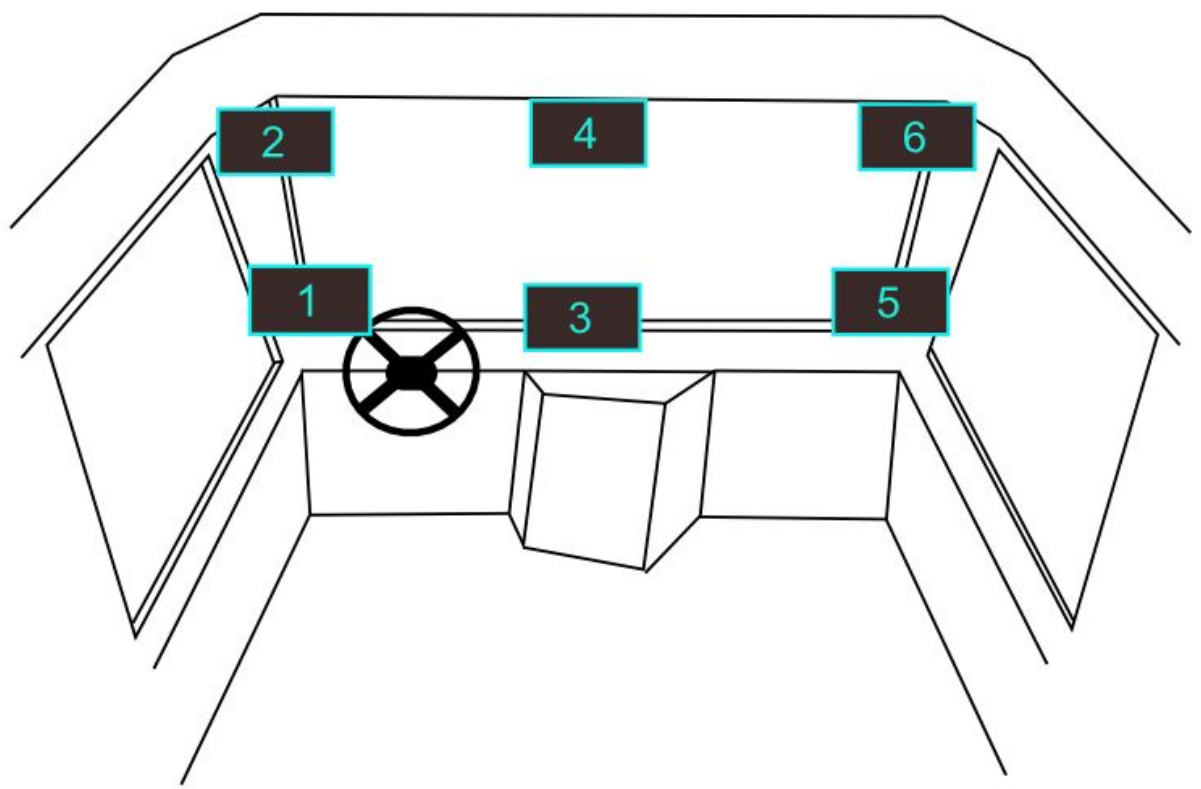

- Left (driver) side (1 or 2 ):

- $\quad$ Right (passenger) side ( 3 or 4 or 5 or 6$)$ :

20. Having in mind the monitors in the bus you drove, would you prefer the same size, bigger or smaller?

- Left monitor

- Right monitor 